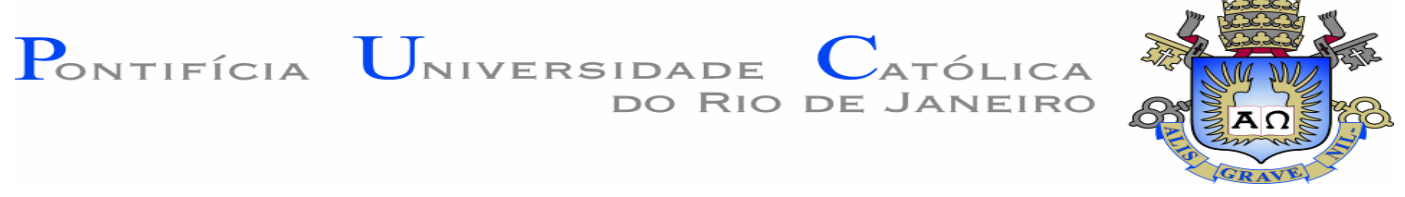

Joyce Ferreira Pessanha da Silva Rocha

Síntese e ancoragem molecular de 1,2,3-triazois para o tratamento da Fibrose Cística

Dissertação de Mestrado

Dissertação apresentada como requisito parcial para obtenção de grau de Mestre pelo programa de Pós-graduação em Química, do Departamento de Química pela PUC-Rio.

Orientador: Prof. a Camilla Djenne Buarque Muller Coorientador: Prof. André da Silva Pimentel

Rio de Janeiro

Fevereiro de 2021 


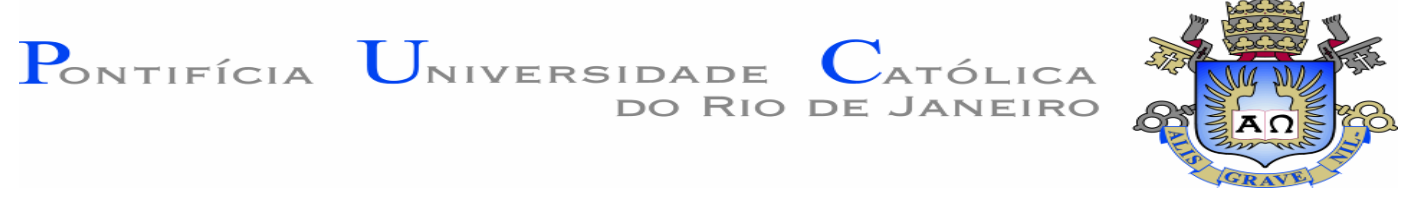

\author{
Joyce Ferreira Pessanha da Silva Rocha
}

\title{
Síntese e ancoragem molecular de 1,2,3-triazois para o tratamento da Fibrose Cística
}

Dissertação apresentada como requisito parcial para obtenção de grau de Mestre pelo programa de Pós-graduação em Química, do Departamento de Química pela PUC-Rio.

Aprovada pela Comissão Examinadora abaixo:

Prof. a Camilla Djenne Buarque Muller

Orientadora

Departamento de Química - PUC-Rio

Prof. André da Silva Pimentel

Coorientador

Departamento de Química - PUC-Rio

Prof. Adriano Defini Andricopulo

Instituto de Física de São Carlos - (IFSC)

Prof. Raoni Schroeder B. Gonçalves Departamento de Química Orgânica - UFRJ

Prof. Jones Limberger

Departamento de Química - PUC-Rio

Rio de Janeiro, 26 de fevereiro de 2021 
Todos os direitos reservados. A reprodução, total ou parcial do trabalho, é proibida sem a autorização da universidade, da autora e do orientador.

\section{Joyce Ferreira Pessanha da Silva Rocha}

Graduou-se em Farmácia na UFRJ (Universidade Federal do Rio de Janeiro). Possui especialização em Manipulação Farmacêutica realizada na mesma Universidade, em 2018.

Ficha Catalográfica

Síntese e ancoragem molecular de 1,2,3-triazois para o tratamento da Fibrose Cística / Joyce Ferreira Pessanha da Silva Rocha ; orientador: Camilla Djenne Buarque Muller ; coorientador: André da Silva Pimentel. - 2021. 126 f. : il. color. ; $30 \mathrm{~cm}$

Dissertação (mestrado)-Pontifícia Universidade Católica do Rio de Janeiro, Departamento de Química, 2021. Inclui bibliografia

1. Química - Teses. 2. Fibrose cística. 3. Ivacaftor. 4. 1,2,3-triazóis.

5. Ciclo adição 1,3-dipolar. 6. Enaminona. I. Muller, Camilla Djenne Buarque. II. Pimentel, André da Silva. III. Pontifícia Universidade Católica do Rio de Janeiro. Departamento de Química. IV. Título. 


\section{Dedicatória}

Dedico este trabalho ao meu querido, amado e eterno avô, Pedro Santos. Apesar de sua partida, seus ensinamentos e palavras de encorajamento ressoam diariamente em minha mente, e por isso, sou incapaz de desistir de qualquer projeto ou missão que em minhas mãos são confiadas. Ele nunca me deixou desistir de nada! Posso imaginar seus gritos de júbilo ao ver-me atravessando essa

linha de chegada, tal como ele fazia em cada vitória que eu alcançava. É por isso que, graças a Deus e a ele, conquistei cada etapa da minha vida até aqui, incluindo este projeto. $\mathrm{O}$ amarei eternamente! 


\section{Agradecimentos}

Ao Deus Todo-Poderoso, por suas infinitas graça e misericórdia, que me sustentam a cada manhã, tanto nos dias bons quanto nos dias ruins. Louvo a Ele por TODAS as coisas!

Ao meu esposo Anderson, por todo amor, apoio, compreensão em todos os momentos! Sem ele, seria bem mais difícil!

À minha família, por me amar tanto e por todo apoio! Sou muito feliz por ter vocês!

À Prof ${ }^{a}$. Dra. Camilla Buarque por ter me orientado e me confiado este projeto.

Ao Prof. Dr. André Pimentel pela coorientação, auxílio e por ter aceitado prontamente o desafio deste trabalho.

Ao Doutor Felipe Rodrigues por toda a ajuda técnica oferecida, por ter tirado minhas dúvidas sempre prontamente e também pelas palavras de incentivo.

À amiga Lígia Farias pelos anos de amizade, pelas palavras de motivação e por todos os momentos de conversas tão aproveitadoras.

Aos amigos que conquistei na PUC-Rio, principalmente, à Francesca, à Raquel, à Kelly, à Rafaela, pelos bons momentos; e às amigas Tatiana e Rosana, pelos excelentes momentos em que tomamos um café que renovava minhas energias!!!

A todo o grupo Labsint, em especial à Talita pelos momentos de descontração no laboratório que fizeram toda a diferença; ao Samuel pela ajuda na bancada, e à Verônica, que, mesmo estando tão longe, me auxiliava com as dúvidas (sempre prontamente).

Aos técnicos da Central Analítica, em especial ao Álvaro, pela análise das amostras de RMN, e por ser sempre muito solícito e gentil em sanar as dúvidas.

À agência de fomento CNPq, pelo apoio financeiro.

Aos funcionários do departamento de química e à PUC-Rio.

O presente trabalho foi realizado com apoio da Coordenação de Aperfeiçoamento de Pessoal de Nível Superior - Brasil (CAPES) - Código de financiamento 001 . 


\section{Resumo}

Rocha, Joyce Ferreira Pessanha da Silva; Buarque, Camilla. Síntese e ancoragem molecular de 1,2,3-triazóis para o tratamento de Fibrose Cística. Rio de Janeiro, 2021. 126p. Dissertação de Mestrado - Departamento de Química, Pontifícia Universidade Católica do Rio de Janeiro.

Por ser uma doença genética, resultado de uma mutação em um gene específico, que gera proteínas (CFTR) defeituosas, a Fibrose Cística é uma patologia difícil de ser tratada. Os custos para os tratamentos atualmente disponíveis são altos, sem os quais, porém, a gravidade da doença tende a crescer ainda mais. Por esse motivo, novos tratamentos farmacológicos vêm surgindo, como o Trikafta®, uma combinação tripla de fármacos com ação sinérgica (elexacaftor, ivacaftor e tezacaftor). Porém, esse medicamento ainda não é disponível no Brasil e o acesso aos tratamentos, em geral, são onerosos. Sendo assim, este trabalho visa a síntese de compostos 1,2,3-triazóis, com possível atividade biológica frente a proteína CFTR, sugerida por ancoragem molecular. Este trabalho também visa selecionar as melhores moléculas quanto aos perfis farmacocinéticos e toxicológicos, avaliados por ferramentas computacionais como swissADME e VirtualToxLab, respectivamente. Dessa forma, a estratégia sintética para a obtenção dos compostos consiste em duas etapas sintéticas. A primeira, envolve a síntese da enaminona - (E)-3-(dimetilamino)acrilaldeido (3a-d) - por organocatálise, a partir de L-prolina e DMA-DMF (1,1-dimetoxi-N,Ndimetillmetanamina) (1). A segunda etapa inclui a reação de cicloadição 1,3-dipolar onpot entre as azidas (5a-h) e as enaminonas previamente obtidas. Assim, foi possível obter 1,2,3-triazóis 1,4-substituídos (6a-k), com rendimentos de 5 a 96\%. Dentre eles, a molécula $\mathbf{6 k}, \quad \mathrm{N}$-(2-(1-(4-metoxifenil)-1H-1,2,3-triazol-4carbonil)fenil)acetamida), destacou-se quanto aos perfis toxicológicos e também pelos resultados observados nos estudos de ancoragem molecular. Os espectros de RMN de ${ }^{1} \mathrm{H}$ e ${ }^{13} \mathrm{C}$ RMN confirmaram a obtenção das estruturas.

Palavras-chave: Fibrose cística; ivacaftor; 1,2,3-triazóis, ciclo adição 1,3dipolar; enaminona; ancoragem molecular; CFTR 


\section{Abstract}

Rocha, Joyce Ferreira Pessanha da Silva; Buarque, Camilla (Advisor). Synthesis and molecular docking of 1,2,3-triazoles for the treatment of Cystic Fibrosis. Rio de Janeiro, 2021. 126p. Dissertação de Mestrado Departamento de Química, Pontifícia Universidade Católica do Rio de Janeiro.

Because it is a genetic disease, the result of a mutation in a specific gene, which generates defective proteins (CFTR), Cystic Fibrosis is a pathology that is difficult to be treated. The costs for currently available treatments are high, without which, however, the severity of the disease tends to increase even more. For this reason, new pharmacological treatments are emerging, such as Trikafta®, a triple combination of drugs with synergistic action (elexacaftor, ivacaftor and tezacaftor). However, this drug is not yet available in Brazil and access to treatments, in general, is expensive. Therefore, this work aims at the synthesis of 1,2,3-triazole compounds, with possible biological activity against the CFTR protein, proposed by molecular anchoring. This work also aims to select the best molecules in terms of pharmacokinetic and toxicological profiles, evaluated by computational tools such as swissADME and VirtualToxpot, respectively. Thus, the synthetic strategy for obtaining the compounds consists of two synthetic steps. The first involves the synthesis of enaminone - (E)-3-(dimethylamino) acrylaldehyde (3a-d) - by organocatalysis, starting from L- proline and DMA-DMF (1,1-dimethoxy-N, Ndimethylmethanamine) (1). The second stage includes the 1,3-dipolar onpot cycloaddition reaction between the azides $(\mathbf{5 a}-\mathbf{h})$ and the previously obtained enaminones. Thus, it was possible to obtain 1,4-substituted 1,2,3-triazoles (6a-k), with yields of 5 to $96 \%$. Among them, the molecule $6 \mathrm{k}, \mathrm{N}-$ (2- (1- (4methoxyphenyl) -1H-1,2,3-triazol-4-carbonyl) phenyl) acetamide), stood out in terms of toxicological profiles and also by results observed in molecular anchorage studies. The ${ }^{1} \mathrm{H}$ and ${ }^{13} \mathrm{C}$ NMR NMR spectra confirmed the structures obtained.

\section{Key words:}

Cystic fibrosis; ivacaftor; 1,2,3-triazoles, 1,3-dipolar addition cycle; enaminone; molecular docking; CFTR. 


\section{Lista de siglas e abreviaturas}

ANVISA - Agência Nacional de Vigilância Sanitária

CFTR - Cystic Fibrosis Transmembrane Regulator

$\mathrm{ABC}-$ ATP-binding cassette

AMPc - Adenosine Cyclic Monophosphate

NBD - Nucleotide Binding Domains

MSD - Membrane-spanning Domain

FDA - Food and Drug Administration

AR - Receptor Andrógeno

ER $\alpha$ e ER $\beta$ - Receptores de Estrogênio

MR - Receptor de Mineralocorticoide

GR - Receptor de Glicocorticóides (), (MR), ();

PR - Receptor da Progesterona receptores nucleares II: Receptores do Fígado X

PPAR - Receptores Ativados por Proliferador do Peroxissoma

TR $\alpha$ e TR $\beta$ - Receptores de Hormônios da Tireoide

AhR - Receptor de Hidrocarboneto Arílico

QED - Quantitative Estimated of Druglikeness

TPSA - Área de superfície polar da molécula

ROTBs - Número de ligações rotacionáveis

nAr - Número de átomos nos anéis aromáticos 


\section{SUMÁRIO}

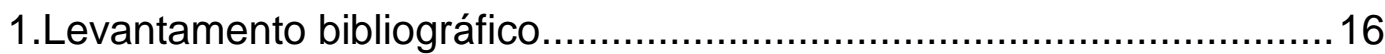

1.1. Fibrose Cística: aspectos gerais ……………........................... 16

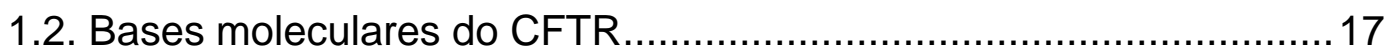

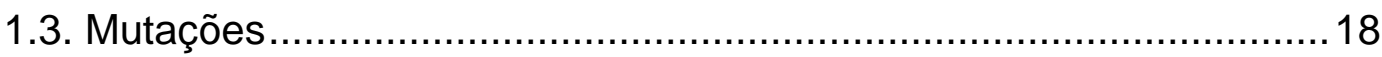

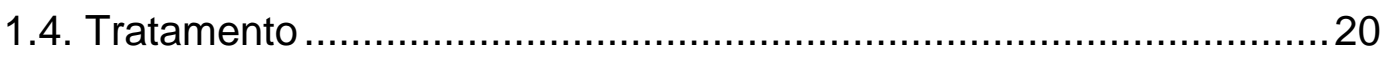

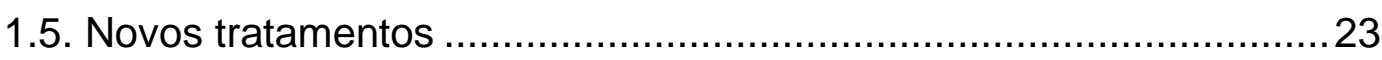

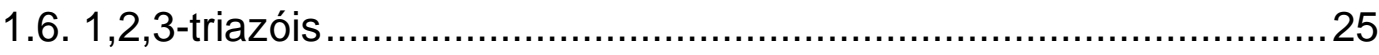

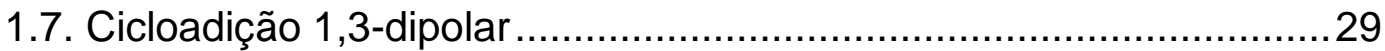

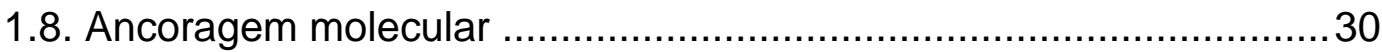

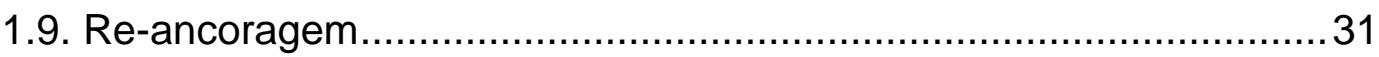

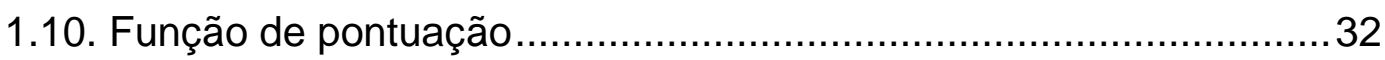

1.11. Análise toxicológica in silico - VirtualToxLab ................................34

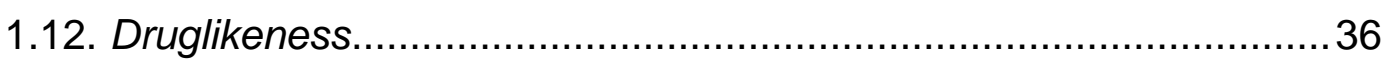

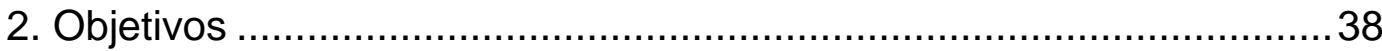

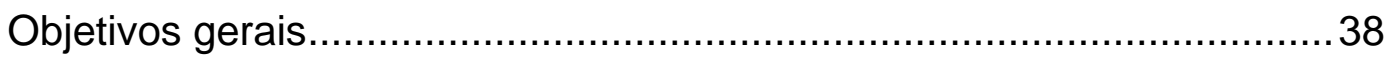

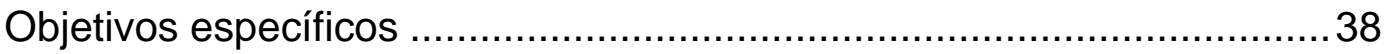

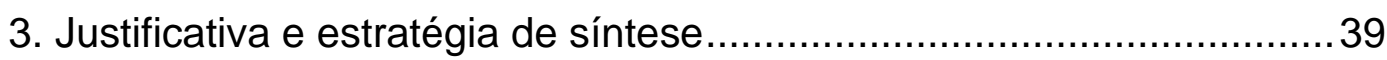

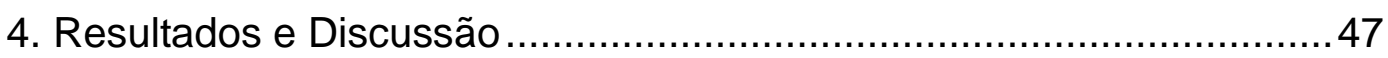

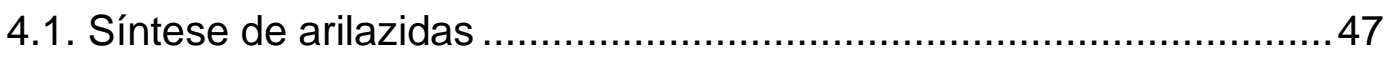

4.2. Síntese da 4-aminobenzoato de 2-etoxietil ( $4 \mathrm{~g})$................................48

4.3. Síntese da $\mathrm{N}$-(2-acetilfenil)acetamida (2c) ...................................... 49

4.4. Síntese da $\mathrm{N}$-(4-acetilfenil)acetamida (2e) ...................................50

4.5. Síntese da N-(2-acetilfenil)-4-metilbenzenosulfonamida (2d) ...........51

4.6. Síntese da N-(4-acetilfenil)-4-metilbenzenosulfonamida (2f) .............52

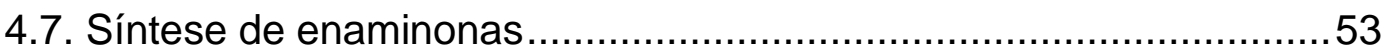

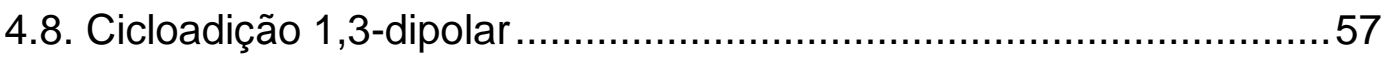




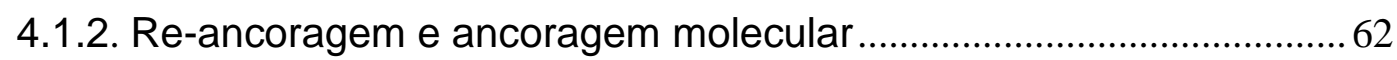

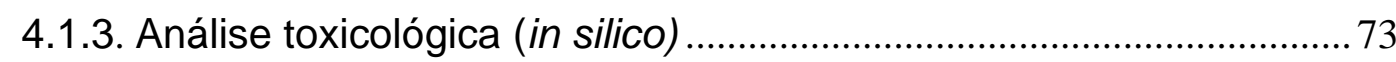

4.1.4. Estudos teóricos de ADME …............................................................... 79

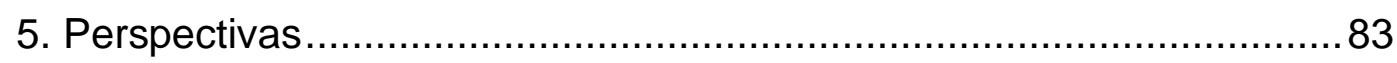

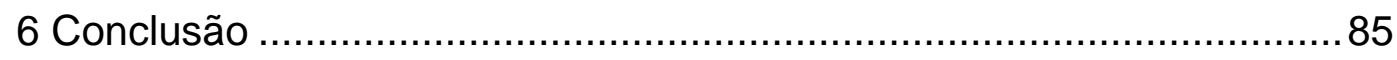

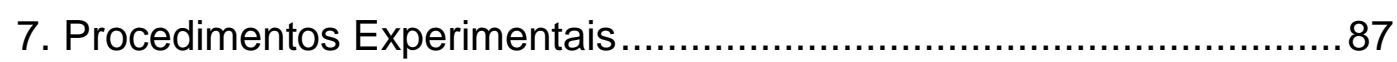

7.1. Procedimentos experimentais (parte sintética)........................... 87

7.1.1. Síntese da 4-aminobenzoato de 2-etoxietil $(4 \mathrm{~g})$.........................87

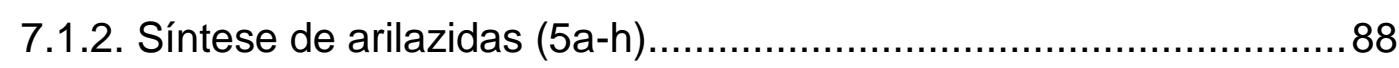

7.1.3. Síntese da $\mathrm{N}$-(2-acetilfenil)acetamida (2c) ............................... 91

7.1.4. Síntese da N-(2-acetilfenil)-4-metilbenzenosulfonamida (2d) ........91

7.1.5. Síntese da $\mathrm{N}$-(4-acetilfenil)acetamida $(2 \mathrm{e})$..............................92

7.1.6. Síntese da N-(4-acetilfenil)-4-metilbenzenosulfonamida (2f) .........93

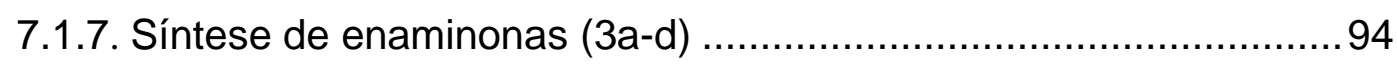

7.1.8. Síntese dos 1,2,3-triazóis-1,4-substituídos..............................95

7.2. Procedimentos experimentais (parte computacional) .....................101

7.2.1. Ancoragem molecular...................................................... 101

7.2.2. Análise toxicológica in silico .............................................. 102

7.2.3. Estudos teóricos in silico .................................................. 102

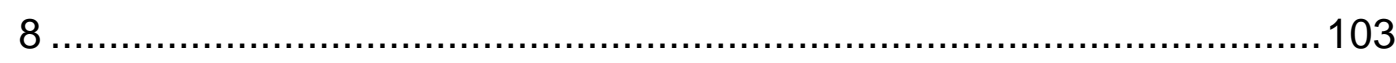

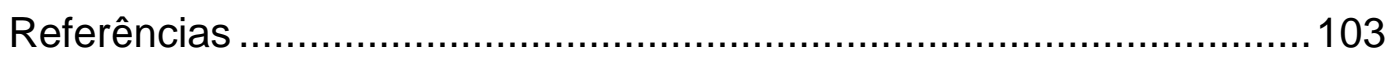




\section{Lista de Figuras}

Figura 1: Proteína CFTR e seus domínios intracelulares e transmembranares (SCHMIDT, HAAF, et al., 2016) 18

Figura 2: Representação esquemática das seis classes de mutação. I, II, II, IV, V , VI , e sua relação com os defeitos na proteína, em comparação com a proteína funcional "wild type. (DECHECCHI, TAMANINI, et al., 2018)

Figura 3: Representação da estrutura química dos fármacos moduladores do CFTR comercializados no Brasil para tratar FC 22

Figura 4: Medicamentos já aprovados e das novas moléculas candidatas a fármacos que se encontram nas fases pré-clínicas e clínicas. Fonte: www.cff.orh/Trials/Pipeline

Figura 5: Estruturas químicas dos novos candidatos ao tratamento da FC

Figura 6: Estruturas dos hetero-aromáticos de cinco membros.a) pirrol; b) tiazol; c) oxazol; d) imidazol; e) 1,2,3-triazol; f) pirazol ; g) 1,2,4-triazol; h) tetrazol; i) pentazol (MELO, DONNICI, et al., 2006)

Figura 7: Exemplos de moléculas com diferentes atividades biológicas contendo o núcleo 1,2,3-triazol (AGALAVE, MAUJAN, et al., 2011; BOLLU, PALEM, et al., 2015) 26

Figura 8: A) Estrutura dos regioisômeros formas de acordo com a posição de substituição do anel triazólico; B) Equilíbrio tautomérico entre as estrututuras do anel triazólico (SOUZA, MIRANDA, 2019) 27

Figura 9: Representação das distâncias dos grupos funcionais transamida (em vermelho) e 1,2,3-triazóis-1,4-dissubstituídos (A). (B) Sobreposição dos grupos funcionais (DOIRON, LE, et al., 2019) 28

Figura 10: Mecanismo geral da reação entre um dipolo e um dipolarófilo em reações de adição 1,3-dipolar (MELO, DONNICI, et al., 2006) 29

Figura 11: Estrutura química do ivacaftor enfatizando os grupamentos quinolinona e amida 
Figura 12: Estruturas dos derivados triazólicos (I - IV) obtidos por Ligia Farias

Figura 13: Espectro de $R M N(H)$ do produto de acetilação 50

Figura 14: Impedimento estérico da amina frente a carbonila na 2aminoacetofenona (A) e a ausência desse efeito na 4-aminoacetofenoa (B) 51

Figura 15: Espectro de RMN de hidrogênio do produto de tosilação ......53

Figura 16: TLC da enaminona: 1. Reagente (acetofenona 2a) e 2.

Enaminona (3a) 54

Figura 17: Espectro de RMN do composto 6c em DMSOd, evidenciando o hidrogênio triazólico $(\mathrm{Ha})$ em 9.81 ppm. 61

Figura 18: Espectro de RMN do composto 6c, feito em $\mathrm{CDCl} 3$ 62

Figura 19: Exemplo de uma molécula que teve a energia minimizada no programa SpartanPro®

Figura 20: Estrutura cristalográfica do complexo proteína (CFTR) - ligante (ivacaftor), obtida do Protein Data Bank, código 6O2P

Figura 21: Representação das poses (em cinza) dos melhores RMSD obtidos. A) Pose 10; B) Pose 2

Figura 22: Estrutura química das moléculas 6I-q; 113m, 114m e JFR49m, incluídas nos estudos de ancoragem molecular 66

Figura 23: Comparação da molécula ivacaftor $(\mathbf{A})$ e os anéis aromáticos circulados em vermelho. (B) mostrando o maior número de ligações rotacionáveis

Figura 24: Interação da CFTR e o ivacaftor no sítio de ligação. Os amoniácidos de interesse podem observados

Figura 25: Representação da interação entre os aminoácidos e as moléculas no sítio de ligação da CFTR. (A) 6q; (B) 6m; (C) 6n; (D) 6i; (E) $6 \mathrm{k}$ e $(\mathbf{F})$ ivacaftor.

Figura 26: Interações entre os resíduos de aminoácidos do receptor $\mathrm{Ar}$ e as moléculas (A) - 6m; (B) - 6e; (C) - DHT; (D) - ivacaftor .77

Figura 27: Interações entre os resíduos de aminoácidos do receptor AhR e as moléculas (A) -6k; (B) - 6e; (C) - 6n; (D) - ivacaftor .78

Figura 28: Informações completas geradas pelo programa SwissADME para a molécula $6 \mathrm{k}$ 
Figura 29: Espectro de RMN 1H do composto 4g............................108

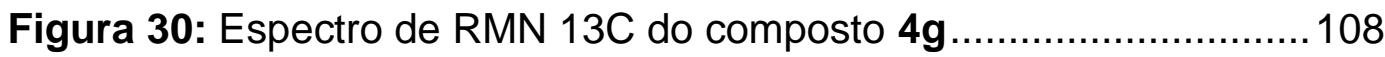

Figura 31: Espectro de RMN 1H do composto $5 \mathrm{~g} \ldots \ldots \ldots \ldots \ldots \ldots \ldots \ldots \ldots \ldots \ldots . . . . . . . . . . . . . .109$

Figura 32: Espectro de RMN 1H do composto 5 h...............................110

Figura 33: Espectro de RMN 13C do composto $5 \mathrm{~h} . . . . . . . . . . . . . . . . . . . . . . . . .111$

Figura 34: Espectro RMN 1H do composto 2c ...................................111

Figura 35: Espectro de RMN 13C do composto 2c ............................112

Figura 36: Espectro RMN H do composto 2d ...................................113

Figura 37: Espectro de RMN 1H do composto 2e ..............................114

Figura 38: Espectro de RMN 13C do composto 2e ............................115

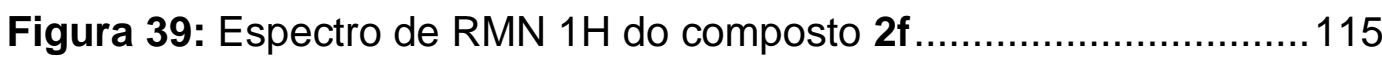

Figura 40: Espectro de RMN 13C do composto 2f .............................116

Figura 41: Espectro de RMN 1H do composto 6a .............................116

Figura 42: Espectro de RMN 1H do composto 6b.............................117

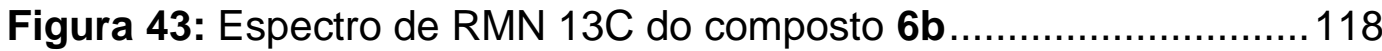

Figura 44: Espectro de RMN 1H do composto 6c .............................118

Figura 45: Espectro de RMN 1H do composto $6 \mathrm{~d}$................................119

Figura 46: Espectro de RMN 1H do composto 6e .............................120

Figura 47: Espectro de RMN 13C do composto 6e .............................120

Figura 48: Espectro de RMN 1H do composto 6f...............................121

Figura 49: Espectro de RMN 13C do composto 6f ..............................121

Figura 50: Espectro de RMN 1H do composto 6g ..............................122

Figura 51: Espectro de RMN 1H do composto 6h..............................122

Figura 52: Espectro de RMN 13C do composto 6h............................ 123

Figura 53: Espectro de RMN 1H do composto 6i ................................123

Figura 54: Espectro de RMN 13C do composto 6i ...............................124

Figura 55: Espectro de RMN 1H do composto 6j..............................124

Figura 56: Espectro de RMN 13C do composto 6j ............................125

Figura 57: Espectro de 1H do composto 6kErro! Indicador não definido.

Figura 58: Espectro de 13C do composto 6k ...................................126 


\section{Lista de Esquemas}

Esquema 1: Estratégia sintética para obtenção de quinolinonas triazois apresentada por Ligia Farias em sua dissertação de mestrado 40

Esquema 2: Estratégia sintética adotada na dissertação de mestrado de Lígia Freitas, em 2019. (A): síntese da enaminona e (B): síntese de 1,2,3triazóis

Esquema 3: Otimização da estratégia sintética para obtenção dos compostos triazólicos (6a-q), baseada nos trabalhos iniciados por Ligia Farias 46

Esquema 4: Preparação de arilazidas (5a-h) a partir de arilanilinas e os respectivos rendimentos obtido

Esquema 5: Reação de obtenção da 4-aminobenzoato de 2-etoxietil ....49

Esquema 6: Reação de acetilação (método de Lamière - Barbier) (CLAYDEN, 2012)

Esquema 7: Reação de obtenção do produto 2e com 4aminoacetofenona (1d)

Esquema 8: Reação de tosilação da 2-aminoacetofenona 1c 52

Esquema 9: Reação de tosilação da 4-amoniacetofenona 1d 52

Esquema 10: Reação de organocatálise para obtenção de enaminonas 54 Esquema 11: Reação de organocatálise das enaminonas obtidas nas seções.

Esquema 12: Mecanismo proposto de organocatálise para formação de enaminona (KUMAR, Dinesh, KOMMI, et al., 2012)

Esquema 13: Cicloadição 1,3-dipolar entre enaminona e azidas para obter os triazóis 1,4-dissubstituídos 6a-k (II)

Esquema 14: Proposta mecanística para a reação de cicloadição 1,3dipolar entre enaminonas (3a-d) e azidas (5a-h) (THOMAS, GOYVAERTS, et al., 2016) 59

Esquema 15: Tentativa de síntese da N-(4-(1-(4-metoxilfenil)-1H-1,2,3triazol-4-carbonil)fenil)-4-metilbenzenosulfonamida $(6 \mathrm{~m})$ 60

Esquema 16: Reação de cloadição 1,3-dipolar para obter a molécula 6q 


\section{Lista de Tabelas}

Tabela 1: Estruturas das quinolinonas-triazois inicialmente planejadas e a energias de interação (Moldock Score). 44

Tabela 2: Relação entre as poses geradas pelo Software e o valor de RMSD, com destaque, em negrito, para as poses 2 e 10, respectivamente 64

Tabela 3: Valores de Moldock Score obtidos em triplicata (ancoragem 1, 2 e 3, respectivamente, e os dados da média e desvio-padrão .67

Tabela 4: Valores de Toxpot obtidos pelo software VirtualToxLab® para todas as moléculas de acordo com a interação com as 16 proteínas-alvo

Tabela 5: Resultados da ancoragem molecular realizada no receptor AhR

Tabela 6: Resultados da ancoragem molecular realizada no receptor $\mathrm{Ar}$ 


\section{Levantamento bibliográfico}

\section{1}

\section{Fibrose Cística: aspectos gerais}

Conhecida como uma doença genética autossômica recessiva, letal, e a mais importante dentre as doenças hereditárias que atingem a raça branca, a Fibrose Cística (FC) é resultado da mutação do gene que expressa a proteína CFTR, do inglês (Cystic Fibrosis Transmembrane Regulator) (BARRY, DONALDSON, et al., 2018; RIBEIRO, RIBEIRO, et al., 2002). A proteína CFTR é necessária para o transporte transmembranar de íons, como cloro, sódio e bicarbonato, sendo encontrada na superfície de células epiteliais do sistema respiratório, no pâncreas, nas glândulas salivares e sudoríparas, no sistema reprodutor e no intestino (REIS, DAMACENO, 1998).

Desde a descoberta do gene da FC, em 1989, cerca de 2000 mutações foram identificadas, sendo que a mais conhecida e estudada é a DF508, que causa depleção de três bases nitrogenadas, uma citosina e duas timinas, implicando na deleção do aminoácido fenilalanina na posição 508 do cromossomo 7 (locus 7q31) (RANG, KEATING, et al., 2020). Sabe-se ainda que cerca de 95\% dos portadores de FC possuem esse tipo de mutação (RUSECKAITE et al., 2017).

Assim, a disfunção da proteína CFTR, decorrente da mutação gênica, resulta no transporte defeituoso de íons, diminuindo o efluxo de cloreto, que torna o interior da célula mais eletronegativo. Isso causa maior fluxo de sódio e água para a célula, preservando o equilíbrio eletrolítico. Verifica-se, pois, o aumento de viscosidade das secreções (que acarreta a oclusão dos ductos), iniciando-se, dessa forma, os processos inflamatórios e posterior fibrose nos diversos tecidos (RIBEIRO, RIBEIRO, et al., 2002). Por esse motivo, a síndrome clínica da FC é multissistêmica e se apresenta de várias formas, sendo as mais comuns: doença pulmonar crônica e progressiva, insuficiência pancreática exócrina, concentração elevada de cloreto no suor (usada para confirmar a doença no teste de suor), infertilidade masculina (azoospermia obstrutiva), dentre outras (CABELLO, 2011).

Apesar de comprometer o funcionamento de diversos órgãos, o quadro mais 
crítico da FC é o acúmulo de muco nos pulmões, que pode provocar insuficiência respiratória, maior responsável pela morbidade e mortalidade associadas à referida patologia (BIEGER, MARSON, et al., 2012).

A FC é a doença genética com maior prevalência em caucasianos, e a incidência é de 1 portador do gene da FC para cada 25 indivíduos desta população, (HAARDT, BENHAROUGA, et al., 1999; REIS, DAMACENO, 1998). No Brasil, a maior incidência é nas regiões sul e sudeste, onde há maior concentração de descendentes europeus, havendo maior semelhança com as populações caucasianas existentes na região centro-sul da Europa (RASKIN, PHILLIPS, 1993).

\section{2}

\section{Bases moleculares do CFTR}

O gene CFTR é composto por 27 exons com $250 \mathrm{~kb}$ por toda a extensão do braço do cromossomo 7, que confere à proteína 1480 aminoácidos. Em geral, a proteína faz parte da família dos transportadores $\mathrm{ABC}$, do inglês (ATP-binding cassette), regulado por AMPc (adenosine cyclic monophosphate), sendo o único dessa família a possuir o domínio R citosólico como regulador da abertura do canal. Esse domínio possui aminoácidos, como serinas e treoninas, que, quando fosforilados por proteína-cinases dependentes de AMPc, induzem mudança conformacional na proteína e permitem o transporte iônico (SCHMIDT, HAAF, et al., 2016).

Para tanto, também é importante a participação de dois domínios de ligação a nucleotídeos, NBD1 e NBD2 (nucleotide binding domains), onde ocorre a ligação do ATP, que resulta na dimerização dos domínios e consequente abertura do transportador iônico (YEH, SOHMA, et al., 2017). A figura 1 exibe o esquema que representa os componentes que constituem a proteína CFTR. 


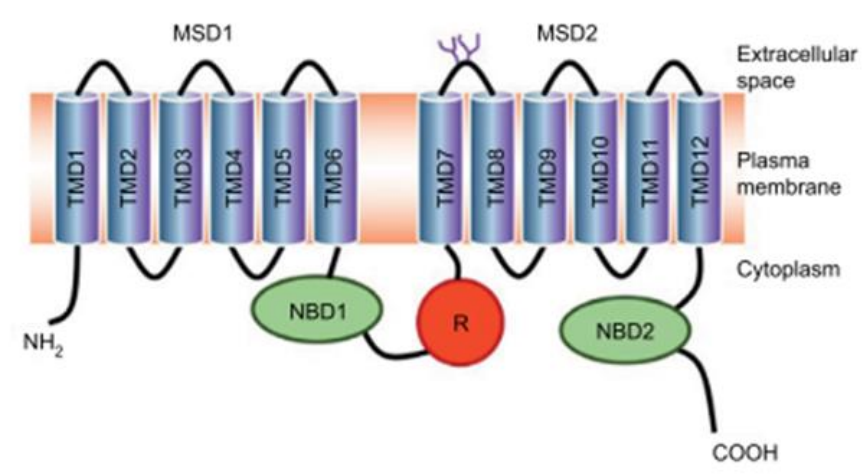

Figura 1: Proteína CFTR e seus domínios intracelulares e transmembranares (SCHMIDT, HAAF, et al., 2016)

Os MSD1 e MSD2 (membrane-spanning domain), são compostos por doze domínios transmembranares, TMD1 e TMD2, cada um contendo seis segmentos hidrofóbicos que, unidos, formam o poro por onde atravessam os íons após a ativação dos domínios R e NBDs citosólicos. (LOPES-PACHECO, 2020).

\section{3}

\section{Mutações}

Recentemente, tem-se classificado as mutações de acordo com a maneira pela qual elas interferem na biossíntese da proteína e comprometem seu funcionamento ideal, sendo possível estabelecer, outrossim, uma conexão com as características fenotípicas da doença (FIRMIDA, 2011). A figura 2 representa didaticamente as etapas da síntese proteica e sua relação com as classificações da mutação (DECHECCHI, TAMANINI, et al., 2018). 


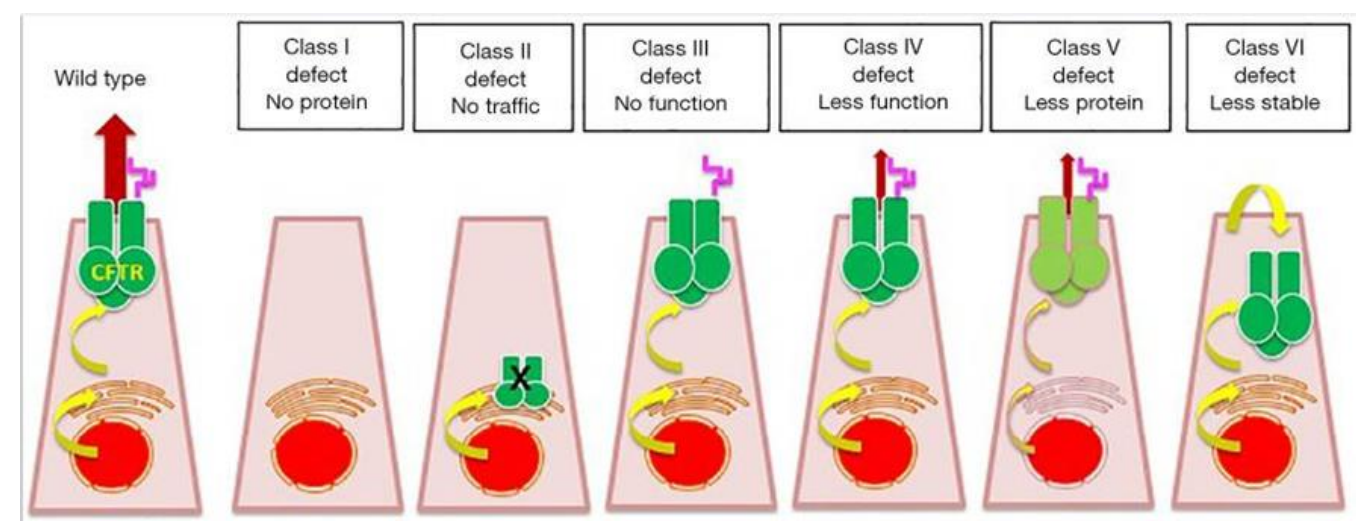

Figura 2: Representação esquemática das seis classes de mutação. I, II, II, IV, V,VI , e sua relação com os defeitos na proteína, em comparação com a proteína funcional "wild type. (DECHECCHI, TAMANINI, et al., 2018)

A classe I abrange as mutações em que há a introdução de um códon de parada no gene, interrompendo a síntese proteica de forma prematura. A classe II envolve as mutações mais comuns (DF508), em que a proteína não se dobra corretamente e perde a conformação ideal devido à ausência de estabilidade. Por isso, é reconhecida pelas chaperonas no retículo endoplasmático como proteína defeituosa, sendo movida ao proteassoma, a fim de ser degradada. Interessante destacar que, como o mecanismo celular de reconhecimento e degradação das proteínas defeituosas não são totalmente efetivos, há casos em que, mesmo incorreta, a CFTR é expressa, exercendo atividade parcial na superfície celular (AMARAL, HUTT, et al., 2020; CABELLO, 2011; SLOANE, ROWE, 2010).

Outra situação peculiar ocorre quando a proteína é expressa normalmente, porém sem atividade, devido aos seguintes fatores: i) disfunção do canal iônico, que são as mutações classe III; ii) comprometimento da condutância dos íons através do canal, que correspondem à mutação de classe IV (CABELLO, 2011).

Quanto à mutação de classe $\mathrm{V}$, verifica-se que há um erro na etapa de splicing do RNA, gerando diminuição da expressão da proteína.

Por fim, na classe VI estão as mutações relacionadas com o truncamento na região carboxi-terminal da proteína, e, consequentemente, a mesma passa a ser expressa na célula por curto período e com baixa atividade (AMARAL, HUTT, et al., 2020; HAARDT, BENHAROUGA, et al., 1999). 


\section{4}

\section{Tratamento}

Devido aos estudos dedicados à maior compreensão do funcionamento da FC, somados aos diagnósticos prévios e a aplicação da terapia apropriada, a expectativa de vida dos fibrocísticos tem aumentado. A literatura aponta que, em países desenvolvidos, o índice de mortalidade reduziu de 1,8 a $2 \%$ ao ano, em um intervalo de aproximadamente 10 anos. Nos Estados Unidos, por exemplo, a sobrevida dos portadores de FC pode chegar a 65 anos para homens e 56 anos para mulheres, considerando que o índice de mortalidade continue decaindo (BALFOUR-LYNN, KING, 2020).

Embora não haja cura para a doença, os dados relatados acima são muito relevantes se comparados à realidade da época em que a doença foi descoberta: a maioria dos nascidos vivos portadores da doença não atingia o final da infância (KOCK, HOIBY, 2000).

Desta forma, além de aumentar a sobrevida dos fibrocísticos, a terapia disponibilizada recentemente visa melhorar a qualidade de vida, uma vez que desacelera a progressão das complicações das lesões nos órgãos acometidos e previne as infecções recorrentes. Como os portadores de FC são mais vulneráveis a infecções pulmonares por Pseudomonas aeruginosa e Staphylococcus aureus, antimicrobianos têm sido muito utilizados. Dentre eles, podem ser citados os aminoglicosídeos, (amicacina lipossomal, tobramicina, por exemplo); $\beta$ lactâmicos, (como o imipenem e meropenem); quinolonas (ciprofloxacino e levofloxacino), etc (DÖRING, FLUME, et al., 2012).

Em combinação com a antibioticoterapia, também são utilizados mucolíticos, anti-inflamatórios (costicosteróides e não-esteroidais), broncodilatadores, além da terapia nutricional, com reposição de enzimas pancreáticas e suplementação de vitaminas lipossolúveis (ATHANAZIO, DA SILVA FILHO, et al., 2017). Além disso, fisioterapia respiratória, oxigenoterapia, suporte psicológico e social são exemplos de medidas não-farmacológicas de apoio ao bem-estar do paciente (FONSECA, BICKER, et al., 2020; ROSA, DIAS, et al., 2008).

O empenho de pesquisadores de todo o mundo e os estudos mais detalhados sobre o funcionamento do canal iônico CFTR, culminaram na descoberta de 
moléculas com capacidade de modular sua atividade. Assim, os agentes moduladores do canal atuam restaurando a função, estabilidade e a expressão proteicas, e são dividos em: read-through, corretores e potenciadores, os quais são classificados de acordo com sua ação específica nas diversas etapas da biossíntese da proteína (SLOANE, ROWE, 2010).

Os agentes red-through suprimem o códon de parada prematuro, e permitem que a proteína seja sintetizada completamente pelo RNAm. Esses fármacos são uma alternativa para o tratamento de mutações de classe I, em que não há tradução da proteína CFTR. Estudos apontam que aminoglicosídeos, como a gentamicina, são eficazes nesse propósito, possibilitando a síntese normal da proteína e sua expressão na superfície apical celular. Porém, em decorrência dos efeitos tóxicos desses antimicrobianos, foi desenvolvida a molécula Ataluren (PTC124), que promove a supressão específica dos códons de parada prematuros, não comprometendo os de parada normais (BEDWELL, KAENJAK, et al., 1997).

Os corretores são um grupo de fármacos que vão agir semelhantemente às chaperonas e reguladores de proteases, conferindo estabilidade conformacional ao CFTR de forma que a regulação do transporte iônico seja eficiente. Assim, essa classe de fármacos é importante para o caso de mutações classe II, em que o transporte do CFTR é bloqueado no retículo endoplasmático (CHENG, Seng H, GREGORY, et al., 1990). Os representantes dessa classe são Lumacaftor (VX-809) e Tezacaftor (VX-661), entretanto, quando utilizados em monoterapia, não produzem melhoras relevantes da função pulmonar. Para pacientes homozigóticos que possuem a mutação DF508, faz-se necessária a terapia combinada com potenciadores (DONALDSON, M.PILEWSKI, et al., 2018).

Potenciadores são uma classe de fármacos utilizados para promover alteração conformacional e estabilidade à proteína - o que a torna ativa - diminuindo a viscosidade das secreções e a susceptibilidade às infecções recorrentes. $\mathrm{O}$ ivacaftor (VX-770) é um exemplo dessa classe e se destaca por ser o primeiro agente modulador descoberto, e é usado principalmente em casos de mutações III e IV, em combinação com corretores (SKILTON, KRISHAN, et al., 2019).

É interessante frisar que o lumacaftor, da primeira geração de corretores, é um indutor enzimático da CYP3A, e o ivacaftor, um substrato dessa enzima. Significa que, quando administrados em associação, o lumacaftor acelera a metabolização do ivacaftor, diminuindo seu efeito biológico. Logo, é necessária uma dose maior do 
que a efetiva desse fármaco, comparada àquela usada em monoterapia, para garantir o efeito farmacológico desejado. Nesse contexto, foi desenvolvido o tezacaftor, baseado na estrutura do lumacaftor, que não possui essa interação farmacodinâmica com o ivacaftor, possuindo também melhores resultados farmacocinéticos e menores efeitos adversos, podendo ser usado na dose efetiva quando em combinação terapêutica (FAJAC, WAINWRIGHT, 2017).

Atualmente, são disponíveis no Brasil os medicamentos Orkambi® (lumacaftor/ivacaftor), Kalydeco® (ivacaftor) e Symdeko® (tezacaftor/ivacaftor + ivacaftor), que podem ser adquiridos pela Vertex Pharmaceuticals. A figura 3 a seguir representa a estrutura química desses fármacos.

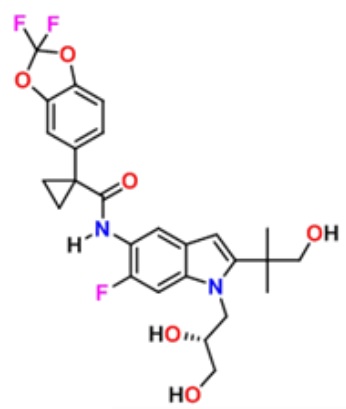

Tezacaftor

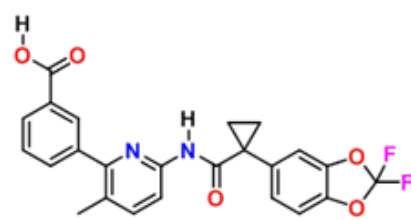

Lumacaftor<smiles>CC(C)(C)c1cc(O)c(NC(=O)c2c[nH]c3ccccc2c3=O)cc1C(C)(C)C</smiles>

Ivacaftor

Figura 3: Representação da estrutura química dos fármacos moduladores do CFTR comercializados no Brasil para tratar FC

A literatura descreve ainda compostos de origem natural que também exercem atividade moduladora no canal CFTR. Dentre eles, destacam-se as xantinas, como a cafeína, teobromina e teofilina presentes no café, chocolate e em alguns chás, que são inibidores de fosfodiesterases (PDEs), aumentando a atividade do transportador, prevenindo sua defosforilação. Além disso, os alimentos que contêm soja são ricos em isoflavonas, como a genisteína, que é um inibidor de tirosina cinase, e assim, ativa o CFTR. O desafio é estabelecer a dose dessas substâncias necessária para garantir esses efeitos, sendo difícil garanti-la na alimentação diária, além de os compostos citados serem inespecíficos, regulando muitos outros processos bioquímicos do organismo (SCHMIDT, HAAF, et al., 2016). 


\section{5}

\section{Novos tratamentos}

A aprovação da comercialização do ivacaftor, em 2012, melhorou consideravelmente a qualidade de vida dos pacientes, gerando grande motivação dos pesquisadores, a fim de compreender detalhadamente o mecanismo de ação desses agentes. Desde então, novas moléculas candidatas a fármacos para FC vêm surgindo, e muitas estão na fase de ensaios pré-clínicos, in-vitro, e nas primeiras etapas dos ensaios clínicos, como mostra a figura 4.

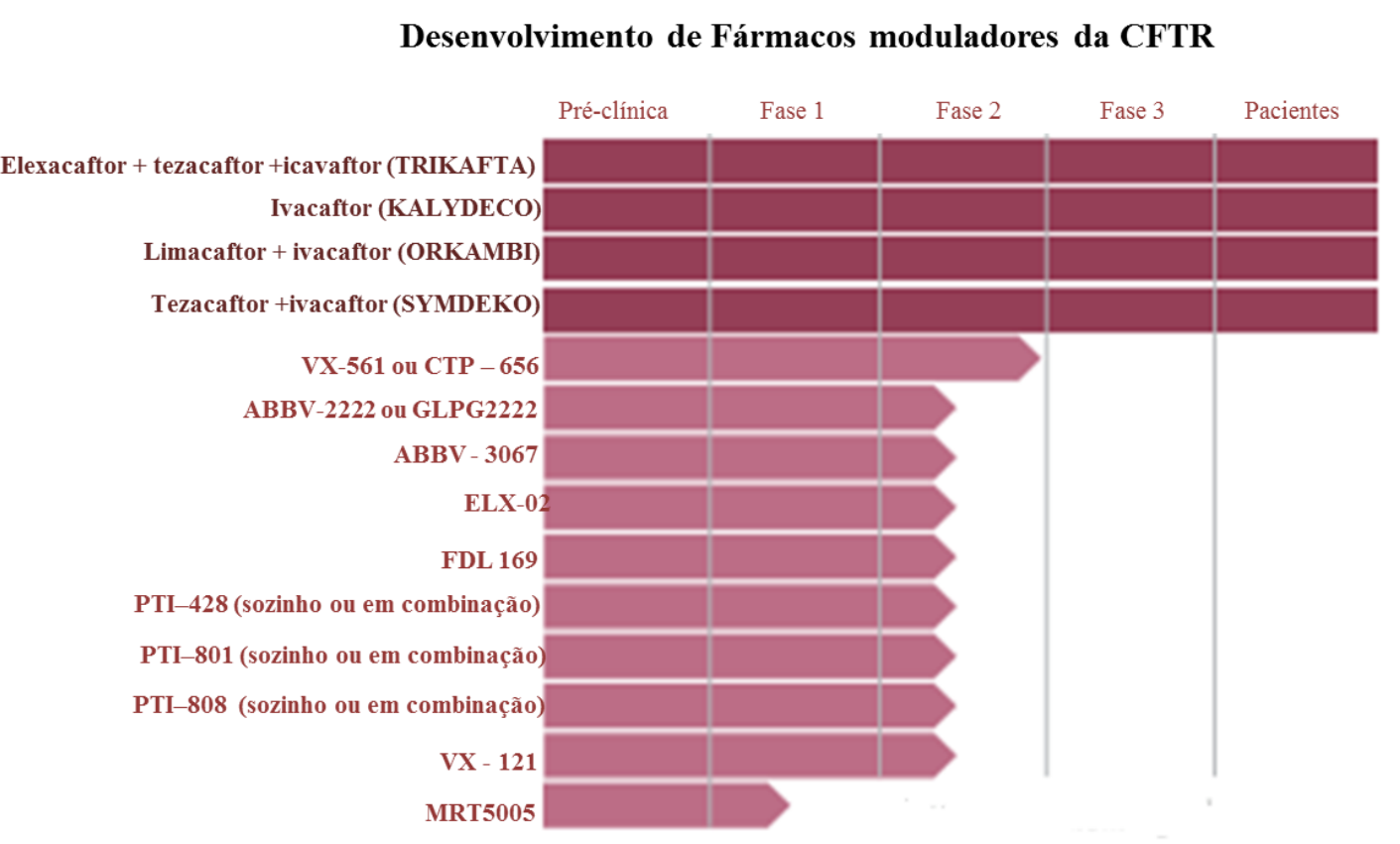

Figura 4: Medicamentos já aprovados e das novas moléculas candidatas a fármacos que se encontram nas fases pré-clínicas e clínicas. Fonte: www.cff.orh/Trials/Pipeline

Em 2019, a FDA aprovou a comercialização do Trikafta® para maiores de 12 anos que possuem pelo menos uma cópia do gene mutado DF508. Produzido pela Vertex Pharmaceutical, o medicamento é a primeira combinação tripla de um potenciador (ivacaftor) com dois corretores, elexacaftor e tezacaftor. $\mathrm{O}$ elexacaftor exerce um efeito aditivo melhorando o processamento e tráfego da proteína CFTR à superfície apical celular (BEAR, 2020).

Apesar da importância dessa combinação tripla, salienta-se o ônus que essa classe de medicamentos representa, principalmente, para países em desenvolvimento, como o Brasil, mesmo que venha a ser aprovado pela Anvisa 
(Agência Nacional de Vigilância Sanitária).

Dentre as novas moléculas que podem ser citadas, destacam-se o Deutivafactor (VX-561), da Vertex Pharmaceutical, que é a forma deuterada do ivacaftor e tem mostrado maior potência, pois é necessário apenas uma dose diária comparado com duas doses diárias do ivacaftor. Além disso, somam-se as vantagens do efeito isotópico relacionado à substituição do hidrogênio pelo deutério.

Dentre as vantagens, podem se destacar a viabilidade de rastreamento dos mecanismos biológicos, visto que o deutério pode se comportar como um biomarcador, o que permite elucidar possíveis mecanismos de ação do medicamento (CLAYDEN, 2012).

Além dele, o Galicaftor (ABBV-2222) e (ABBV-3067) são corretores desenvolvidos pela Abbvie/Galapagos, sendo o primeiro muito promissor, mais potente do que tezacaftor e lumacaftor. Ainda é relevante citar o posenacaftor (PTI801), um corretor que tem demonstrado ser mais potente do que os já existentes no mercado, e apresenta sinergismo quando combinados in vitro com lumacaftor ou tezacaftor (LOPES-PACHECO, 2020).

Curiosamente, novas classes de moduladores estão em fase de estudo: os estabilizadores e amplificadores, representados por casovonstat (N91115) e nesolicaftor (PTI-428), respectivamente. Os primeiros prolongam a expressão da proteína mutante na membrana apical ao inibir sua degradação precoce mediada pela maquinaria celular; e os amplificadores aumentam a expressão do RNAm, permitindo que mais proteínas imaturas sejam sintetizadas e direcionadas para a próxima etapa de maturação (DONALDSON, SOLOMON, et al., 2017; GIULIANO, WACHI, et al., 2018). A figura 5 expõe as estruturas químicas das novas moléculas candidatas a fármacos supracitadas. 


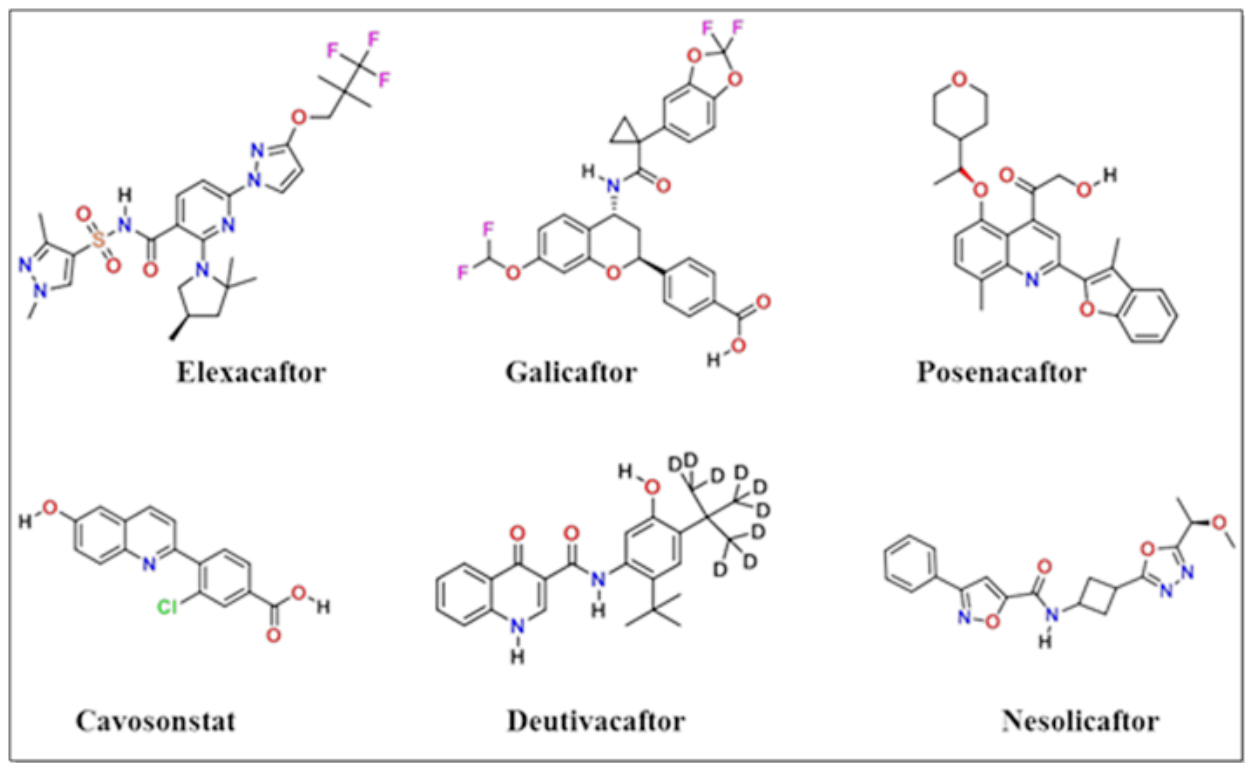

Figura 5: Estruturas químicas dos novos candidatos ao tratamento da FC

\section{6}

\section{1,2,3-triazóis}

Em geral, substâncias heterocíclicas aromáticas que contêm ao menos um átomo de nitrogênio são chamadas de azol, sendo o pirrol o representante mais simples desta classe. Estes compostos heterocíclicos podem ainda possuir os átomos de enxofre ou oxigênio em sua estrutura, sendo chamados de tiazol e oxazol, respectivamente, representados na figura 6. (MELO, DONNICI, et al., 2006).

\begin{tabular}{|c|c|c|c|c|c|c|c|c|}
\hline$\frac{U}{a}$ & $\underset{\mathrm{N}}{\mathbb{\mathrm { b }}}$ & $\mathrm{N}-\frac{}{\mathrm{c}}$ & $\mathbb{N}_{\mathrm{N}}^{\substack{\mathrm{H} \\
\mathrm{N}}}$ & 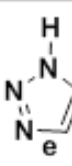 & $\underbrace{\mathrm{N}_{\mathrm{f}}^{\mathrm{N}}}_{\frac{1}{\mathrm{~N}}}$ & $\prod_{\mathrm{g}}^{\mathrm{N}-\mathrm{N}}$ & $\prod_{\substack{\mathrm{N}-\mathrm{N} \\
\mathrm{N}}}^{\substack{\mathrm{H} \\
\mathrm{N}}}$ & $\underbrace{\substack{H \\
N}}_{\substack{H \\
N}}$ \\
\hline
\end{tabular}

Figura 6: Estruturas dos hetero-aromáticos de cinco membros.a) pirrol; b) tiazol; c) oxazol; d) imidazol; e) 1,2,3-triazol; f) pirazol ; g) 1,2,4-triazol; h) tetrazol; i) pentazol (MELO, DONNICl, et al., 2006).

Os triazóis compreendem o grupo mais estudado dentre esses compostos heterocíclicos aromáticos azoicos devido suas aplicações biológicas, estando presentes nas estruturas de fármacos utilizados para diversas morbidades. Os triazóis são classificados em vicinais (1,2,3-triazóis), figura 6e ou simétricos (1,2,4triazóis), figura 6g. Ganham destaque os vicinais, que constituem os grupos 
farmacofóricos de moléculas importantes com atividade antimicrobiana (1 e 2), anticâncer (3 e 5), antiviral (4), por exemplo, dentre muitas outras (figura 7) (AGALAVE, MAUJAN, et al., 2011).

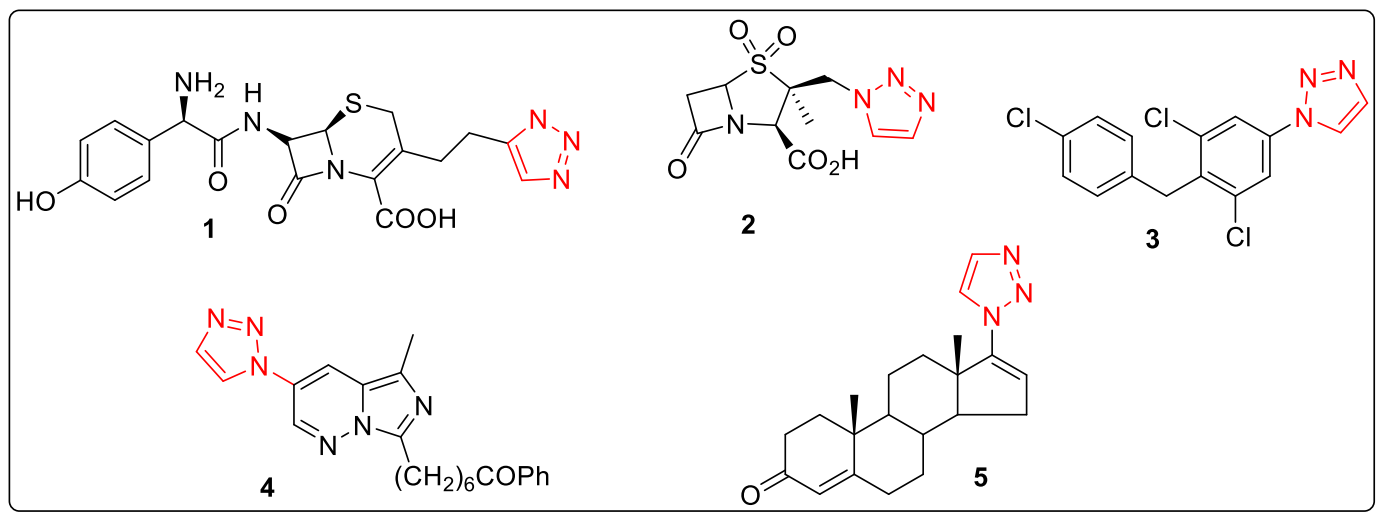

Figura 7: Exemplos de moléculas com diferentes atividades biológicas contendo o núcleo 1,2,3-triazol (AGALAVE, MAUJAN, et al., 2011; BOLLU, PALEM, et al., 2015)

Os triazóis vicinais podem ser substituídos nos átomos de nitrogênio e carbono, podendo, então, ser obtidos os regioisômeros, como mostrado na figura $8 \mathrm{~A}$. E ainda, de acordo com a 8B, os 1,2,3-triazóis, substituídos ou não, podem se apresentar de diferentes formas tautoméricas que vão depender da posição da ligação nitrogênio - hidrogênio $(\mathrm{N}-\mathrm{H})$, do nitrogênio $1(1 \mathrm{H})$, do nitrogênio $2(2 \mathrm{H})$ ou do nitrogênio 3 $(3 \mathrm{H})$ do anel triazólico. A literatura relata que o equilíbrio tautomérico vai depender de fatores relacionados com solvente, temperatura e concentração.

Todavia, em solução aquosa, estudos indicam que o $2 H$ 1,2,3-triazol é o tautômero mais predominante em função da repulsão eletrônica dos pares de elétrons do nitrogênio 1 do tautômero $1 H$ 1,2,3-triazóis.

Nesse contexto, importa destacar que metodologias sintéticas regiosseletivas vêm sendo muito desenvolvidas, principalmente, para a obtenção de triazóis vicinais 1,4 substituídos, visto que a metodologia tradicional utiliza azidas e acetilenos em refluxo na presença de tolueno, resultando em uma mistura de regioisômeros. Dessa forma, além de outros métodos sintéticos, o estudo da utilização de sais de cobre para a obtenção de triazóis regiosseletivos tem sido de grande interesse na química orgânica e medicinal (SOUZA, MIRANDA, 2019). 


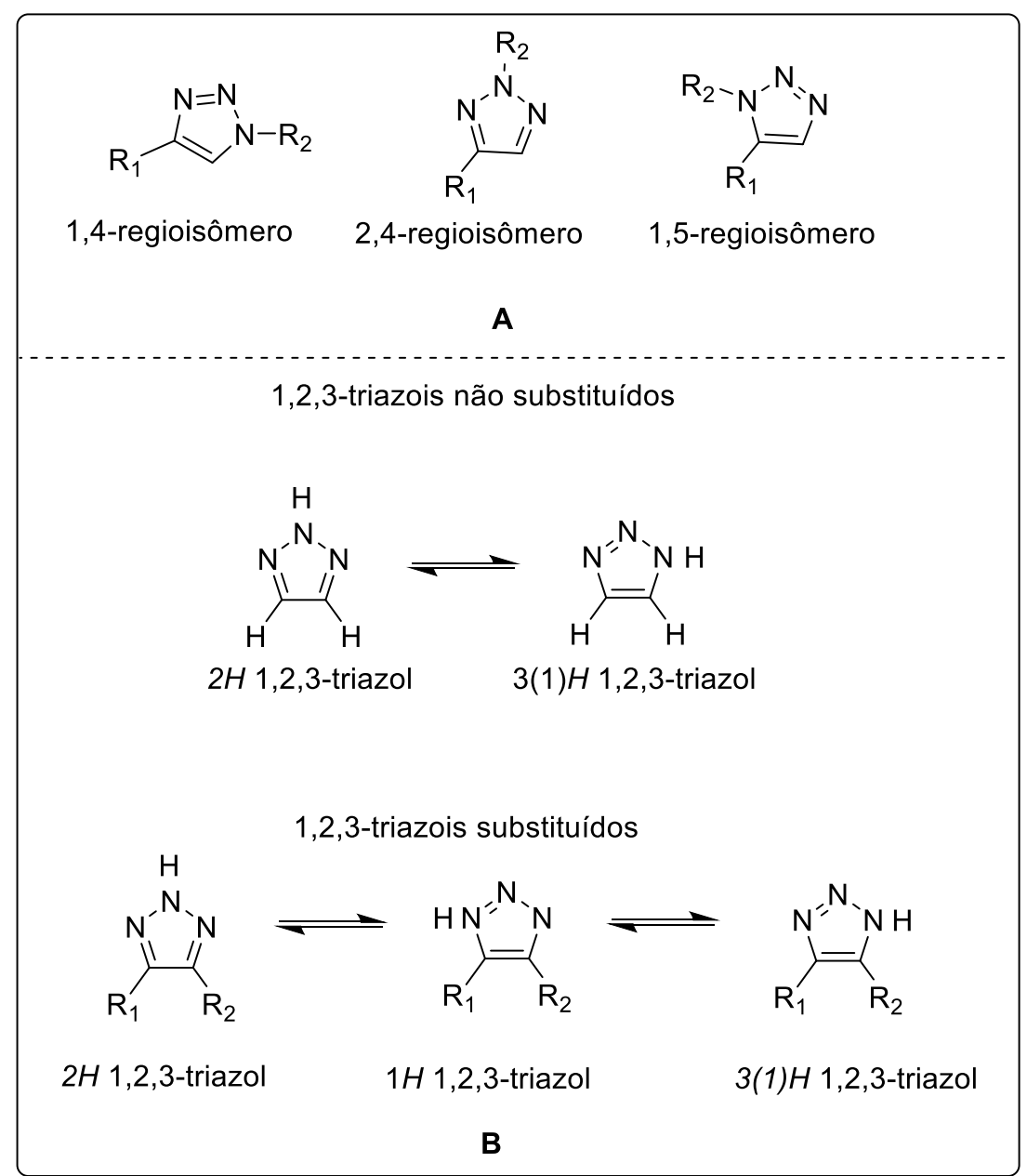

Figura 8: A) Estrutura dos regioisômeros formas de acordo com a posição de substituição do anel triazólico; B) Equilíbrio tautomérico entre as estrututuras do anel triazólico (SOUZA, MIRANDA, 2019)

O núcleo 1,2,3-triazol é o bioisóstero bastante usado para o grupamento amida na química medicinal. Isso se deve, por exemplo, à semelhança de padrões eletrônicos e sobreposição dos átomos entre 1,2,3-triazois-1,4-disubstituídos e as trans-amidas, pois, como mostra a figura 9, substituintes ligados nas posições 1 e 4 do triazol conferem uma distância de aproximadamente $5 \AA$, próxima à distância de 3,9 ̊̊ entre os substituintes da amida, $\mathrm{R}_{1}$ e $\mathrm{R}_{2}$.

Somado a isso, o átomo N3 e o C5 do triazol são aceptores e doadores de hidrogênio, respectivamente, características essas semelhantes às dos átomos de oxigênio e nitrogênio da amida. Isso sugere que os triazóis ocupam a mesma posição espacial das trans-amidas, ou seja, amidas que possuem os substituintes $\mathrm{R}_{1}$ e $\mathrm{R}_{2}$ em lados opostos do plano. Outra questão importante é que a substituição bioisistérica de 1,2,3-triazol aumenta tanto a estabilidade química (sendo mais tolerante à hidrólise), quanto metabólica, o que pode aumentar a biodisponibilidade 
do fármaco a ser desenvolvido (DOIRON, LE, et al., 2019).

A

Aceptor de $\mathrm{H}$

ภु<smiles>[R]C(=O)N([R2])[Tl]</smiles>

Doador de $\mathrm{H}$
Aceptor de $\mathrm{H}$

\section{Diståncia de}

$\mathrm{R}_{1}$ para $\mathrm{R}_{2}=$

$3.8-3.9$ angstron

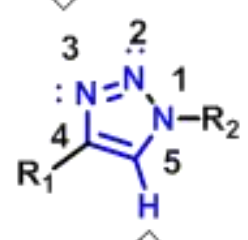

仓े

Doador de $\mathrm{H}$
Distância de

$R_{1}$ para $R_{2}=$

$5.0-5.1$ angstron

B

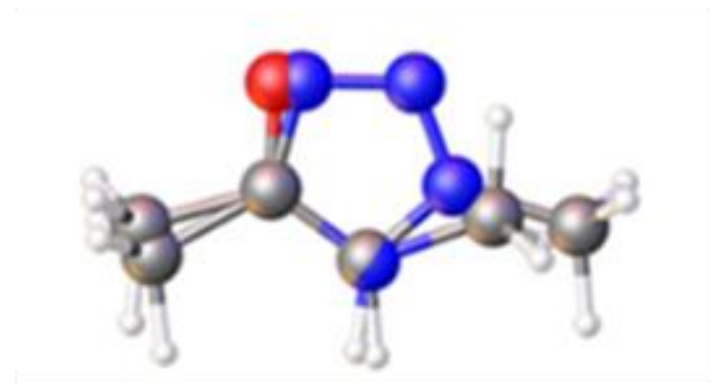

Figura 9: Representação das distâncias dos grupos funcionais trans-amida (em vermelho) e 1,2,3-triazóis-1,4-dissubstituídos (A). (B) Sobreposição dos grupos funcionais (DOIRON, LE, et al., 2019)

Vale destacar que os 1,2,3-triazóis podem se sintetizados por meio da reação de click chemistry, que constitui uma metodologia sintética muito utilizada e bem conhecida para a obtenção desses compostos. Essa estratégia trata-se de uma reação de cicloadição 1,3-dipolar que inclui a participação de cobre (I) como catalisador (THOMAS, GOYVAERTS, et al., 2016).

Porém, atualmente, é possível sintetizar triazóis vicinais a partir de outras metodologias, ganhando destaque, principalmente, as de cicloadição 1,3-dipolar utilizados neste trabalho para obtenção dos compostos 1,2,3-triazóis de interesse. Vale destacar que, neste caso, dispensa-se o uso de metais como cobre e chumbo, tornando a reação menos nociva ao meio ambiente e também bem mais econômica. 


\section{7}

\section{Cicloadição 1,3-dipolar}

A reação de cicloadição 1,3-dipolar tem uma enorme representatividade em síntese orgânica, dentre outros fatores, por permitir atualmente a obtenção de uma grande variedade de compostos triazóis vicinais, que, como já descrito, têm ocupado consideravelmente sua relevância no âmbito farmacêutico. Tal êxito deve ser atribuído a pesquisadores como Huisgen, Sharpless e Meldal, responsáveis pela descoberta da reação de cicloadição envolvendo alcino e azidas, AAC, do inglês Alkyne azide cycloaddition (WAN, CAO, et al., 2016).

De maneira geral, a reação ocorre entre um dipolo (1,3-dipolos) e um dipolarófilo composto por elétrons $\pi$, que vão interagir de forma concertada - o que justifica a estereoespecificidade da reação - resultando em um ciclo-aduto. Importa enfatizar que o elemento 1,3-dipolo se trata de uma estrutura de Lewis com dois orbitais atômicos preenchidos e um vazio, permitindo a deslocalização dos elétrons ao longo da estrutura, e são representados pelos ânions alilas e propargilas (figura 12).

A nomenclatura (1,3-dipolo) faz referência ao fato de esses compostos possuírem ao menos uma estrutura de ressonância com cargas opostas nos átomos adjacentes. Quanto aos dipolarófilos, são estruturas representadas por alcenos ou alcinos com ligação $\pi$, a exemplo de grupamentos como carbonil, imina, azo e nitroso, incluindo as azidas, que são os dipolos mais conhecidos em síntese (CAREY, SANBERG, 2007).

É sabido que o ponto crítico dessa reação é a baixa regiosseletividade quando são utilizados acetilenos não simétricos, gerando formas isoméricas de 1,2,3triazóis (MELO, DONNICI, et al., 2006). A figura 10 ilustra o mecanismo geral da reação, e o ciclo-aduto formado.

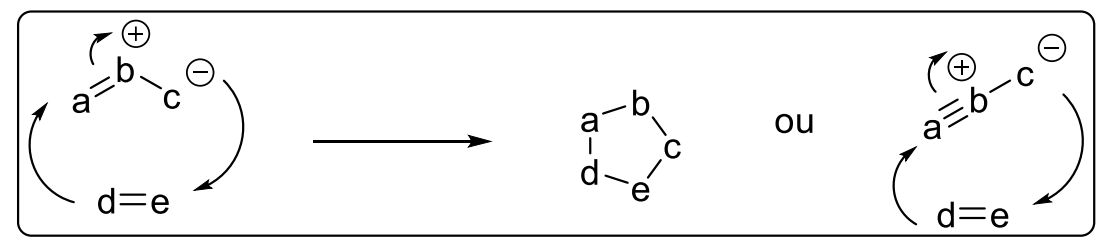

Figura 10: Mecanismo geral da reação entre um dipolo e um dipolarófilo em reações de adição 1,3-dipolar (MELO, DONNICI, et al., 2006) 
Assim, essa metodologia sintética vem sendo melhorada, sobretudo para atender à demanda de síntese de produtos triazólicos com alta regiosseletividade e rendimentos satisfatórios, evitando a formação de subprodutos. Como exemplo, reações de cicloadição organocatalítica envolvendo azidas e cetonas enolizáveis ou aldeídos, por meio da formação de enaminas, íon imínio ou enolatos como intermediários, são estratégias sintéticas de grande interesse na síntese orgânica atualmente. (THOMAS, GOYVAERTS, et al., 2016).

\section{8}

\section{Ancoragem molecular}

A simulação computacional aplicada ao planejamento de fármacos tem sido grande aliada no sentido de reduzir custos e tempo associados ao processo da descoberta de fármacos. De fato, a ferramenta computacional é de extrema relevância porque permite, principalmente, concentrar esforços naquelas moléculas que realmente possuem uma energia de ligação mais significativa na proteína de interesse.

Assim, os testes in vitro seriam aplicados para confirmar ou melhorar os resultados daqueles compostos obtidos por triagem virtual, que é mais veloz e econômico do que apenas o processo experimental de avaliação biológica de uma série de moléculas por tentativa e erro frente a um alvo específico (HEBERLE, F. DE AZEVEDO, 2011).

Nesse contexto, a ancoragem molecular é uma ferramenta computacional que, de maneira geral, se baseia na ideia do modelo chave-fechadura, em que a chave é representada por um ligante e a fechadura, o sítio de ligação da proteína ou receptor de estudo. Assim, analogamente, os estudos de docking ou ancoragem molecular permitem avaliar e selecionar, de acordo com critérios bem estabelecidos (mediante uma molécula de referência), quais conformações geradas do ligante são capazes de melhor interagir com a proteína-alvo (HEBERLE, F. DE AZEVEDO, 2011).

Entretanto, por trás desse modelo mais simples, sabe-se que os programas de ancoragem utilizam diversos parâmetros físico-químicos associados aos átomos que compõem os ligantes e a proteína, como distâncias e ângulo de ligação, interações intermoleculares e eletrostáticas, ângulo de torsão, dentre outros, para 
prever a melhor conformação do ligante.

Pelo exposto, ainda é relevante destacar que, apesar de o modelo chavefechadura retratar bem o funcionamento básico do programa, sabe-se que não é totalmente correto, uma vez que induz afirmar que a proteína é rígida e apenas os ligantes são flexíveis e se moldam à fechadura. Também, os efeitos dinâmicos e entrópicos são desprezados na ancoragem molecular.

Os estudos de ancoragem, porém, permitem que ambos (proteína e ligante) tenham flexibilidade, proporcionando um número ainda maior de possibilidades conformacionais do sistema. No entanto, uma das maiores desvantagens dessa abordagem é que o programa irá demandar mais tempo para retornar as melhores poses devido à maior capacidade de processamento exigida. (VERLI, BARREIRO, 2005).

\section{9}

\section{Re-ancoragem}

Geralmente, antes da realização da etapa de ancoragem molecular propriamente dita, faz-se necessário estabelecer a validação do método, processo conhecido como re-ancoragem, cujo objetivo é a padronização dos parâmetros a serem aplicados nas etapas posteriores. $\mathrm{O}$ processo pode ser comparado à validação de algum procedimento experimental, em que a estrutura cristalográfica do ligante complexado à proteína de interesse, obtida experimentalmente, é considerada o padrão ouro da análise. Assim, avalia-se a capacidade do software de realocar o ligante (ivacaftor) no sítio ativo da proteína e comparar a sua posição (ou pose) de encaixe com a posição da estrutura cristalográfica do ligante.

A ferramenta de análise usada para estudar os resultados desta etapa de validação é a raiz do desvio quadrático médio (da sigla RMSD em Inglês Rootmean Square Deviation), que é expresso pela equação matemática mostrada abaixo, em que $N$ faz referência ao número total de átomos.

$$
\begin{array}{r}
R M S D=\sum_{j=1}^{N}\left[\left(x_{\text {posej- }} x_{\text {cristalj }}\right)^{2}+\left(y_{\text {pose j- }} y_{\text {cristalj }}\right)^{2}+\right. \\
\left.\left(z_{\text {posej- }-} z_{\text {cristalj }}\right)^{2}\right]^{1 / 2}
\end{array}
$$


Pela equação, o RMSD pode ser interpretado como a média das distâncias entre os átomos do ligante em uma dada posição (pose), ( $\mathrm{x}_{\text {pose }}, \mathrm{y}_{\text {pose }}, \mathrm{z}_{\text {pose }}$ ) e da estrutura cristalográfica do mesmo ( $\left.\mathrm{x}_{\text {cristal }}, \mathrm{y}_{\text {cristal }}, \mathrm{z}_{\text {cristal }}\right)$. Nota-se que as orientações $\mathrm{x}, \mathrm{y}, \mathrm{z}$, são as coordenadas dos átomos que traduzem na sua posição espacial. Com base nisso, considera-se que a pose ou a conformação do ligante dada pelo software no sítio ativo da proteína será adequada se o RMSD obtido for menor que $2.0 \AA$ (THOMSEN, CHRISTENSEN, 2006).

\subsection{0}

\section{Função de pontuação}

É importante a compreensão do que seja a função de pontuação como critério de análise adotado no presente trabalho para cada conformação obtida. Esse critério é o valor da função de energia Moldock Score fornecido pelo software Molegr (THOMSEN, CHRISTENSEN, 2006).

De forma geral, esse dado é resultado de uma equação matemática onde se calcula a soma das energias de interação do complexo ligante-proteína e da energia interna do ligante, considerando todos os átomos envolvidos, tanto da proteína quanto do ligante. No cálculo, são consideradas as interações eletrostáticas entre os átomos com carga, com base na Lei de Coulomb, e também ligações de hidrogênio.

É imprescindível citar que, neste modelo matemático, igualmente são incluídas as contribuições das interações estéricas entre os átomos, van der waals, levandose em conta a presença de átomos doadores e aceptores de hidrogênio, tanto no ligante quanto na proteína (THOMSEN, CHRISTENSEN, 2006).

Evidente que essa resolução matemática não é tão trivial, porém, o atual objetivo dessa exposição teórica é compreender como o programa alcança os valores de Moldock Score - parâmetro de análise escolhido neste trabalho, para fundamentar as interações entre as moléculas de interesse e o alvo farmacológico.

Após obter uma pequena noção do que seja a função de energia, é necessário entender como os valores fornecidos por ela podem ser interpretados.

Desta forma, o Moldock Score é correlacionado com a constante de dissociação $\mathrm{K}_{\mathrm{D}}$ e a energia livre de ligação $(\Delta \mathrm{G})$ envolvidos em um equilíbrio químico como 
exemplificado a seguir:

$$
[\mathrm{P}]+[\mathrm{L}] \rightleftharpoons[\mathrm{PL}]
$$

Sabendo que $\mathrm{P}=$ proteína $(C F T R) ; \mathrm{L}=$ ligante (ivacaftor); $\mathrm{PL}=$ complexo Proteína + Ligante, a relação da constante de equilíbrio $K_{D}$, pode ser escrita da seguinte forma:

$$
\mathrm{Kd}=\frac{[P L]}{[P][L]}(\mathbf{I})
$$

De maneira geral, para relacionar a constante de dissociação com a energia livre de Gibbs, $\Delta \mathrm{G}$, tem-se da físico-química que:

$$
\Delta \mathrm{G}^{\mathrm{o}}=-\mathrm{R} \mathrm{T} \ln \left(\mathrm{K}_{\mathrm{D}}\right),(\mathbf{I I})
$$

onde $: \mathrm{R}=$ constante universal dos gases; $\mathrm{T}=$ temperatura; $\mathrm{K}_{\mathrm{a}}=$ constante de afinidade

Logo, relacionando as equações (I) e (II), pode-se inferir que, quanto maior o valor de $\mathrm{K}_{\mathrm{D}}$, maior a afinidade da interação entre a proteína e o ligante no sítio de ligação. Sendo assim, mais negativo será o valor de $\Delta \mathrm{G}$, que, da segunda lei da termodinâmica, significa que o processo é espontâneo, e, portanto, neste caso, a ligação [PL] é mais favorecida (THOMSEN, CHRISTENSEN, 2006).

Neste contexto, é válido destacar o Rerank Score, parâmetro também fornecido pelo software Molegro. Esse dado traduz a etapa de re-ranqueamento, onde os resultados obtidos nas corridas de ancoramento molecular são "refinados" de modo que são consideradas funções de pontuação mais complexas que incluem as torções sp2-sp2 e o potencial de Lennard-Jones.

A literatura indica que esse processo adotado pelo software aumenta a acurácia dos resultados obtidos em cada ciclo de ancoragem molecular (THOMSEN, CHRISTENSEN, 2006). 
É relevante destacar que a função de pontuação Moldock Score baseia-se no conceito de evolução diferencial, tratando-se de um algoritmo genético, onde o programa é capaz de gerar e selecionar novas poses ou conformações, considerando as ligações hidrogênio e as interações eletrostáticas existentes entre as ligações do ligante e da proteína (THOMSEN, CHRISTENSEN, 2006).

\subsection{1}

\section{Análise toxicológica in silico - VirtualToxLab}

Sabe-se que a toxicidade advém da capacidade de agentes ativos promoverem modulação no sistema fisiológico por meio da interação com a maquinaria celular, funcionando como se fossem hormônios exógenos no organismo, desencadeando os efeitos adversos.

Embora nenhuma substância ativa esteja livre de toxicidade, é crucial prever seu potencial tóxico, afinal, o objetivo da síntese voltada para química medicinal é que os compostos sintetizados sejam candidatos à fármacos.

Para esse fim, o software VirtualToxLab®, é muito bem empregado, pois é capaz de simular e quantificar a força de ligação entre um composto de interesse e as proteínas-alvo. Com tal propósito, o programa utiliza as técnicas de ancoragem molecular e fatores termodinâmicos do sistema envolvido para prever o potencial tóxico dos compostos. O VirtualToxLab® dispõe de 16 proteínas-alvo, onde são incluídas aquelas já conhecidas por causarem efeitos adversos ou as que estão sob suspeitas. Essas 16 proteínas-alvo representam importante papel nas etapas de biotransformação de agentes químicos e nas funções de regulação do sistema fisiológico (VEDANI, DOBLER, et al., 2015). São elas:

- receptores nucleares I: Receptor Andrógeno (AR), Receptores de Estrogênio- ER $\alpha$ e ER $\beta$-, Receptor de Glicocorticóides (GR), Receptor de Mineralocorticoide (MR), Receptor da Progesterona (PR);

- receptores nucleares II: Receptores do Fígado X (LXR), Receptores Ativados por Proliferador do Peroxissoma (PPAR), Receptores de Hormônios da Tireoide (TR $\alpha$ e TR $\beta$ ); 
- receptor de hidrocarboneto arílico (AhR)

- enzimas do citocromo P450: 1A2, 2C9, 2D6, 3A4

- canal de íon potássio (hERG)

A análise do potencial tóxico é feita pelo valor de Toxpot (fornecido pelo programa) que expressa a afinidade da ligação entre as moléculas testadas e as 16 proteínas-alvo, respectivamente, já citadas.

O Toxtpot pode variar de 0.0 (quando não há interação) a 1.0 (ligação extremamente forte). Logo, quanto mais próximo de 1 se encontrar o Toxpot, maior o potencial tóxico da molécula e sua capacidade de gerar efeitos adversos.

As equações matemáticas a seguir expõem como o software calcula o potencial tóxico dos compostos, até alcançar o valor numérico traduzido pelo Toxpot. De forma geral, o programa considera, inicialmente, o Potencial Tóxico individual ( $\mathrm{TP}_{\text {individual }}$ ) para cada uma das 16 proteínas-alvo, conforme a equação abaixo (VEDANI, DOBLER, et al., 2015).

$$
\left(\mathrm{TP}_{\text {individual }}=\mathrm{K}_{\text {normalizado }} \mathrm{x} \mathrm{W}\right)
$$

onde $\mathrm{K}$ é a afinidade de ligação e $\mathrm{W}$, representa o peso da proteína, que é dado por $\mathrm{K}=(1-0,125) \times\left(\sigma_{\text {desvio padrão }} / \mathrm{K}\right)$.

Assim, o valor obtido de $\mathrm{TP}_{\text {total }}$ (Toxpot) é determinado pela soma das contribuições dos valores de $\mathrm{TP}_{\text {individual, }}$ como mostra equação abaixo:

$$
T P_{\text {total }}=\sum_{n-1}^{16}\left(T P_{\text {total,atual }}\right) x\left(T P_{\text {individual }, n}\right) x\left(W_{\text {superfamília }}\right)
$$

onde $: \mathrm{W}=1 / \mathrm{n}, \mathrm{n}=$ número de membros de uma superfamília 


\subsection{2}

\section{Druglikeness}

Os parâmetros toxicológicos são imprescindíveis para selecionar as melhores moléculas para os testes in vitro. Contudo, mesmo que a toxicidade para uma molécula seja baixa e os estudos de ancoragem molecular forneçam energias de interação ótimas como o alvo farmacológico, ainda se fará necessário que a mesma tenha o perfil de druglikeness. Ou seja, é preciso identificar se, de fato, a molécula em análise apresenta características físico-químicas e farmacocinéticas que a tornem biodisponíveis.

Para isso, utiliza-se o software swissADMET, disponível gratuitamente, que avalia os parâmetros com base na estrutura química das moléculas, de modo a prever seu comportamento mediante as etapas de Administração, Distribuição, Metabolização, Excreção e Toxicidade (DAINA, MICHIELIN, et al., 2017).

As características farmacocinéticas são avaliadas a partir das características físico-químicas dos compostos, de acordo com a regra de Lipinski, ou regra dos cinco, que é o método mais conhecido para determinar se um composto será bem absorvido ao ser administrado na forma oral. A regra dos cinco inclui os seguintes fatores: peso molecular (MW) $\leq 500$; coeficiente de partição octanol/água (iLOGP) $\leq 5$; número de doadores de ligação de hidrogênio $\leq 5$; número de aceptores de ligação de hidrogênio $\leq 10,6$. Segundo a regra, o composto é aprovado se não apresentar mais de uma violação dos fatores citados. (ISYAKU, UZAIRU, et al., 2020).

Entretanto, esses limites estabelecidos são mais aplicáveis para moléculas que possuam menor peso molecular e que sejam disponíveis oralmente. Tais fatores representam algumas das limitações descritas para a regra de Lipinski que permitiram o desenvolvimento de outros multiparâmetros ou filtros para melhor avaliar as características de druglikeness. Nesse contexto, os filtros de Ghose e Eger e a regra de Veber são exemplos de outros parâmetros considerados pelo software. (MIGNANI, RODRIGUES, et al., 2018).

Vale citar ainda o conceito de QED, Quantitative Estimated of Druglikeness, que, além de considerar os quatro parâmetros da regra dos cinco, soma, ainda, outros importantes: área de superfície polar da molécula (TPSA), número de 
ligações rotacionáveis (ROTBs), número de átomos nos anéis aromáticos (nAr) e número de subestruturas presentes nas moléculas tidas como não-desejadas (representadas por PAINS e BRANK) (ISYAKU, UZAIRU, et al., 2020). Este último item é extremamente relevante por permitir ao swissADMET identificar se a molécula em estudo apresenta alguma estrutura química que origine fragmentos de metabolização que sejam tóxicos, instáveis, ou responsáveis por comprometer a farmacocinética (DAINA, MICHIELIN, et al., 2017). 


\section{Objetivos}

\section{Objetivos gerais}

Este trabalho visa à síntese de moléculas que sejam ativas frente à proteína CFTR, modulando sua atividade, de modo que representem uma alternativa para o tratamento oral da Fibrose Cística.

\section{Objetivos específicos}

- Sintetizar 1,2,3-triazóis 1,4-substituídos (6a-q) através da reação de cicloadição 1,3-dipolar, entre enaminonas (3) e azidas (5)

- Investigar a interação dos compostos propostos frente à proteína alvo, CFTR, por ancoragem molecular.

- Avaliar a toxicologia in silico dos compostos propostos através do Software VirtualToxLab®.

- Verificar os parâmetros farmacocinéticos através do software SwissADME das moléculas sintetizadas que tiveram melhores resultados toxicológicos.

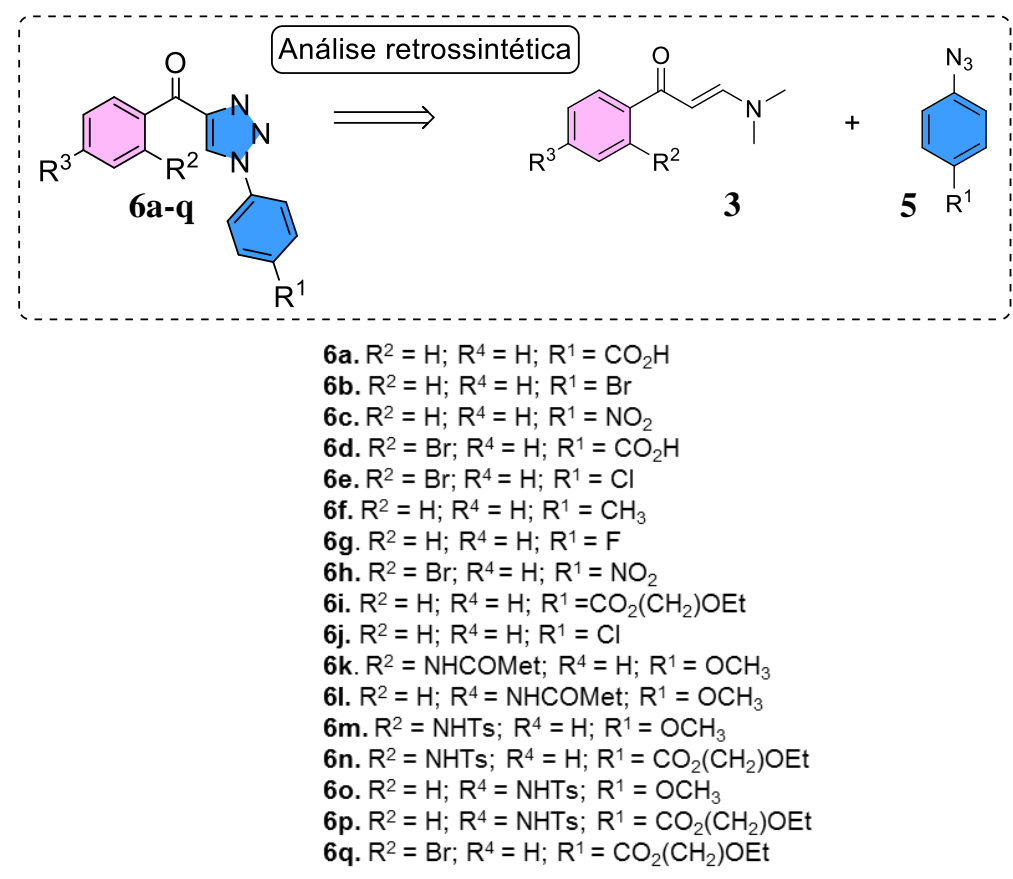




\section{3}

\section{Justificativa e estratégia de síntese}

A Fibrose Cística é uma doença progressiva que debilita seus portadores, comprometendo o funcionamento de diversos órgãos vitais, sobretudo os pulmões, que pode levar ao óbito se não for devidamente tratada.

Sendo assim, o desenvolvimento de novos fármacos para o tratamento da FC é extremamente necessário, visando, principalmente, que os fibrocísticos tenham maior acesso ao tratamento. Isso porque o custo anual total do tratamento para FC é de US\$40.308.420, e só o ivacaftor, por exemplo, custa US\$344.100 anuais por paciente (AUGUSTO, MARSON, 2020). Não há dúvidas de que tais valores trazem uma sobrecarga imensa tanto para o sistema público de saúde quanto para as unidades hospitalares (AUGUSTO, MARSON, 2020).

Além disso, novas alternativas farmacológicas são necessárias para desacelerar a progressão da doença e sua gravidade. Estudos comprovam que o custo médio por paciente para tratar níveis mais severos da doença é três vezes maior do que para casos mais leves (VAN GOOL, NORMAN, et al., 2013).

Nesse contexto em que se evidencia o desenvolvimento de novos fármacos para tratar FC, importa enfatizar que, desde 2019, o Laboratório de Síntese da PUC-Rio (LabSint) busca a obtenção de novas moléculas com atividade frente a FC.

A partir desse momento, o planejamento foi baseado na estrutura química do ivacaftor, mantendo o núcleo quinolinonas triazóis, realizado pela farmacêutica Ligia Farias em seu projeto de dissertação de mestrado, sob o título: "Síntese e relação estrutura e atividade de derivados de triazóis para o tratamento da Fibrose Cística". O objetivo era sintetizar quinolinonas triazois por meio de uma reação de ciclização intramolecular mediada pela reação de Cadogan, como mostra o esquema 1. 


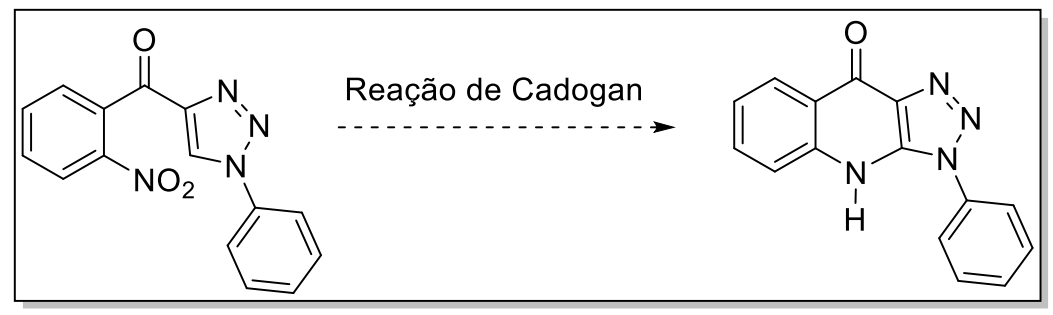

Esquema 1: Estratégia sintética para obtenção de quinolinonas triazois apresentada por Ligia Farias em sua dissertação de mestrado (FARIAS, 2019).

A abordagem das quinolinonas triazóis adotada no trabalho em questão advém da estrutura química do ivacaftor (quinolinona-3-carboxamida), em que há o grupamento quinolona diretamente ligado à amida, mostrado a figura 11. Assim, foi proposta a substituição do grupo amida por 1,2,3-triazóis com base nos relatos da literatura discutidos no item 1.6.

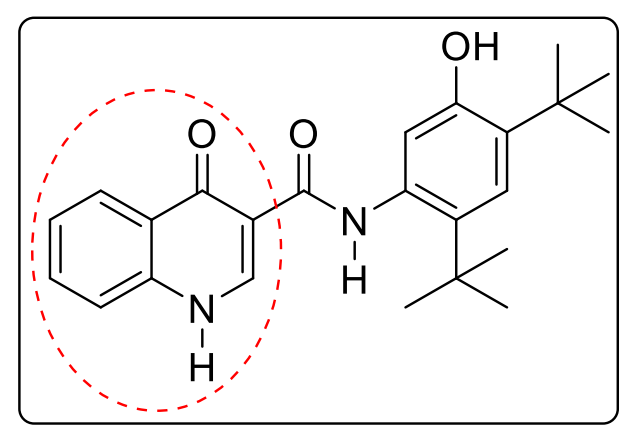

Figura 11: Estrutura química do ivacaftor enfatizando os grupamentos quinolinona e amida.

Apesar de o principal objetivo de sintetizar as quinolinonas triazóis pela reação de Cadogan não ter sido alcançado através do projeto citado, foram gerados compostos intermediários (I-IV), figura 12. 


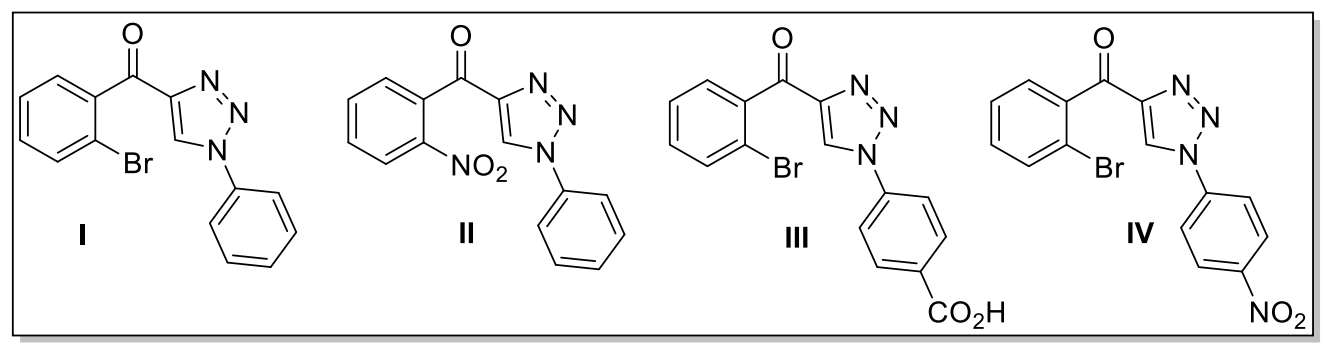

Figura 12: Estruturas dos derivados triazólicos (I - IV) obtidos por Ligia Farias.

Esses intermediários despertaram a atenção por já terem sido sintetizados e caracterizados, além de possuírem em sua estrutura o grupo triazólico, que tem sido intensamente discutido dentro da química medicinal.

Assim, a estratégia sintética abordada no trabalho da farmacêutica Lígia Farias para obter esses intermediários triazólicos está apresentada no esquema 2.

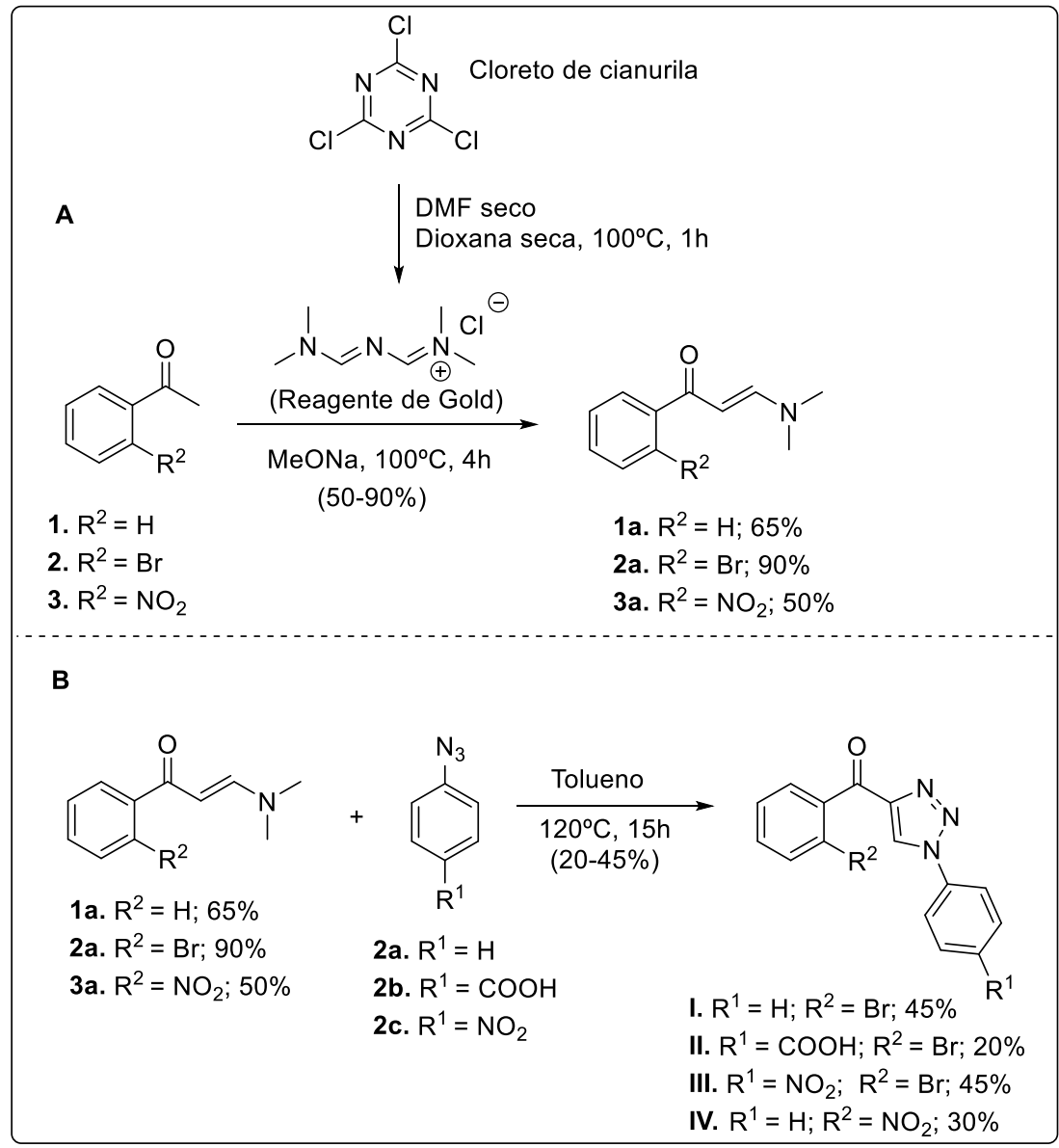

Esquema 2: Estratégia sintética adotada na dissertação de mestrado de Lígia Freitas, em 2019. (A): síntese da enaminona e (B): síntese de 1,2,3-triazóis 
Vale ressaltar que, inicialmente, o objetivo do atual trabalho era reproduzir a metodologia sintética abordada a fim de obter maior variedade dos compostos, bem como ampliar a quantidade de massa daqueles preparados previamente. Essa meta foi estabelecida com a intenção de testar novas estratégias sintéticas de reações de acoplamento C-N (a partir dos compostos sintetizados), para, finalmente, obter os produtos de ciclização intramolecular, visto que, pela reação de Candogan, não se obteve êxito.

Enquanto transcorriam as tentativas de reproduzir a metodologia em questão tendo em vista a estratégia sintética mostrada no esquema 2 - inicialmente para os compostos (I-IV), foi selecionada uma série de 20 quinolinonas triazóis. Esses compostos foram planejados de acordo com os reagentes disponíveis no LabSint.

Para essas moléculas, foram realizados estudos de ancoragem molecular onde se verificou que os resultados das energias de interação, Moldock Score, com a proteína foram maiores, em módulo, do que para o ivacaftor, sugerindo que haja uma interação ainda maior dessas moléculas com a proteína. A tabela 1, na página a seguir, mostra as moléculas planejadas bem como as energias de interação obtidas.

Sendo assim, a partir desses valores de energia preliminares, foi possível especular que tais moléculas seriam interessantes para a abordagem da Fibrose Cística. Todavia, as tentativas para reproduzir, na prática, a metodologia sintética já apresentada, não lograram êxito.

Por essa razão, foi feita a otimização da estratégia sintética para os carboniltriazóis (esquema 3) que permitiu, então, obter uma variedade de compostos intermediários em um primeiro momento. Os padrões de substituição foram empregados de acordo com os reagentes disponíveis no laboratório de síntese.

Desta forma, dada a importância do núcleo 1,2,3-triazol (principalmente no âmbito farmacológico), sua relevância como bioisósteros da amida na química medicinal, além da possibilidade de obter os intermediários com maiores rendimentos, foi proposto neste trabalho a síntese dos derivados 1,2,3-triazólicos (6a-q), sem priorizar a abordagem das quinolinonas-triazóis.

Junto com o interesse de otimização da metodologia sintética, veio a necessidade de estudar e constatar, por métodos computacionais (como a ancoragem molecular), a energia de ligação dos novos compostos intermediários na proteína CFTR, à medida que foram sendo obtidos. Com esse critério, visa-se 
evitar o investimento em compostos que não possuírem energias de ligação proeminentes. 
Tabela 1: Estruturas das quinolinonas-triazois inicialmente planejadas e a energias de interação (Moldock Score)

\begin{tabular}{|c|c|c|c|c|}
\hline \multicolumn{5}{|c|}{ Quinolinonas-triazóis } \\
\hline & & & & \\
\hline Molécula & $\mathbf{R}^{2}$ & $\mathbf{R}^{4}$ & $\mathbf{R}^{6}$ & $\begin{array}{c}\text { Moldock } \\
\text { Score } \\
\text { (Kcal/mol) }\end{array}$ \\
\hline 1 & $-\mathrm{H}$ & $-\mathrm{H}$ & $-\mathrm{H}$ & -96 \\
\hline 2 & $-\mathrm{H}$ & $-\mathrm{NO}_{2}$ & $-\mathrm{H}$ & -95 \\
\hline 3 & $-\mathrm{H}$ & $-\mathrm{Br}$ & $-\mathrm{H}$ & -96 \\
\hline 4 & $-\mathrm{H}$ & $-\mathrm{OCH}_{3}$ & $-\mathrm{H}$ & -98 \\
\hline 5 & $-\mathrm{H}$ & $-\mathrm{Cl}$ & $-\mathrm{H}$ & -97 \\
\hline 6 & $-\mathrm{H}$ & $-\mathrm{CO}_{2} \mathrm{H}$ & $-\mathrm{H}$ & -97 \\
\hline 7 & $-\mathrm{H}$ & $-\mathrm{OH}$ & $-\mathrm{H}$ & -97 \\
\hline 8 & $-\mathrm{H}$ & $-F$ & $-\mathrm{H}$ & -97 \\
\hline 9 & $-\mathrm{Cl}$ & $-\mathrm{Cl}$ & $-\mathrm{H}$ & -98 \\
\hline 10 & $-\mathrm{H}$ & $-\mathrm{CH}_{3}$ & $-\mathrm{H}$ & -98 \\
\hline 11 & $-\mathrm{H}$ & $-\mathrm{CO}_{2} \mathrm{CH}_{3}$ & $-\mathrm{H}$ & -98 \\
\hline 12 & $-\mathrm{H}$ & $-\mathrm{SCH}_{3}$ & $-\mathrm{H}$ & -100 \\
\hline 13 & $-\mathrm{H}$ & $\begin{array}{c}-1,3- \\
\text { dioxolano }\end{array}$ & $-\mathrm{H}$ & -101 \\
\hline 14 & $-\mathrm{NO}_{2}$ & $-\mathrm{F}$ & $-\mathrm{H}$ & -110 \\
\hline 15 & $-\mathrm{I}$ & $-\mathrm{Br}$ & $-\mathrm{H}$ & -101 \\
\hline 16 & $-\mathrm{I}$ & $-\mathrm{H}$ & $-\mathrm{H}$ & -98 \\
\hline 17 & $-\mathrm{NO}_{2}$ & $-\mathrm{H}$ & $-\mathrm{H}$ & -106 \\
\hline 18 & $-\mathrm{Br}$ & $-\mathrm{Cl}$ & $-\mathrm{H}$ & -101 \\
\hline 19 & $-\mathrm{OH}$ & $-\mathrm{H}$ & $-\mathrm{H}$ & -98 \\
\hline 20 & -tercBut & $-\mathrm{H}$ & -terBut & -103 \\
\hline
\end{tabular}


Cabe ressaltar neste contexto, a importância frisar o processo de Virtual Screening (etapa do processo computacional que permite selecionar, dentre um enorme número de moléculas, as melhores, frente um alvo específico).

Por meio dele, pode-se economizar tempo e custo no processo de síntese de forma geral, evitando investir em compostos que não serão ativos ou candidatos a fármacos. Porém, como já abordado, logo no início deste trabalho, o interesse estava muito voltado para a otimização da parte sintética para obter os intermediários, por isso, neste trabalho, essa etapa de Virtual Screening não foi prioritária.

É relevante destacar que a estratégia sintética abordada anteriormente (figura 13), exige que a reação seja seca (etapa A), além da necessidade de isolar o produto obtido neste estágio, por coluna cromatográfica para que depois fosse submetido à reação do triazol propriamente dita. Assim, a otimização da rota sintética foi muito importante para não só obter maiores quantidades dos intermediários (que antes, não era possível), mas também de reduzir tempo e custo no processo.

A metodologia abordada neste trabalho desperta grande interesse, pois dispensa o uso de metais no meio reacional, tratando-se de uma síntese relativamente rápida, econômica e regiosseletiva, fatores que favorecem a otimização de estudos de relação estrutura-atividade na preparação dos triazóis em questão (THOMAS, GOYVAERTS, et al., 2016).

Logo, como descrito no esquema 3, para a obtenção dos compostos (6a-q) a estratégia é a reação de cicloadição 1,3-dipolar, partindo de arilazidas (5) e enaminonas (3). Estas podem ser obtidas pela reação de organocatálise a partir de $N, N$-dimetilformamida acetal (1) e acetofenonas (2a-f).

O planejamento das enamoninas (3c-f), particularmente, foi realizado com base na estratégia da utilização de grupos de proteção, como tosil e acetila (figura 14) já que não foi possível obter a enaminona diretamente a partir da 2-aminoacetofenona (Ic) e da 4-aminoacetofenona (Id), respectivamente.

Além disso, o trabalho propõe estudos in silico das moléculas propostas, para prever sua toxicidade e também o perfil farmacocinético, de forma a selecionar os compostos menos tóxicos para os testes in vitro. 


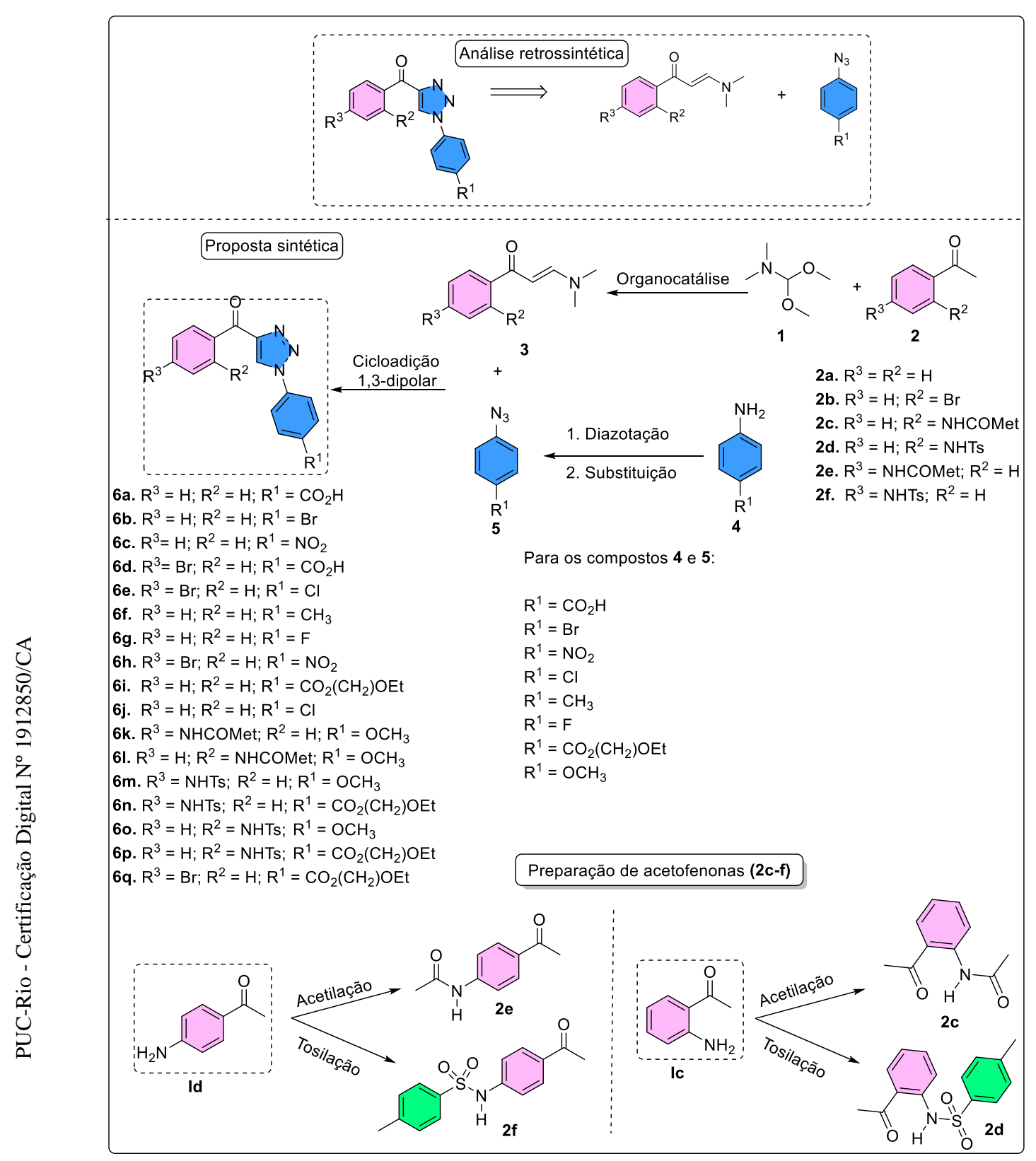

Esquema 3: Otimização da estratégia sintética para obtenção dos compostos triazólicos $(\mathbf{6 a - q})$, baseada nos trabalhos iniciados por Ligia Farias 


\section{4}

\section{Resultados e Discussão}

4.1

Síntese de arilazidas

Para as etapas posteriores de cicloadição, primeiramente, foram sintetizadas uma variedade de arilazidas (5a-h) obtidas a partir de anilinas (4a-h) (ZHAO, GUO, et al., 2019). Essa metodologia sintética, baseada nos trabalhos de Zhao e colaboradores permite obter produtos com rendimentos entre $42-95 \%$, sem necessidade de purificação (esquema 4). 


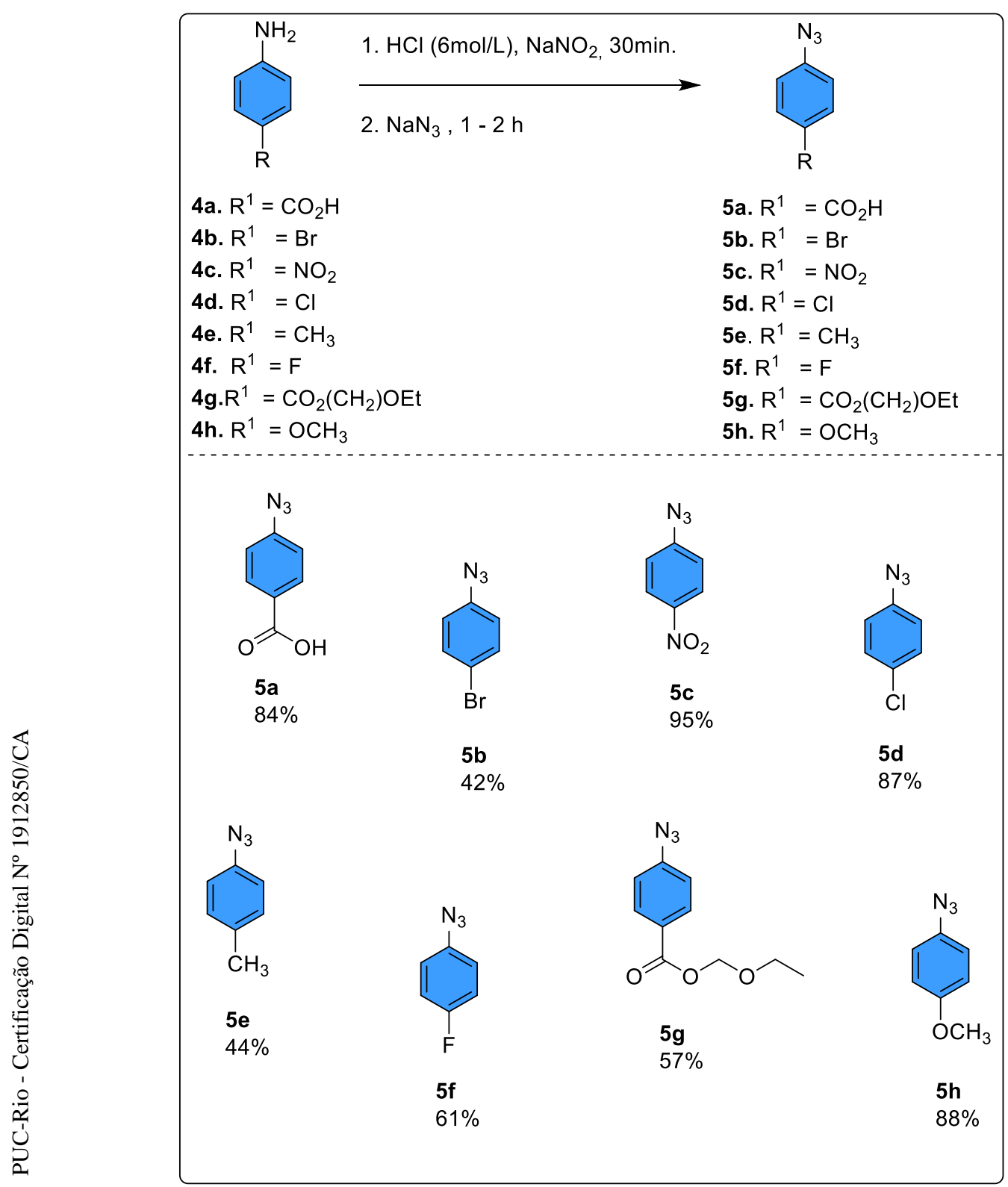

Esquema 4: Preparação de arilazidas (5a-h) a partir de arilanilinas e os respectivos rendimentos obtido

\section{2}

\section{Síntese da 2-etoxietil 4-aminobenzoato (4g)}

A síntese de todas as arilazidas foi feita a partir de anilinas comercialmente obtidas, exceto para a obtenção da azida 5g. Neste caso, foi realizada a reação de esterificação de Fischer, para o preparo a 2-etoxietil 4-aminobenzoato $\mathbf{4 g}$ partindo 
de outra anilina, o ácido 4-aminobenzoico, na presença de ácido sulfúrico e 2etoxietanol (esquema 5).

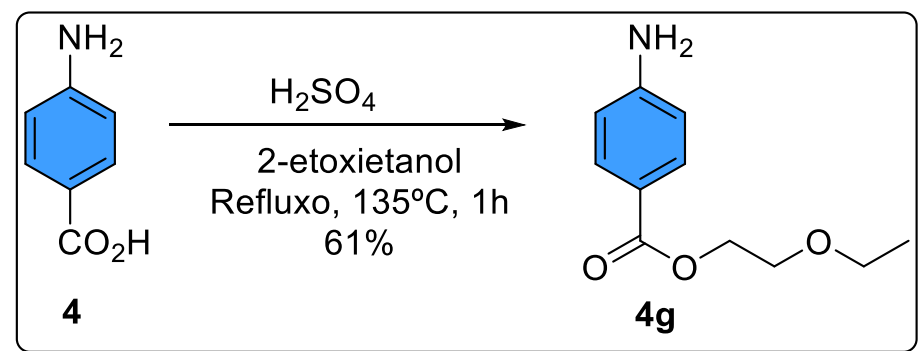

Esquema 5: Reação de obtenção da 2-etoxietil 4-aminobenzoato

Após o término da reação e resfriamento, foi necessário neutralizar a reação, utilizando uma solução saturada de bicarbonato de sódio, o que possibilitou a obtenção dos cristais, com rendimento de $61 \%$.

\section{3}

\section{Síntese da N-(2-acetilfenil)acetamida (2c)}

A reação da 2-aminoacetofenona 1c (34\%), para formar o produto $2 \mathbf{c}$, foi embasada na metodologia de acetilação de aminas, em solução aquosa, na presença de anidrido acético. A literatura especifica este método, chamando-o de método de Lamière - Barbier, esquema 6 (CLAYDEN, 2012).

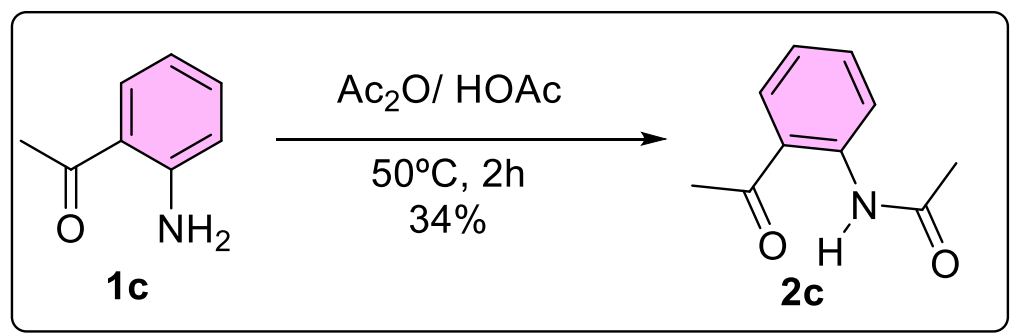

Esquema 6: Reação de acetilação (método de Lamière - Barbier) (CLAYDEN, 2012)

A obtenção da amida é confirmada pela presença do singleto em 2.23 ppm (A), relacionado com a metila da porção amida. Esse grupamento metílico está mais 
blindado devido a maior densidade eletrônica gerada pelo par de elétrons do átomo de nitrogênio vizinho. Além disso, o singleto em 11.69 ppm, referente a um hidrogênio, também confirma a obtenção do produto, como mostrado na figura 13. Os sinais $(\mathbf{C}),(\mathbf{D}),(\mathbf{E}) \mathbf{e}(\mathbf{F})$, respectivamente, apontam para os hidrogênios do anel aromático.

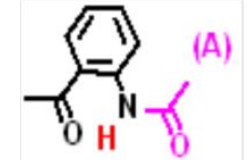

(G)
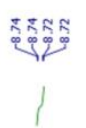

\section{G (s)}

11.69

$$
\begin{array}{|c|}
\hline F(d d) \\
8.73 \\
\hline H
\end{array}
$$
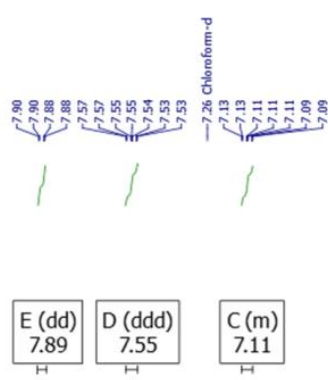

7.89
$\mathrm{H}$

\section{4}

\section{Síntese da N-(4-acetilfenil)acetamida (2e)}

Seguindo a mesma metodologia da reação anterior, foi proposta a preparação de acetanilidas, desta vez, da 4-aminoacetofenona 1d, esquema 7. Essa estratégia foi utilizada com o objetivo de estudar com mais detalhes os diferentes padrões de substituição das moléculas propostas. 


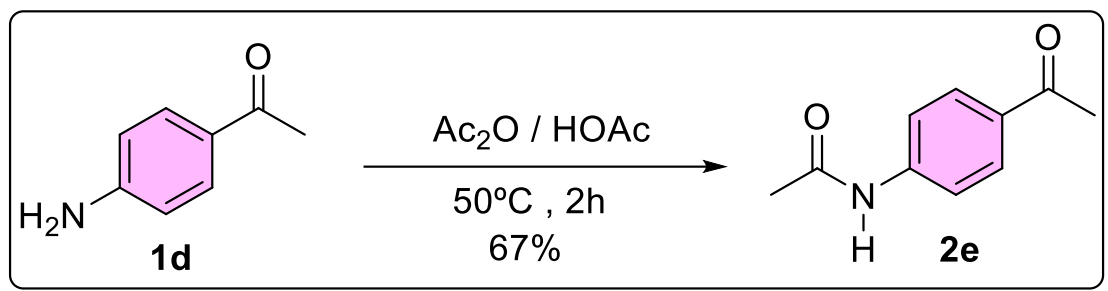

Esquema 7: Reação de obtenção do produto 2e com 4-aminoacetofenona (1d).

O rendimento da reação foi de $67 \%$, maior do que o obtido quando o grupamento amina encontra-se na posição orto, indicando que nesta posição, há um maior impedimento estérico, devido à proximidade com o grupo cetona, em comparação à posição para, figura 14. Infere-se, então, que a nucleofilicidade da amina pode diminuir, quando o reagente de partida for a 2-aminoacetofenona, tornando a reação mais lenta.

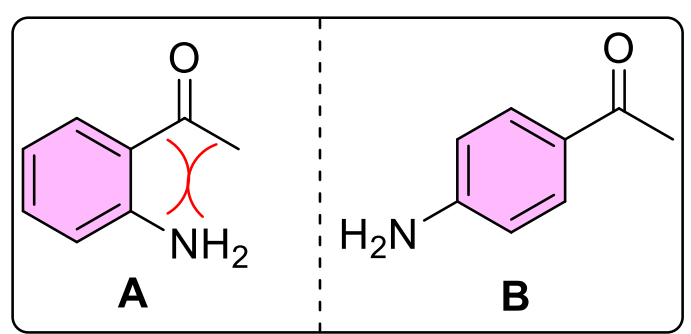

Figura 14: Impedimento estérico da amina frente a carbonila na 2-aminoacetofenona $(\mathbf{A})$ e a ausência desse efeito na 4-aminoacetofenona (B).

\section{5}

\section{Síntese da N-(2-acetilfenil)-4-metilbenzenosulfonamida (2d)}

Como no caso anterior, a proposta para síntese da molécula $\mathbf{2 d}$ surgiu com a abordagem de utilização de grupos de proteção, que nesse caso é o grupo tosila, na presença de piridina a $0^{\circ} \mathrm{C}$. A molécula foi preparada através da reação de tosilação baseada, como mostra esquema 8 (KAKUDA et. al, 2016). Por meio dessa estratégia, foi possível obter o produto com $73 \%$ de rendimento. 


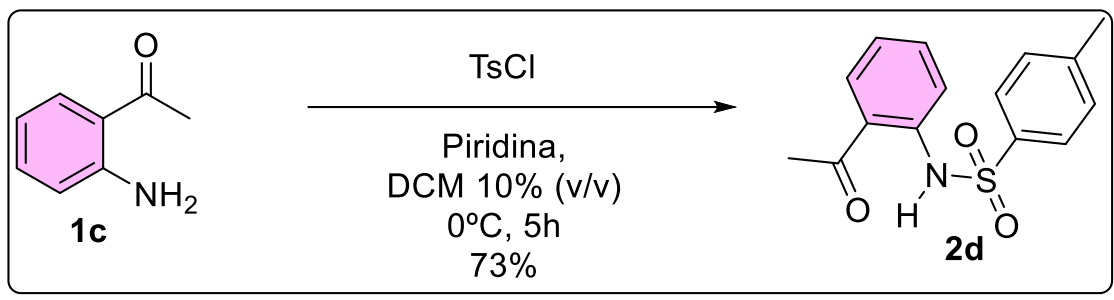

Esquema 8: Reação de tosilação da 2-aminoacetofenona 1c

\section{6}

Síntese da N-(4-acetilfenil)-4-metilbenzenosulfonamida (2f)

A 4-aminoacetofenona 1d também foi submetida à reação de tosilação (esquema 9).

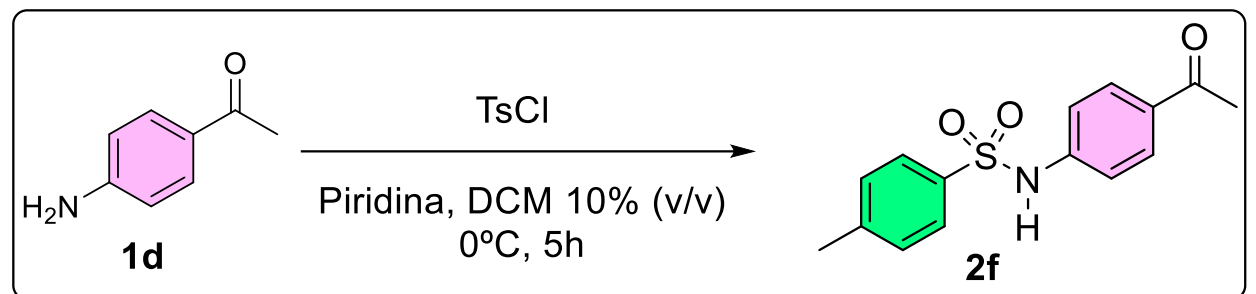

Esquema 9: Reação de tosilação da 4-amoniacetofenona 1d

Sendo assim, o espectro de RMN (figura 15) indica que a reação funcionou pela presença dos hidrogênios da metila pertencente ao grupo tosil (Ha, $2.53 \mathrm{ppm}$ ), bem como dos hidrogênios He em 7.84 ppm, que se encontram mais deslocados por estarem diretamente ligados ao grupo sulfonila, que atrai a nuvem eletrônica para si. 


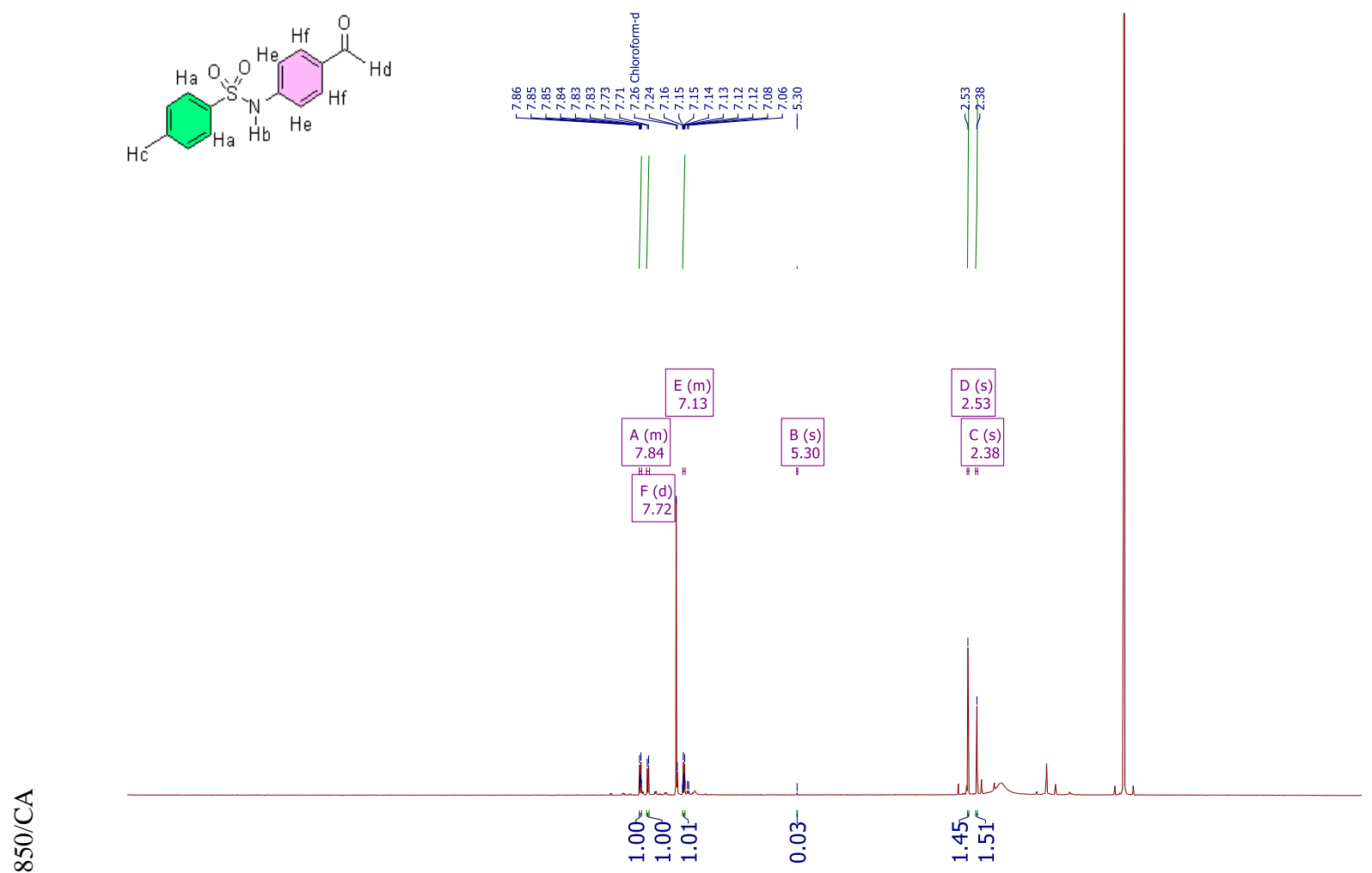

Figura 15: Espectro de RMN de hidrogênio do produto de tosilação $2 f$

Importa ressaltar que a TLC da reação mostrou traços muito sutis do material de partida. Em função disso, foi proposto dar continuidade à etapa seguinte preparação da enaminona correspondente - sem purificar o produto.

\section{7}

\section{Síntese de enaminonas}

As enaminonas, por sua vez, foram sintetizadas por reação de organocatálise mediada pelo aminoácido L-prolina, que promove a condensação de compostos ativos metilênicos, chamados de N,N-dimetilformamidadimetilacetato (DMFDMA), resultando na obtenção de enaminonas (3a-d), esquema 10. (KUMAR, Dinesh, KOMMI, et al., 2012). 


1) DMA-DMF, $80^{\circ} \mathrm{C}$
2) L-prolina, 1-5h

Esquema 10: Reação de organocatálise para obtenção de enaminonas

Vale destacar que na reação em questão a enaminona não é isolada. O acompanhamento da mesma é feito por CCD (Cromatografia em Camada Delgada), como mostra a figura 16 a seguir, que representa a enaminona $\mathbf{3 a}$.

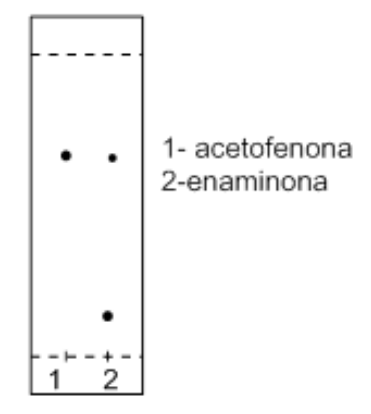

Figura 16: TLC da enaminona: 1. Reagente (acetofenona 2a) e 2. Enaminona (3a)

A TLC em questão mostra que, após o término da reação, há resquícios de material de partida não reagido. Por essa razão foi necessária a otimização do tempo reacional, da temperatura e dos equivalentes dos reagentes. Dessa forma, para a preparação das enaminonas 3c e 3d, especialmente, foi aplicado um tempo de reação de $5 \mathrm{~h}$, mantendo a temperatura de aproximadamente $150^{\circ} \mathrm{C}$.

O procedimento em questão surtiu efeito para a enaminona $\mathbf{3 c}$, em que se observou que a presença majoritária do produto após 5h de reação. Entretanto, para a molécula 3d, essa otimização parecia não ser adequada, uma vez que mesmo após o tempo estabelecido, apenas o reagente era observado na TLC. 
Sendo assim, neste caso, foi decidido deixar a reação ocorrendo overnight. Posteriormente, ao realizar uma nova TLC, verificou-se que a reação, de fato, não ocorreu.

Nota-se que a molécula proposta $2 \mathbf{d}$ possui o substituinte tosil (volume molecular bem considerável) na posição orto, fator que pode justificar a não obtenção da enaminona 3d, relacionado com o impedimento estérico.

A fim de confirmar a hipótese descrita acima, foi proposta a síntese das enaminonas substituídas em para (3e-f), em detalhes no esquema 11. A reação foi feita a partir das acetofenonas previamente obtidas, como exposto nas seções 4.4 e 4.6.

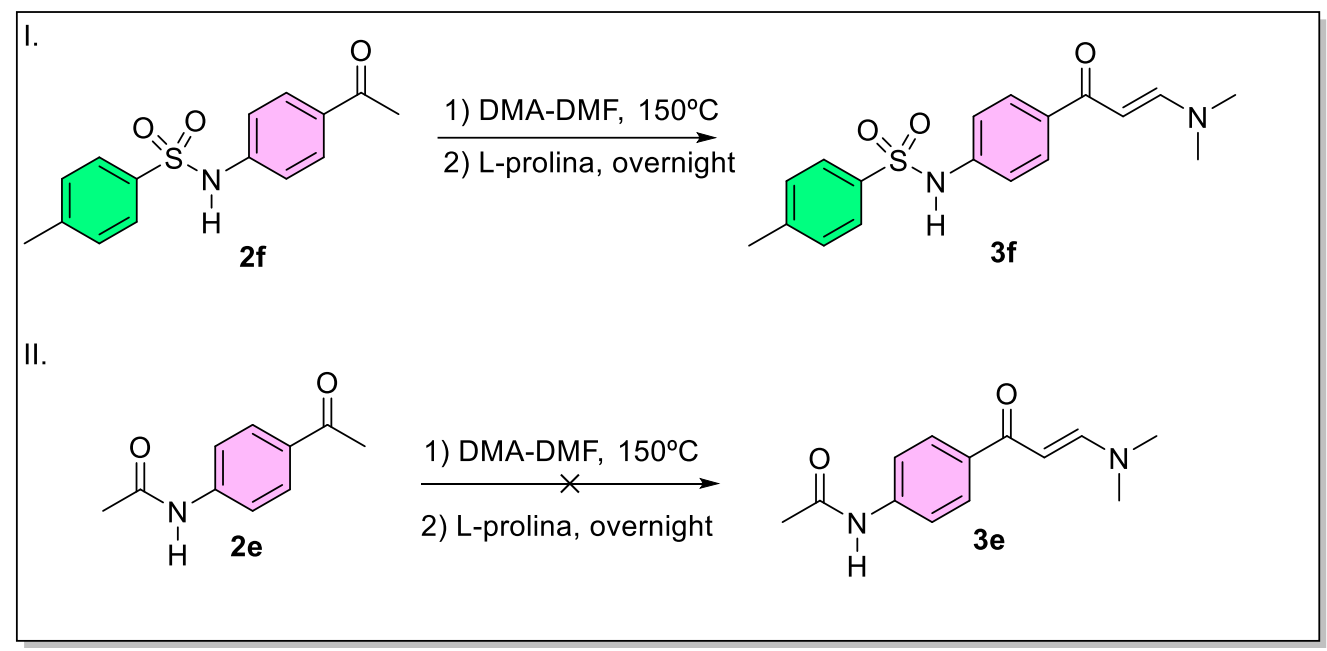

Esquema 11: Reação de organocatálise das enaminonas obtidas nas seções

Como pode ser observado, a reação ocorreu apenas para a molécula descrita no caso I, verificado por TLC, em que se verificou traços do produto.

O resultado, então, confirma a ocorrência de impedimento estérico na posição orto, entre os grupamentos tosil e a acetofenona.

No entanto, curiosamente, no caso II, não houve sinal algum na TLC que confirmasse a obtenção do produto em questão, uma vez que, teoricamente, a reação em para é menos impedida, ocorrendo mais rapidamente.

O mecanismo de ação de organocatálise mediada pela L-prolina (esquema 12), proposto por Kuman e colaboradores, envolve primeiramente a ativação nucleofílica do composto carbonílico, as metilcetonas (2a-d), por condensação com 
o grupamento pirrolidínico do catalisador. Essa condensação (favorecida pela capacidade do núcleo pirrolidina de doar hidrogênio), resulta nos intermediários Ia, Ib e Ic, até que neste último, ocorre o ataque do átomo de oxigênio negativamente carregado ao $\mathrm{H}_{\beta}$, que leva à liberação de água e do nucleófilo enamina, I.

Consequentemente, o hidrogênio do ácido carboxílico forma uma ligação com o átomo de oxigênio de uma das metoxilas do DMF-DMA (II) o que aumenta o caráter eletrofílico do carbono terciário do mesmo grupamento, gerando metanol no meio reacional e o intermediário carboxilato, III. Como resultado, o ataque nucleofílico do oxigênio do carboxilato abstrai o hidrogênio ligado ao íon imínio (IV), formando o intermediário $\mathbf{V}$ que, após a etapa de hidrólise, gera o produto enaminona (3a-d).

Neste contexto, é importante destacar o papel crucial da L-prolina na catálise bifuncional que ocorre no mecanismo proposto, uma vez que é necessária a ativação nucleofílica como primeira etapa, gerando a enamina, bem como a ativação eletrofílica, pela formação do íon imínio para que haja a formação do produto de interesse.

Desta forma, a etapa seguinte consiste na síntese propriamente dita dos compostos triazólicos de interesse por reação de cicloadição 1,3-dipolar. 


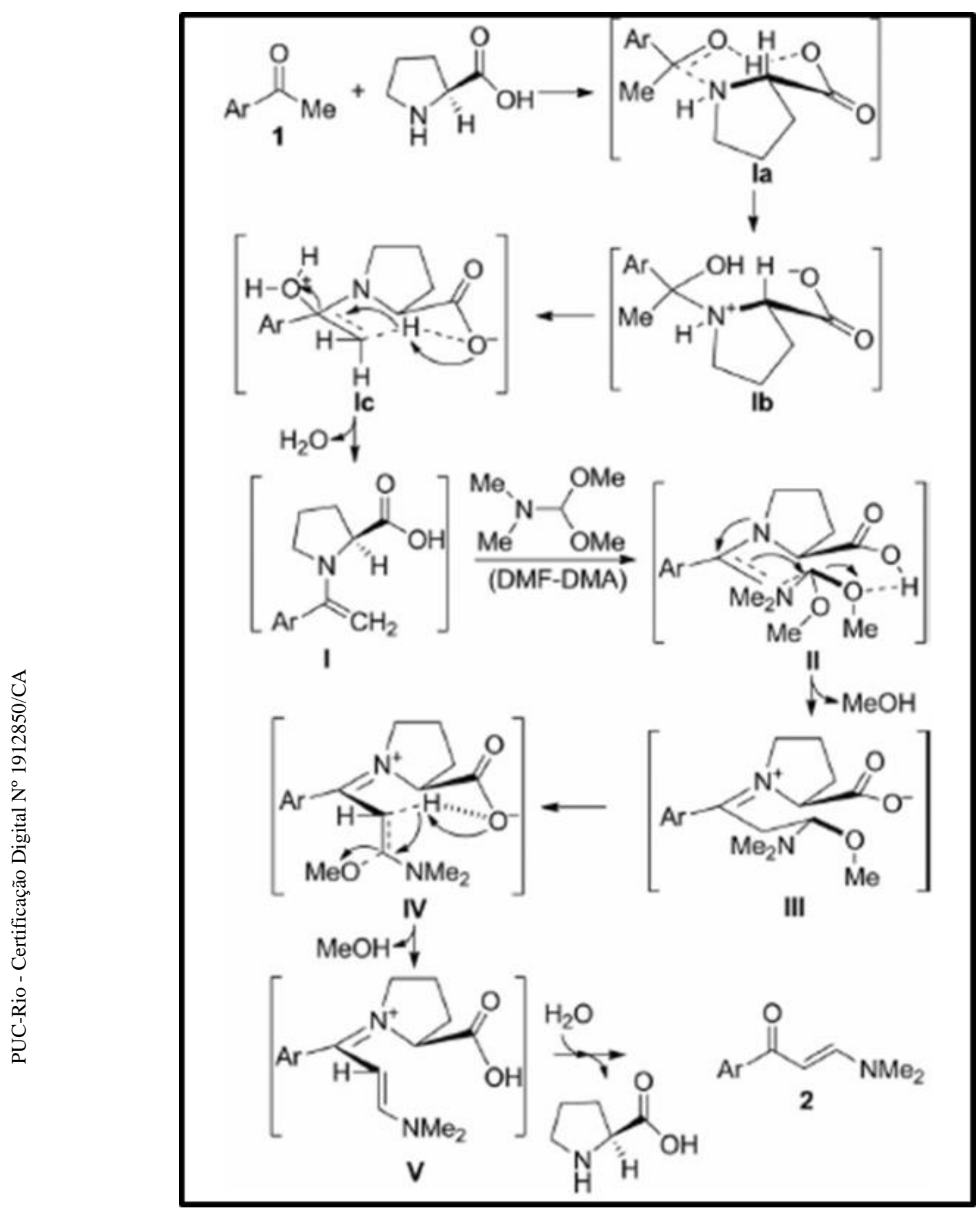

Esquema 12: Mecanismo proposto de organocatálise para formação de enaminona (KUMAR, Dinesh, KOMMI, et al., 2012)

\section{8}

\section{Cicloadição 1,3-dipolar}

A etapa da reação de cicloadição 1,3-dipolar é realizada onepot, pois a enaminona não é isolada, e ocorre na presença de DMSO e da azida correspondente, 
a $90^{\circ} \mathrm{C}$, levando a formação dos compostos 1,2,3-triazóis-1,4-dissubstituídos (6ak), com rendimento entre 5 e 96\%, esquema 13 (KUMAR, Rajiv, VATS, et al., 2018).

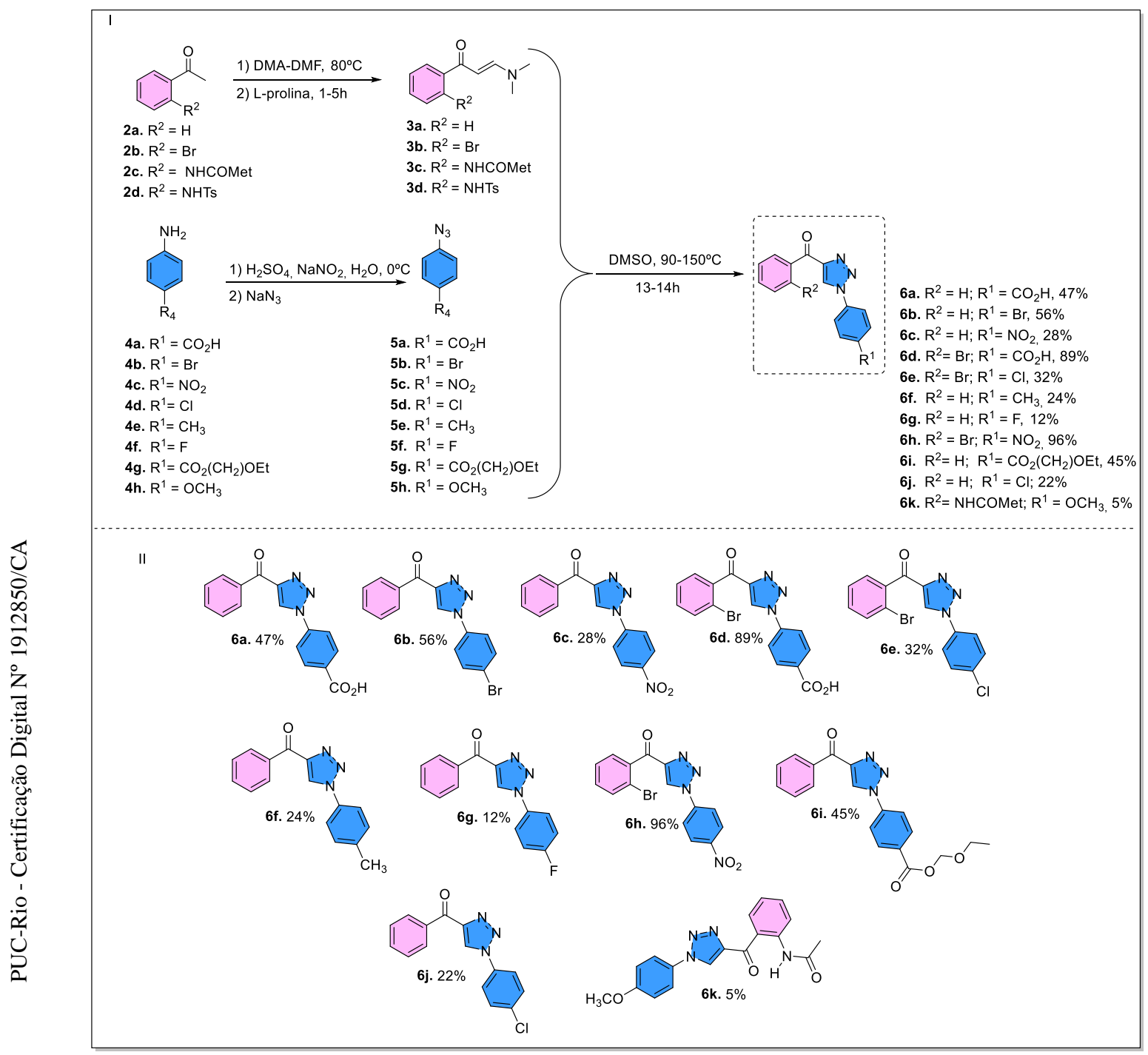

Esquema 13: Cicloadição 1,3-dipolar entre enaminona e azidas para obter os triazóis 1,4dissubstituídos 6a-k (II)

O mecanismo da reação de cicloadição 1,3-dipolar é dito pelos estudos de química teórica como um mecanismo que ocorre pela formação de estado de transição concertado, controlados por orbitais de fronteira, funcionando muito bem quando realizada na presença de solventes polares (ESS, HOUK, 2008). O mecanismo proposto para a reação 1,3-dipolar está detalhado no esquema 14. 


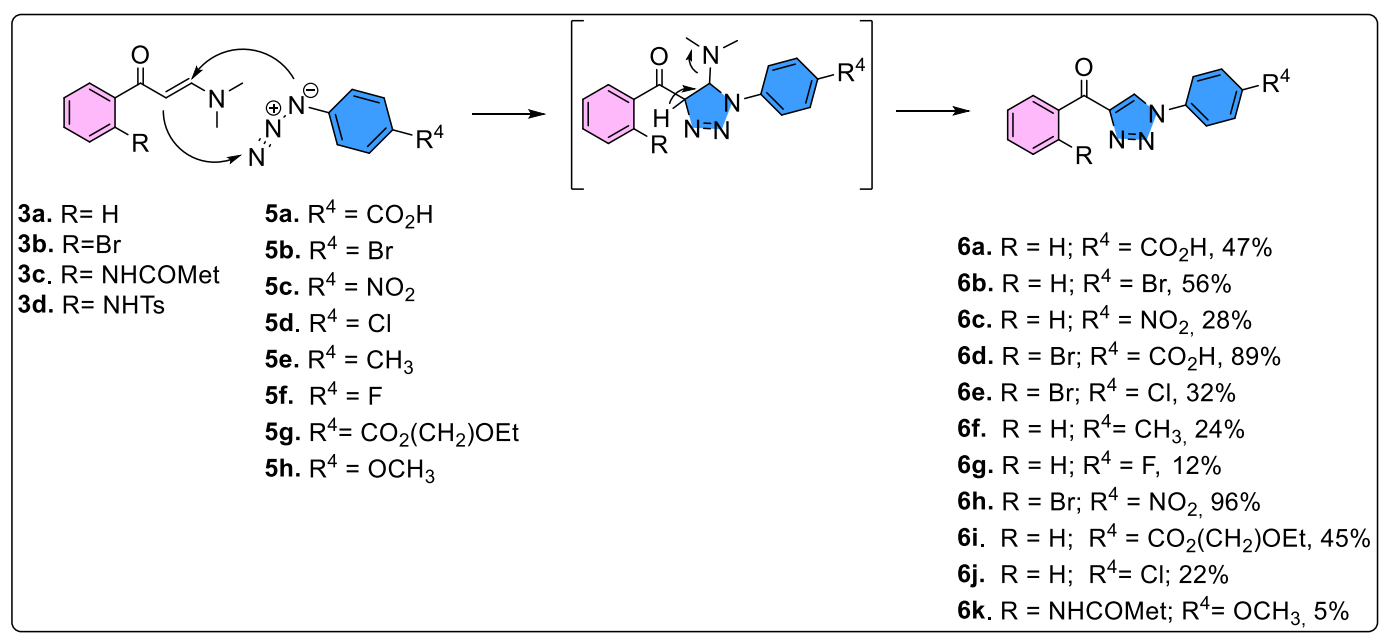

Esquema 14: Proposta mecanística para a reação de cicloadição 1,3-dipolar entre enaminonas (3a-d) e azidas (5a-h) (THOMAS, GOYVAERTS, et al., 2016)

De acordo com o exposto, o dipolarófilo, que possui orbital preenchido de mais alta energia (HOMO), representado por um dos carbonos da ligação dupla da enaminona (3a-3d), ataca o dipolo, que é o átomo de nitrogênio positivamente carregado. Por consequência, o carbono com momento dipolo positivo é atacado pelo nitrogênio com carga negativa, formando o intermediário que, após a migração da ligação de hidrogênio, leva à obtenção do 1,2,3-triazol-1,4-dissubstituído.

A literatura indica que o sucesso da reação de cicloadição, descrita acima, depende de parâmetros eletrônicos, em que a redução do gap de energia entre o HOMO (enaminona) e o LUMO (azida) constitui os fatores essenciais para a ocorrência da reação. Logo, significa dizer que, substituintes doadores de elétrons na enaminona e retiradores de elétrons nas azidas, respectivamente, podem formar uma combinação que refletirá em rendimentos satisfatórios na obtenção dos 1,2,3triazóis.

Essa afirmativa pode ser corroborada ao se deparar com o rendimento de 5\% obtido para o composto 6k. O substituinte da azida $\mathbf{5 h}$ é uma metoxila, com características eletro doadoras. A enaminona 3c, por sua vez, possui o grupo acetamida, cujo par de elétrons do átomo de nitrogênio compromete-se com a ressonância junto à carbonila, deixando-o menos disponível para o anel aromático. Portanto, as propriedades eletrônicas dos reagentes, neste caso, não estão de acordo com a teoria apresentada anteriormente, o que pode justificar o rendimento baixo.

Neste escopo, cabe destacar que foi realizada a tentativa de submeter a $\mathbf{3 f}$ à 
reação de cicloadição 1,3-dipolar com a azida corresponde, $4 \mathbf{h}$, de modo a obter 6m, representada no esquema 15 . Porém, mesmo submetendo a reação por $24 \mathrm{~h}$ a $150^{\circ} \mathrm{C}$ (geralmente a reação ocorre em $90^{\circ} \mathrm{C}$ ), não se observou a formação do produto, podendo-se utilizar a mesma explicação do ponto de vista eletrônico para os reagentes.

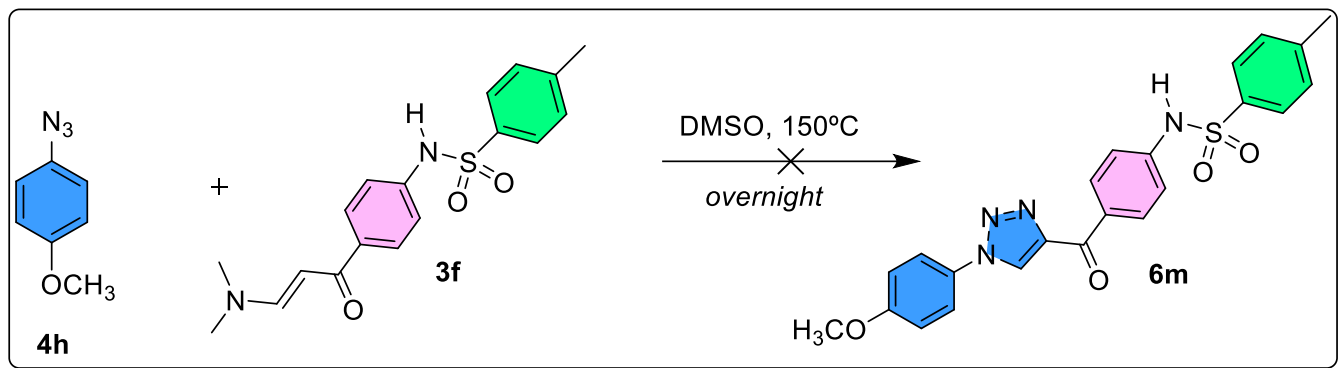

Esquema 15: Tentativa de síntese da N-(4-(1-(4-metoxilfenil)-1H-1,2,3-triazol-4carbonil)fenil)-4-metilbenzenosulfonamida $(6 \mathrm{~m})$

A síntese do composto $\mathbf{6 q}$ não foi muito bem sucedida, uma vez que se observou a presença de arilazida (5g), após o término da reação (esquema 16). Por esse motivo, de imediato, cogitou-se realizar a purificação do material por cromatografia em coluna. Entretanto, a acetofenona $\mathbf{2 b}$ (necessária para formação da enaminona 3b) é adquirida pelo LabSint em pequenas quantidades (trata-se de um reagente oneroso), por isso, a síntese é feita em pequena escala. Portanto, não seria vantajoso colunar o material para obter uma quantidade ínfima, insuficiente, de produto puro.

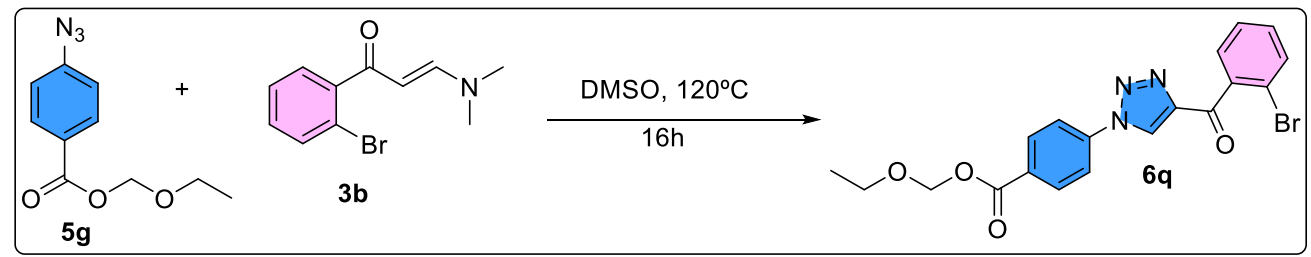

Esquema 16: Reação de cloadição 1,3-dipolar para obter a molécula 6q

A confirmação da síntese dos compostos (6a-k) foi feita através da análise dos espectros de RMN de hidrogênio e carbono. A obtenção dos compostos 1,2,3 
triazólicos pode ser facilmente verificada pela identificação do singleto do hidrogênio referente ao triazol, que geralmente está localizado na região de alto deslocamento, entre 8 - 9,0 ppm. Esse valor se deve à presença da carbonila, diretamente ligada ao triazol, que concentra maior densidade eletrônica no oxigênio, por ser mais eletronegativo que o carbono, desblindando o átomo de hidrogênio. XU, ZHUANG, et al., 2013)

Dessa forma, a figura 17 mostra o espectro de hidrogênio, feito em DMSOd, obtido para uma das moléculas sintetizadas, 6c, por exemplo. Neste caso, ganha destaque o sinal em $9.81 \mathrm{ppm}(\mathrm{Ha})$ do singleto referente ao triazol, e os sinais dos hidrogênios $\mathrm{Hb}, \mathrm{Hc}$, Hd e Hf, respectivamente, relacionadas aos anéis aromáticos.

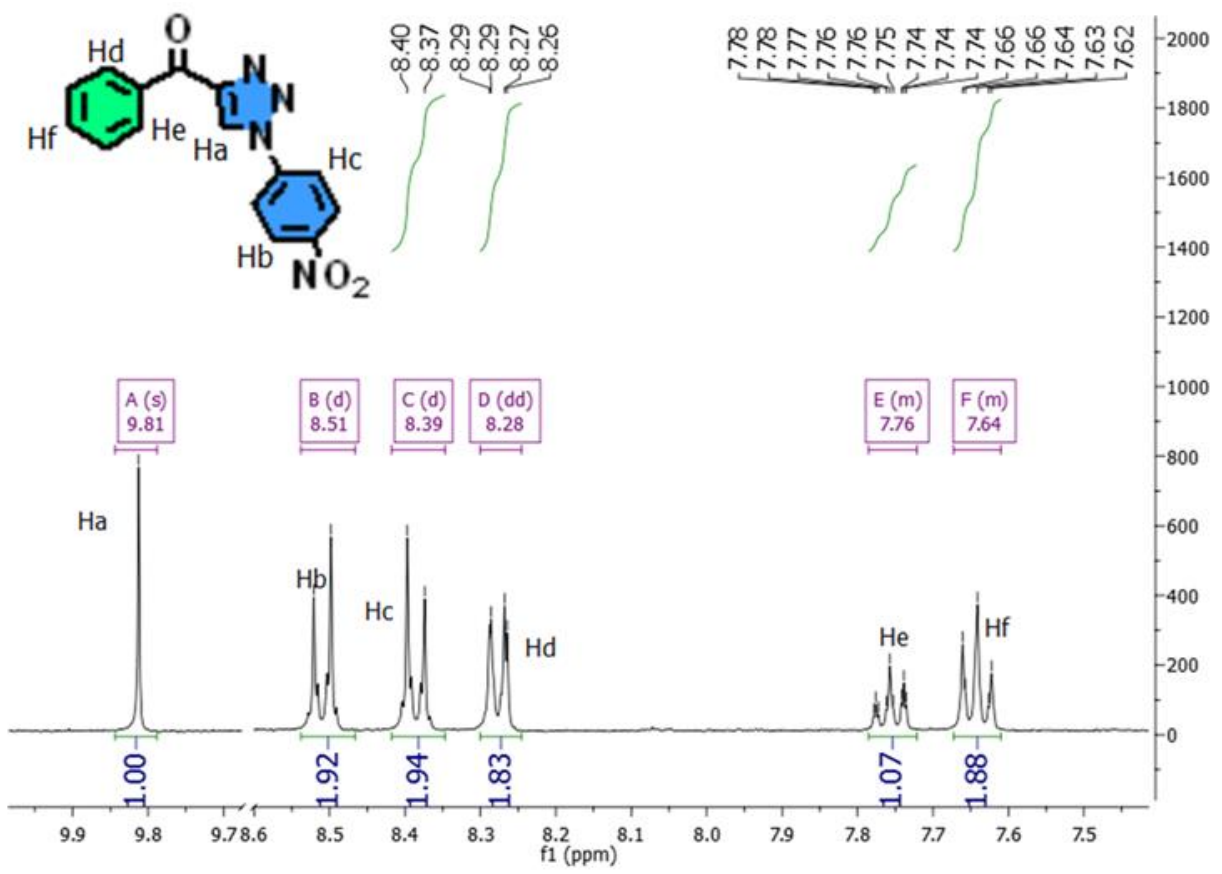

Figura 17: Espectro de RMN do composto 6c em DMSOd, evidenciando o hidrogênio triazólico $(\mathrm{Ha})$ em 9.81 ppm

A literatura assegura que a reação de cicloadição 1,3-dipolar apresentada neste trabalho é regiosseletiva, levando à formação majoritária de triazóis 1,4substituídos. A afirmativa também pode ser explicada por RMN, pois estudos apontam que substituições na posição 4 de 1,2,3-triazóis implicam em singletos com maiores deslocamentos em comparação com as substituições na posição 5 . (CALDERONE, GIORGI, et al., 2005; KUMAR, Rajiv, VATS, et al., 2018; XU, ZHUANG, et al., 2013). 
O detalhe é que, quando o espectro é feito em DMSOd, os sinais para os triazóis 1,4-substituídos são mais deslocados do que em clorofórmio deuterado, mas, em geral, esses deslocamentos são mais acentuados.

Para comprovar a teoria, a figura 18 mostra o espectro de hidrogênio do composto realizado em clorofórmio deuterado. Em comparação com os resultados visualizados na figura 18, nota-se que o singleto do triazol está situado em $8.82 \mathrm{ppm}$ (menos deslocado) do que em DMSOd, em que o mesmo sinal é localizado em 9.81 ppm.

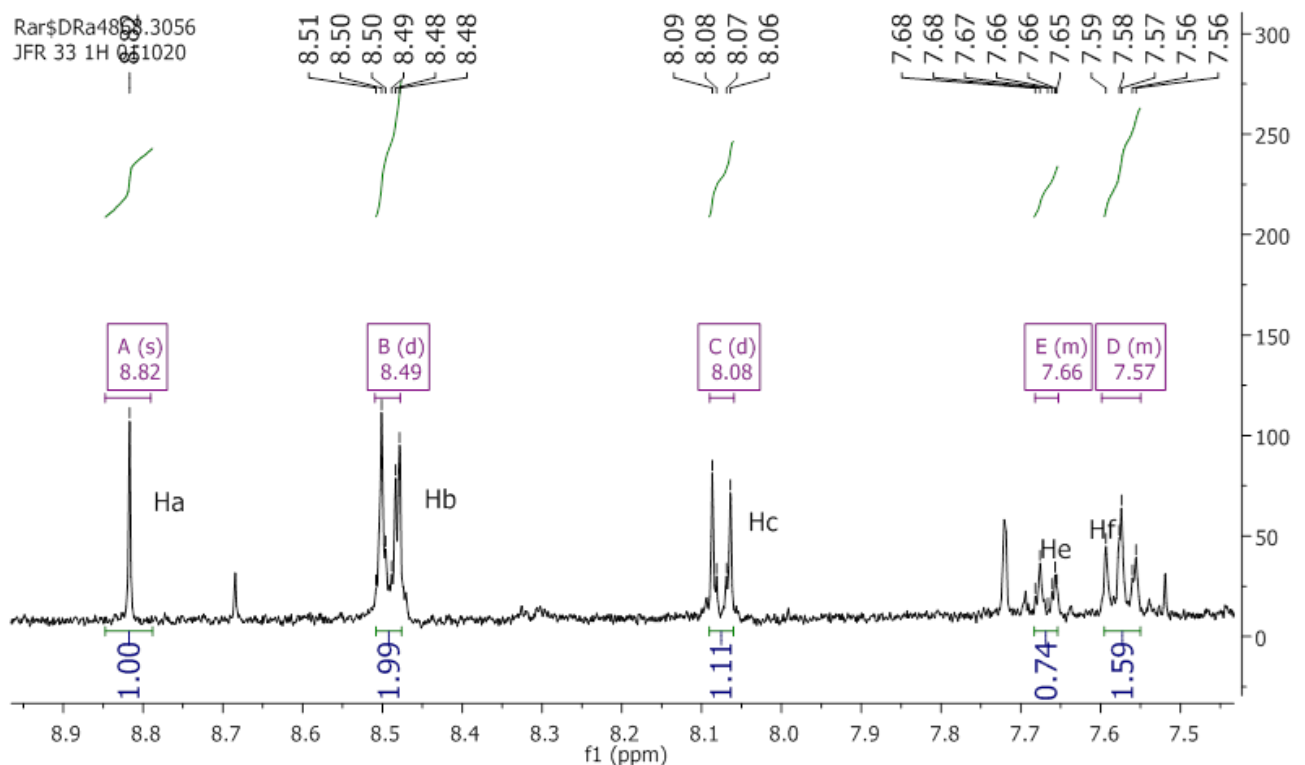

Figura 18: Espectro de RMN do composto 6c, feito em $\mathrm{CDCl} 3$

\subsection{2}

\section{Re-ancoragem e ancoragem molecular}

Nesta etapa, deseja-se avaliar a energia de ligação das moléculas sintetizadas frente à proteína CFTR, através do método de ancoragem molecular. Entretanto, é relevante destacar que nesta etapa, todas as moléculas propostas inicialmente (não necessariamente sintetizadas), foram estudadas.

Assim, foi realizada a otimização de cada estrutura química dos compostos propostos no SpartanPro®. A figura 19 exemplifica o resultado obtido nessa etapa 
para a molécula $6 \mathbf{k}$.
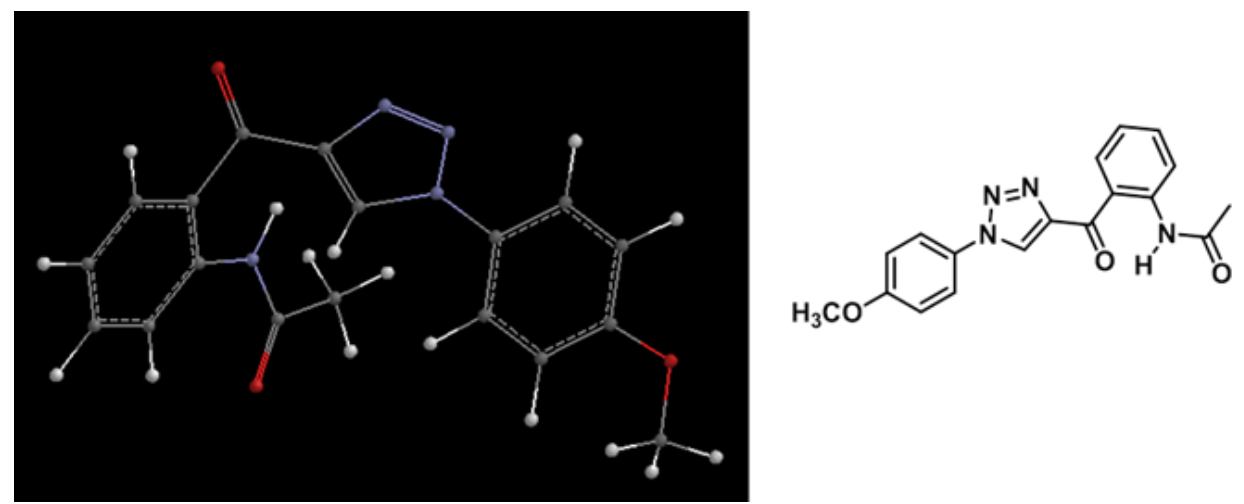

Figura 19: Exemplo de uma molécula que teve a energia minimizada no programa SpartanPro®

A proteína de interesse (CFTR) está disponível no banco de dados PDB (Protein Data Bank), complexada com o ligante de estudo, ivacaftor. O complexo foi obtido no PDB, sob o código 6O2P, como mostra a figura 20.

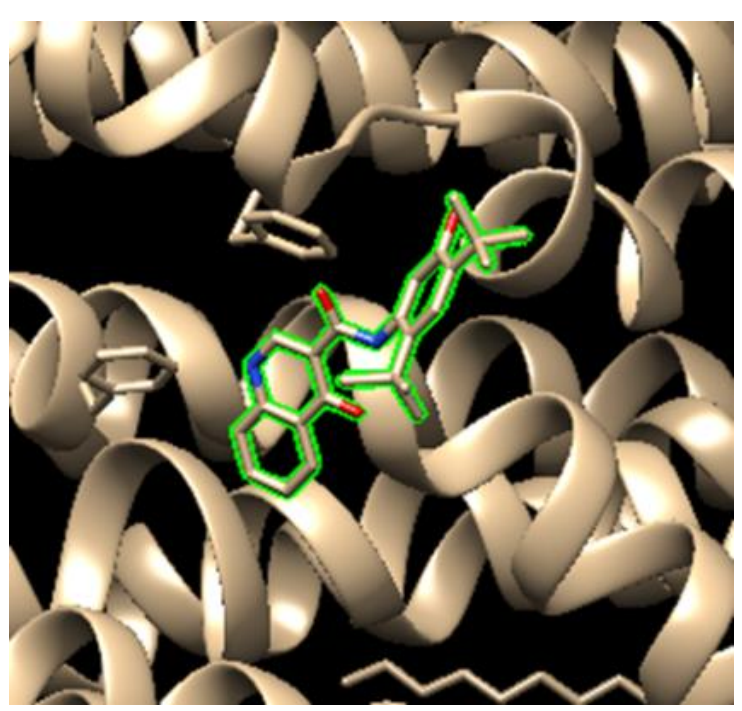

Figura 20: Estrutura cristalográfica do complexo proteína (CFTR) - ligante (ivacaftor), obtida do Protein Data Bank, código 6O2P 
Porém, antes de submeter os compostos aos estudos de ancoragem molecular, propriamente dito, foi realizado o processo de validação do método que é a reancoragem molecular.

Assim, a tabela 2 apresenta os valores de RMSD obtidos nesta etapa, onde se destacam os dados encontrados para as poses 2 e $\mathbf{1 0}$ - (1.3 e $\mathbf{1 . 6} \AA$, respectivamente - que são menores que $2.0 \AA$ A). Logo, de acordo com os conceitos descritos na seção 1.9 deste trabalho, infere-se que o programa é capaz de não só encontrar o sítio de ligação da proteína em questão como também de encaixar o ligante nesse sítio, gerando conformações satisfatórias.

Tabela 2: Relação entre as poses geradas pelo Software e o valor de RMSD, com destaque, em negrito, para as poses 2 e 10, respectivamente

\begin{tabular}{cc}
\hline $\begin{array}{c}\text { Pose } \\
\text { (conformação) do } \\
\text { ligante no sítio de } \\
\text { interação }\end{array}$ & RMSD $(\mathbf{A})$ \\
\hline 1 & \\
\hline $\mathbf{2}$ & 2.8 \\
3 & $\mathbf{1 . 3}$ \\
4 & 8.9 \\
5 & 8.2 \\
6 & 5.0 \\
7 & 8.3 \\
8 & 9.5 \\
9 & 8.6 \\
$\mathbf{1 0}$ & 7.8 \\
\hline & $\mathbf{1 . 6}$ \\
\hline
\end{tabular}

Para fins de ilustração, na figura 21, podem ser observadas as poses 10 (A) e 2 (B), interagindo com o ligante ivacaftor (em amarelo) no sítio de interação da proteína. Nota-se a sobreposição das conformações geradas em relação à posição 
do ligante.

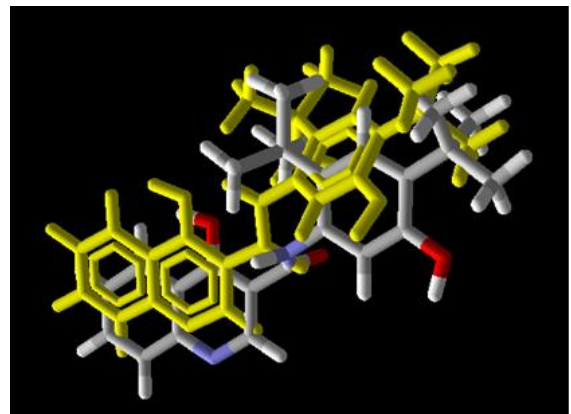

$\mathbf{A}$

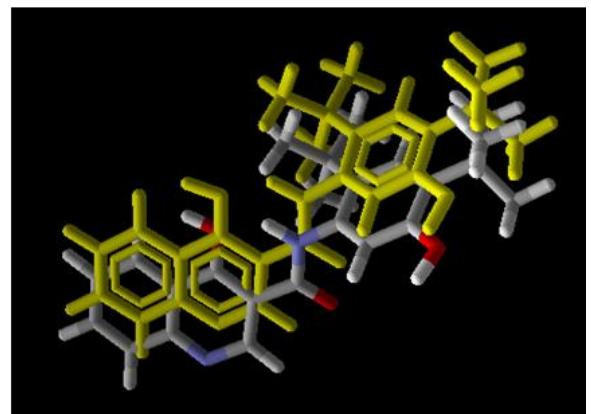

B

Figura 21: Representação das poses (em cinza) dos melhores RMSD obtidos. A) Pose 10; B) Pose 2

Após a validação do método, prosseguiu-se com a etapa de ancoragem molecular. Sendo assim, com o objetivo de aumentar a confiabilidade dos resultados obtidos de Moldock Score, a ancoragem molecular dos compostos planejados foi realizada em triplicata.

Convém destacar que, como discutido nas seções anteriores, não foi possível obter as moléculas 61-p, cujas estruturas estão mostradas na figura 22. Entretanto, neste momento, deseja-se buscar compreender como as moléculas propostas (mesmo as que não foram sintetizadas), interagem com a proteína alvo. Assim, para complementar esses estudos, também foram incluídas mais três moléculas: 113m, 114m e JFR49m, codificadas aleatoriamente.

É relevante, ainda, enfatizar, que a proposta de incluir todas as moléculas sugeridas adveio após o insucesso da tentativa de obter as moléculas, inclusive 61q, uma vez que representam diferentes padrões de substituição. Com isso, pretendese analisar se há alguma alteração quanto à energia de ligação dos compostos caso haja mudança na posição de substituintes específicos. 


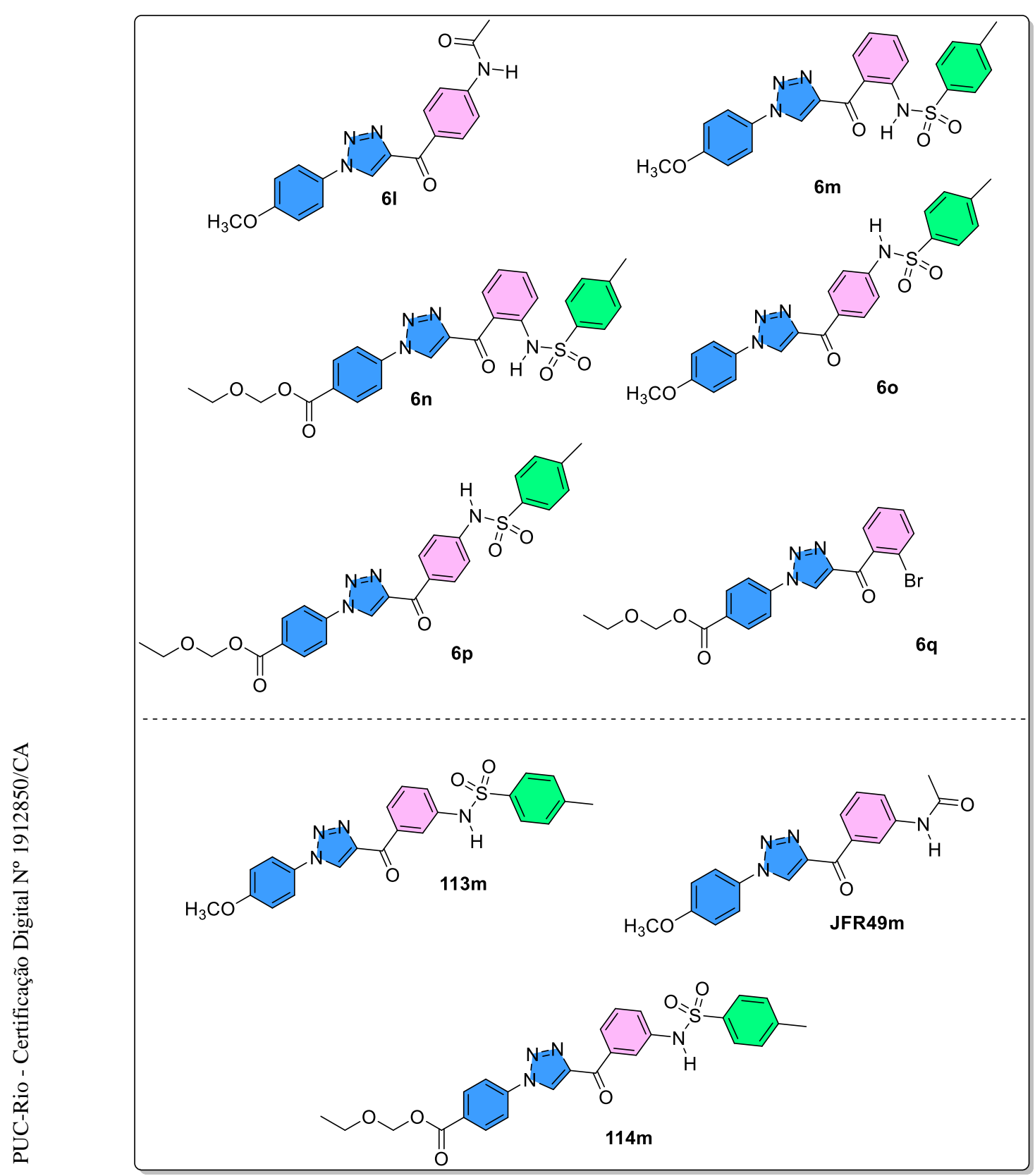

Figura 22: Estrutura química das moléculas 6l-q; 113m, 114m e JFR49m, incluídas nos estudos de ancoragem molecular

A tabela 3 mostra os resultados feitos em triplicata para os valores de Moldock Score, além da média obtida e o desvio-padrão calculado em cada caso. Os números significativos dos valores de Moldock Score após a casa decimal foram preservados, arredondando o valor apenas no cálculo da média para facilitar a análise dos dados. 
Tabela 3: Valores de Moldock Score obtidos em triplicata (ancoragem 1, 2 e 3, respectivamente, e os dados da média e desvio-padrão

\begin{tabular}{|c|c|c|c|c|c|}
\hline \multirow[t]{2}{*}{ Molécula } & \multirow{2}{*}{$\begin{array}{c}\text { Ancoragem } 1 \\
\text { Moldock Score } \\
\text { (Kcal/mol) }\end{array}$} & \multirow{2}{*}{$\begin{array}{c}\text { Ancoragem } 2 \\
\text { Moldock Score } \\
\text { (Kcal/mol) }\end{array}$} & \multirow{2}{*}{$\begin{array}{c}\text { Ancoragem 3 } \\
\text { Moldock Score } \\
\text { (Kcal/mol) }\end{array}$} & \multicolumn{2}{|c|}{ Variáveis } \\
\hline & & & & Média & $\begin{array}{l}\text { Desvio } \\
\text { padrão }\end{array}$ \\
\hline $6 a$ & $-113,784$ & $-113,89$ & $-114,772$ & -114 & 0,44 \\
\hline $6 b$ & $-104,071$ & $-104,151$ & $-104,367$ & -104 & 0,13 \\
\hline $6 c$ & $-109,174$ & $-109,076$ & $-109,213$ & -109 & 0,06 \\
\hline 6d & $-115,508$ & $-115,563$ & $-115,548$ & -116 & 0,02 \\
\hline $6 e$ & $-109,1$ & $-109,14$ & $-108,89$ & -109 & 0,11 \\
\hline $\mathbf{6 f}$ & $-113,493$ & $-113,543$ & $-113,513$ & -114 & 0,02 \\
\hline $6 \mathrm{~g}$ & $-104,719$ & $-105,373$ & $-105,473$ & -105 & 0,33 \\
\hline $6 h$ & $-134,112$ & $-132,807$ & $-134,578$ & -134 & 0,75 \\
\hline $6 \mathbf{i}$ & $-104,408$ & $-103,16$ & $-104,383$ & -104 & 0,58 \\
\hline $\mathbf{6 j}$ & $-105,568$ & $-105,558$ & $-105,24$ & -105 & 0,15 \\
\hline $6 k$ & $-125,722$ & $-125,68$ & $-125,891$ & -126 & 0,09 \\
\hline 61 & $-129,259$ & $-129,224$ & $-129,333$ & -129 & 0,045 \\
\hline $6 \mathrm{~m}$ & $-128,862$ & $-132,067$ & $-133,679$ & -132 & 2,00 \\
\hline $6 n$ & $-132,22$ & $-134,836$ & $-150,919$ & -139 & 8,27 \\
\hline 60 & $-131,026$ & $-132,355$ & $-137,862$ & -134 & 2,96 \\
\hline $6 p$ & $-141,985$ & $-147,75$ & $-147,764$ & -146 & 2,72 \\
\hline $6 q$ & $-135,834$ & $-138,695$ & $-128,425$ & -134 & 4,33 \\
\hline $113 m$ & $-144,886$ & $-152,86$ & $-153,088$ & -150 & 3,81 \\
\hline $114 \mathrm{~m}$ & $-124,598$ & $-127,625$ & $-130,296$ & -146 & 2,33 \\
\hline JFR49m & $-127,907$ & $-128,545$ & 128,42 & -129 & 0,12 \\
\hline Ivacaftor & $-85,809$ & $-85,652$ & $-85,646$ & -86 & 0,08 \\
\hline
\end{tabular}

O primeiro ponto que desperta a atenção é que os valores das energias de interação (Moldock Score) encontrados para as moléculas em estudo são superiores, em módulo, em comparação ao valor obtido para o ligante de referência, o ivacaftor (-86 kcal/mol). Diante dos dados obtidos despertou-se um interesse ainda maior pelas estruturas propostas.

Assim, foi verificado que os maiores valores de Moldock Score obtidos estão relacionados com as moléculas mais volumosas e com ligações de grau de liberdade mais elevado.

A afirmativa baseia-se na teoria de que, quanto maior o número de rotações existentes para as compostos em estudo, as possibilidades de conformações geradas que poderão interagir com os aminoácidos no sítio de ligação da CFTR serão superiores. 
Para exemplificar o que foi descrito anteriormente, a figura 23 apresenta uma comparação da estrutura química da 6n, após otimização, em comparação com a estrutura do ivacaftor. Nota-se que as ligações em 6n possuem maior grau de liberdade, enquanto que o ivacaftor apresenta dois anéis ciclícos rígidos não rotacionáveis (circulado em vermelho). Esse sistema mais rígido parece limitar o grau de rotação da molécula, o que pode resultar o menor número de conformações que este ligante pode assumir no sítio de ligação.

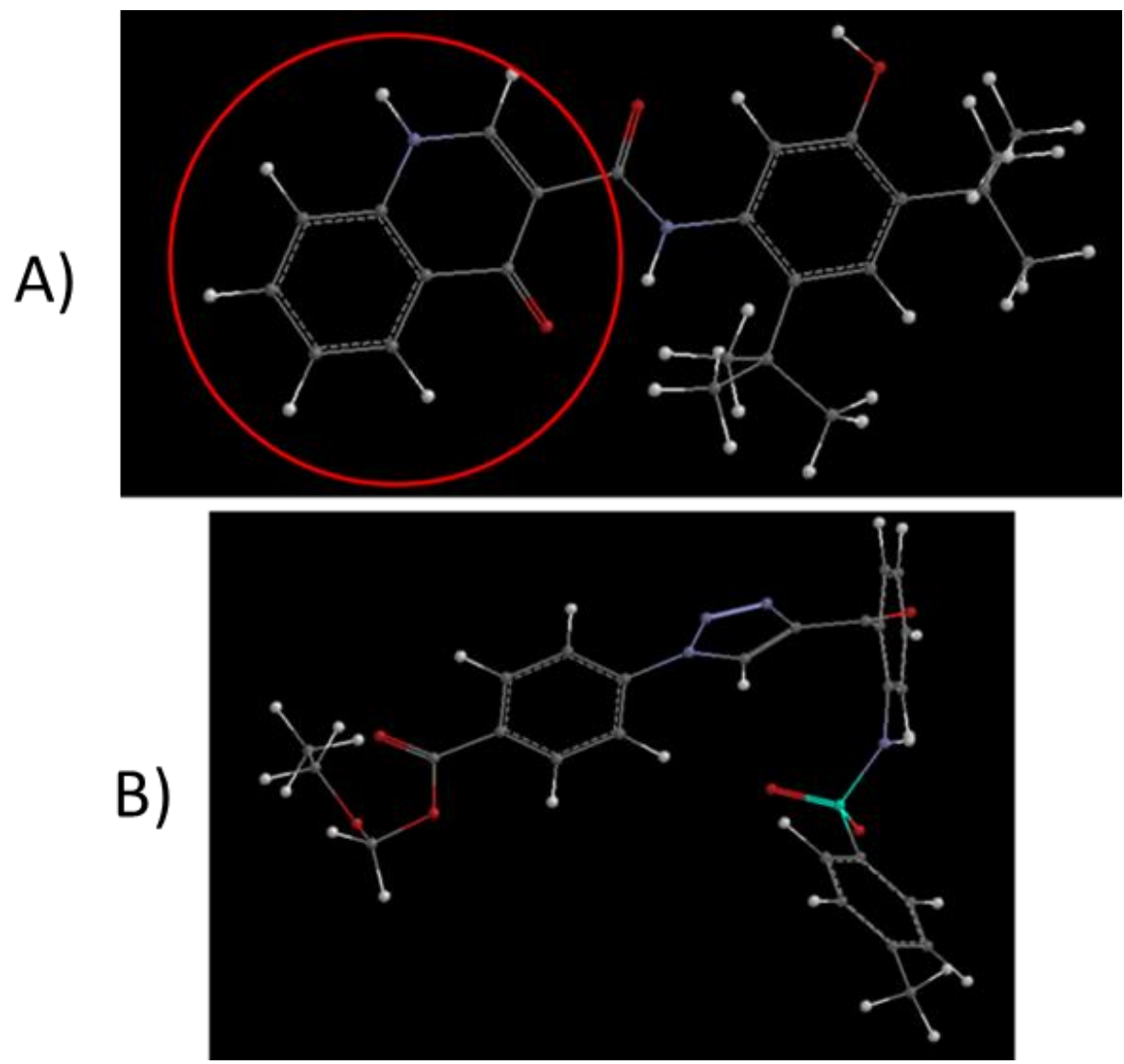

Figura 23: Comparação da molécula ivacaftor $(\mathbf{A})$ e os anéis aromáticos circulados em vermelho. (B) mostrando o maior número de ligações rotacionáveis

A partir desses dados, foi realizada uma análise qualitativa a fim de verificar se as moléculas em estudo interagem com os aminoácidos que, de fato, são importantes para a interação no sítio de ligação da CFTR.

É válido, antes, destacar os estudos de ancoragem molecular realizados por Liu e colaboradores, em que apresentam os aminoácidos relevantes para a interação da 
CFTR com o ivacaftor, realizados a partir da mesma estrutura cristalográfica do complexo CFTR-ivacaftor obtida para este trabalho. Por esses estudos, foi concluído que, dentre os aminoácidos identificados, os mais importantes para a interação da proteína com o ivacaftor no sítio de interação foram: Ser308, Phe312, Arg933, Tyr304 e Phe931 (LIU, ZHANG, et al., 2019).

A Ser308 e Phe312 interagem com o grupo funcional quinolinona do ivacaftor, sendo a primeira, responsável pela ligação de hidrogênio com o nitrogênio, e a segunda, pela interação por empilhamento da ligação $\pi$. Arg933 e Tyr304 formam ligação de hidrogênio com o grupo carbonila, representando uma interação importante para a estabilização do ligante em uma estrutura da proteína chamada TM8, que parece atuar como uma dobradiça localizada no sítio de ligação. O estudo descreve que a estabilização do ligante nessa estrutura pode ser um indicativo do mecanismo de ação do ivacaftor, de exercer a mudança conformacional da CFTR e permitir o fluxo iônico adequado.

Outro aminoácido relevante citado, a Phe931 que forma uma interação estérica com o anel aromático do fenol. A substituição desse aminoácido por alanina diminui a afinidade do ivacaftor pela proteína em dez vezes, o que justifica sua importância para a interação. Além disso, outros aminoácidos como Phe932 e Phe305 também foram importantes para as interações hidrofóbicas. A figura 24 representa os aminoácidos descritos pelo trabalho realizado por Liu e colaboradores, em que podem ser observadas as interações do ivacaftor e CFTR e a região TM8. 


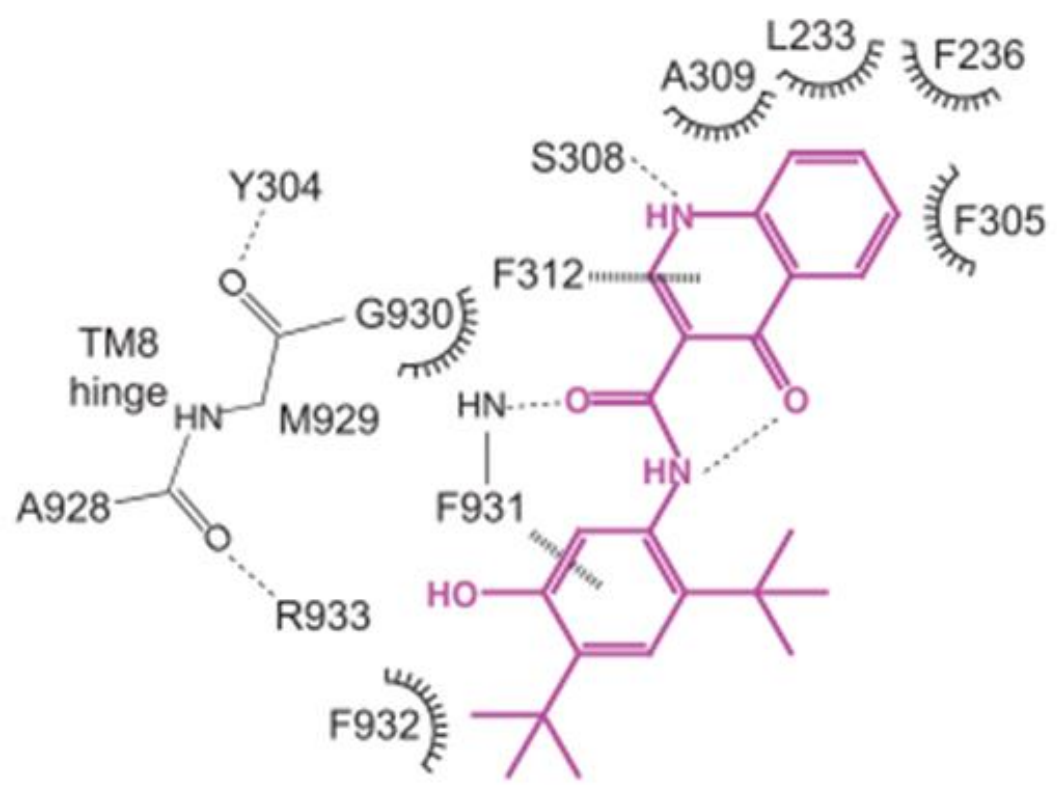

Figura 24: Interação da CFTR e o ivacaftor no sítio de ligação. Os amoniácidos de interesse podem observados

Diante das considerações feitas previamente, na figura $25(\mathbf{F})$, observa-se que as ligações intermoleculares envolvidas na interação entre CFTR e a molécula de referência (icavaftor) através da metodologia aplicada neste trabalho foram: ligações de hidrogênio (entre Tyr304 e Phe931 e a carbonila do ivacaftor) e interações estéricas (entre Phe932, Phe931, Phe312, Gly 930, Ser308, Phe305 e os anéis aromáticos do ivacaftor).

Nota-se que os mesmos aminoácidos aqui encontrados coincidem com aqueles citados na literatura, principalmente Phe931, que se mostrou importante para a afinidade da interação com a CFTR e a Tyr304, relevante para o encaixe no sítio de ligação.

Assim, infere-se que o método de ancoragem molecular utilizado neste trabalho é fidedigno, podendo ser reproduzido para as moléculas de estudo, uma vez que são capazes de alocá-las no sítio de ligação da CFTR importante para mediação da resposta biológica. Sabendo disso, espera-se encontrar os mesmos aminoácidos interagindo com as moléculas de interesse. Para essa verificação, foram selecionadas algumas moléculas que apresentaram valores de Moldock Score interessantes: 6q, 6m, 6n, 6i e 6k, identificadas pelas letras A, B, C, D e E, respectivamente. 


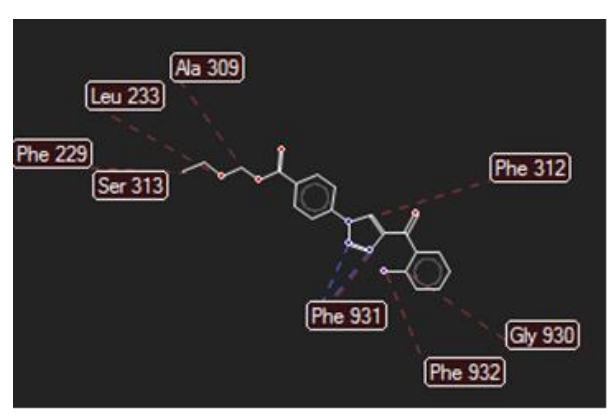

A

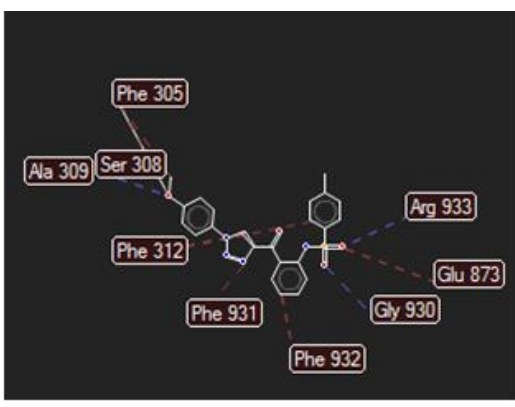

B

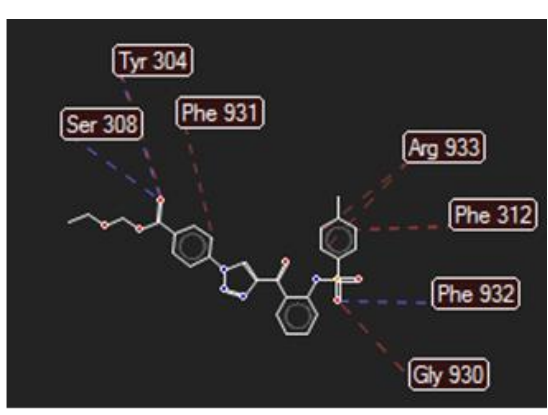

C

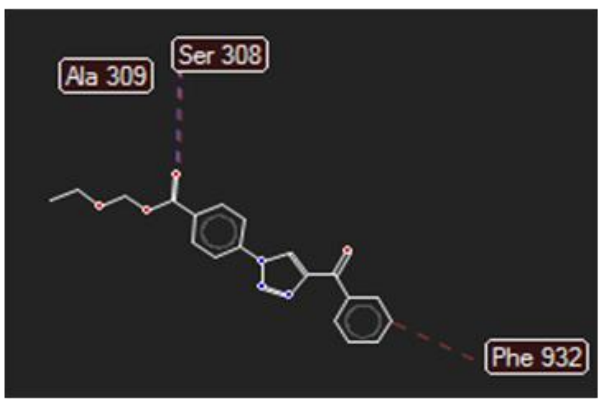

D

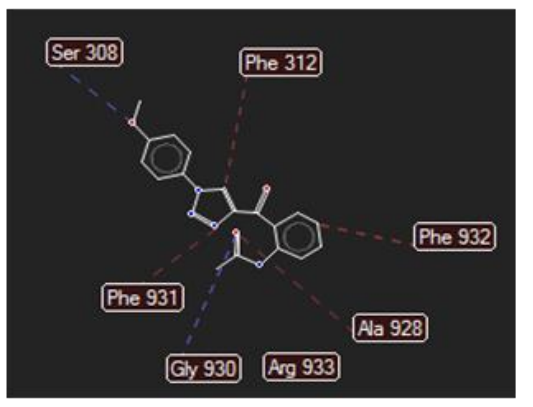

$\mathrm{E}$

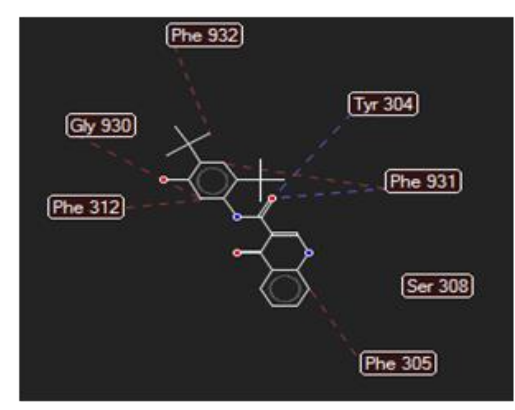

F

Figura 25: Representação da interação entre os aminoácidos e as moléculas no sítio de ligação da CFTR. (A) 6q; (B) 6m; (C) 6n; (D) 6i; (E) 6k e (F) ivacaftor. 
Verificou-se que, embora as moléculas testadas tenham estruturas químicas diferentes do ivacaftor, os aminoácidos citados necessários para a interação no sítio de ligação foram encontrados. A Phe931, por exemplo, dita como importante para a afinidade da ligação, está presente efetuando ligações de hidrogênio com o nitrogênio do anel triazólico das moléculas 6q (A), e interações estéricas com o mesmo anel nas moléculas 6q (A), 6m (B), 6n (C) 6k e (E) 6k. O interessante é que esse aminoácido interage com o grupamento amida do ivacaftor por ligação hidrogênio, e, no caso da molécula 44, essa mesma interação é feita com o grupo triazólico, o que pode corroborar com o fato de os triazóis serem representados como bioisósteros da amida.

Destaca-se a presença da Arg933 e Tyr304 na interação com as moléculas 6m e 6n, pois, como já foi citado, a presença de ambos os aminoácidos se mostraram importantes na estabilização das estruturas no sítio de ligação para mediarem o efeito biológico.

Insta frisar que, as moléculas 113m, 114m e JFR49m apresentaram resultados de Moldock Score ligeiramente maiores (em mem relação aos compostos com padrões de substituição diferentes. Por essa razão, conclui-se que a energia de ligação frente à proteína CFTR não foi alterada com a mudança da posição dos substituintes tosil ou acetamida do anel aromático dos compostos 1,2,3-triazóis estudados.

Portanto, diante do exposto, pode-se afirmar que as moléculas então propostas podem representar importantes agentes ativos frente à fibrose cística, dada a capacidade de interagir com aminoácidos relevantes, no sítio de ligação da CFTR. Logo, ao alcançá-lo, espera-se que essas moléculas promovam a estabilidade conformacional na proteína, permitindo a abertura do canal e o fluxo adequado de íons através da membrana, tal como ocorre com o ivacafto 


\subsection{3}

\section{Análise toxicológica (in silico)}

Os resultados obtidos através do VirtualToxLab® estão dispostos na tabela 4. As moléculas $6 \mathbf{k}, \mathbf{6 m}, \mathbf{6 n}$, e $\mathbf{6 p}$ despertaram grande interesse por apresentarem interações mais fracas, indicadas pela cor verde mais clara, ou nenhuma interação (espaços em branco) com as proteínas-alvo, refletindo em valores de Toxpot mais baixos. Nesse contexto, destaca-se que, quantitativamente, a força de ligação entre as 16 proteínas e cada molécula é dada pela intensidade da cor a ela atribuída, acompanhada de um valor numérico que vai traduzir essa intensidade.

Diante desses dados, buscou-se compreender melhor como as moléculas interagem com as proteínas - alvo, a fim de angariar alguma correlação da toxicidade com a estrutura das mesmas. Com esta finalidade, foi realizada a ancoragem molecular nos receptores $\mathrm{Ar}$ e AhR, respectivamente, de um dos compostos mais tóxicos, segundo o valor de Toxpot - $\mathbf{6 c}$ e $\mathbf{6 e}-\mathrm{e}$ dos menos tóxicos: 6m e 6n. No caso do Ar, foi mantido o DHT (Di-hidrotestosterona) que é o ligante complexado à proteína em sua estrutura cristalográfica.

Interessante que, para o receptor $\mathrm{AhR}$, houve uma interação mais intensa, de moderada a forte, para a maioria das moléculas, fator que pode estar contribuindo para o valor mais acentuado de Toxpot, o que justifica a escolha para a realização da ancoragem molecular neste caso. É válido destacar que este receptor é um fator de transcrição que, enquanto inativo, fica localizado no citoplasma ligado às proteínas chaperonas. 


\begin{tabular}{|c|c|c|c|c|c|c|c|c|c|c|c|c|c|c|c|c|c|}
\hline Molécula & Toxpot & $\mathbf{A R}$ & AhR & CYP1A2 & \begin{tabular}{|l|} 
CYP2C9 \\
\end{tabular} & CYP2D6 & CYP3A4 & ERa & ERb & GR & hERG & LXR & MR & PPARg & PR & Tra & TRb \\
\hline \begin{tabular}{|c|}
$\mathbf{j}$ \\
\end{tabular} & 0,598 & 6,50 & 7,90 & 5,10 & \begin{tabular}{|l|}
4,90 \\
\end{tabular} & 4,50 & 4,60 & 5,50 & 5,40 & 6,10 & 4,50 & 5,30 & 4,50 & 6,20 & 6,00 & 6,10 & 7,30 \\
\hline $6 b$ & 0,665 & 6,80 & 8,50 & 4,60 & 5,30 & 5,60 & 5,90 & 6,10 & 6,20 & 6,70 & 6,50 & 5,50 & 5,00 & 6,40 & 6,60 & 6,70 & 6,80 \\
\hline $6 e$ & 0,681 & 7,00 & 8,70 & 5,80 & 5,50 & 6,30 & 5,40 & 5,80 & 5,10 & 6,90 & 5,00 & 5,00 & 5,40 & 7,30 & 6,40 & 7,00 & 6,60 \\
\hline $6 q$ & 0,635 & 4,50 & 6,60 & 4,60 & 5,50 & 0,00 & 4,60 & 5,70 & 4,60 & 6,50 & 7,20 & 8,20 & 6,60 & 5,80 & 7,30 & 7,40 & 5,90 \\
\hline $6 \mathrm{~m}$ & 0,225 & 0,00 & 4,30 & 0,00 & 0,00 & 0,00 & 0,00 & 0,00 & 0,00 & 4,30 & 0,00 & 0,00 & 0,00 & 4,10 & 4,20 & 4,30 & 0,00 \\
\hline $6 \mathbf{k}$ & 0,267 & 4,00 & 0,00 & 0,00 & 0,00 & 0,00 & 0,00 & 4,20 & 4,30 & 4,30 & 4,30 & 0,00 & 4,10 & 4,70 & 4,70 & 0,00 & 4,50 \\
\hline $6 \mathrm{~g}$ & 0,64 & 6,60 & 8,30 & 4,90 & 4,70 & 4,40 & 4,70 & 5,50 & 5,40 & 6,10 & 4,70 & 5,30 & 4,60 & 6,30 & 5,30 & 6,50 & 6,90 \\
\hline $6 \mathbf{i}$ & 0,629 & 5,80 & 7,30 & 4,90 & 0,00 & 4,20 & 0,00 & 4,40 & 4,40 & 5,50 & 5,90 & 8,20 & 0,00 & 5,30 & 6,50 & 6,20 & 6,40 \\
\hline $6 n$ & 0,219 & 0,00 & 0,00 & 0,00 & 0,00 & 0,00 & 0,00 & 0,00 & 0,00 & 0,00 & 0,00 & 0,00 & 0,00 & 4,30 & 4,00 & 0,00 & 0,00 \\
\hline $6 f$ & 0,656 & 7,00 & 8,50 & 5,70 & 4,50 & 5,60 & 5,40 & 6,00 & 6,70 & 6,20 & 4,50 & 5,70 & 5,40 & 7,10 & 5,70 & 7,70 & 7,00 \\
\hline $6 \mathrm{~h}$ & 0,641 & 6,20 & 8,30 & 6,10 & 6,20 & 5,00 & 5,80 & 6,20 & 5,90 & 6,40 & 5,80 & 6,10 & 5,40 & 7,30 & 0,00 & 6,60 & 6,10 \\
\hline $6 d$ & 0,541 & 5,30 & 5,90 & 0,00 & 0,00 & 5,20 & 5,30 & 6,10 & 4,60 & 5,70 & 0,00 & 5,70 & 5,50 & 7,40 & 6,70 & 6,40 & 6,20 \\
\hline $6 c$ & 0,672 & 6,10 & 8,60 & 6,50 & 5,40 & 5,40 & 4,90 & 5,50 & 5,50 & 6,00 & 6,10 & 5,00 & 4,90 & 6,60 & 5,50 & 7,20 & 6,90 \\
\hline $6 \mathbf{6}$ & 0,504 & 7,00 & 6,20 & 0,00 & 5,20 & 0,00 & 5,70 & 4,80 & 4,10 & 4,70 & 4,40 & 6,30 & 6,00 & 6,90 & 4,90 & 7,10 & 5,90 \\
\hline JFR49m & 0,372 & 0,00 & 4,40 & 0,00 & 0,00 & 0,00 & 0,00 & 0,00 & 5,20 & 0,00 & 4,80 & 4,20 & 4,80 & 5,20 & 4,40 & 5,80 & 4,40 \\
\hline $114 \mathrm{~m}$ & 0,348 & 0,00 & 4,50 & 4,80 & 0,00 & 0,00 & 4,50 & 0,00 & 4,40 & 4,80 & 0,00 & 4,10 & 0,00 & 4,50 & 5,30 & 4,60 & 5,60 \\
\hline $113 \mathrm{~m}$ & 0,433 & 5,50 & 5,20 & 4,10 & 0,00 & 5,80 & 4,40 & 5,40 & 6,10 & 6,40 & 5,70 & 5,50 & 5,30 & 5,70 & 5,90 & 5,30 & 5,10 \\
\hline $6 p$ & 0,28 & 0,00 & 4,40 & 0,00 & 0,00 & 0,00 & 0,00 & 0,00 & 0,00 & 0,00 & 0,00 & 0,00 & 0,00 & 4,50 & 5,00 & 4,20 & 4,00 \\
\hline 60 & 0,516 & 5,10 & 4,50 & 0,00 & 4,30 & 4,70 & 4,90 & 4,60 & 5,10 & 6,60 & 0,00 & 4,60 & 4,40 & 5,70 & 7,10 & 5,60 & 6,70 \\
\hline \begin{tabular}{|l|}
61 \\
\end{tabular} & 0,414 & 0,00 & 4,40 & 4,10 & 0,00 & 0,00 & 0,00 & 4,40 & 4,40 & 4,90 & 6,20 & 0,00 & 4,40 & 4,70 & 4,10 & 5,50 & 4,60 \\
\hline ivacaftor & 0,172 & 0,00 & 0,00 & 0,00 & 0,00 & 0,00 & 0,00 & 0,00 & 0,00 & 0,00 & 0,00 & 0,00 & 0,00 & 0,00 & 0,00 & 0,00 & 0,00 \\
\hline
\end{tabular}

Tabela 4: Valores de Toxpot obtidos pelo software VirtualToxLab® para todas as moléculas de acordo com a interação com as 16 proteínas-alvo 
Ao ser ativado, o AhR é encaminhado ao núcleo onde induz a expressão de vários genes, sendo capaz, então, de modular diversas funções celulares e incitar efeitos adversos importantes. (CHENG, Lin, QIAN, et al., 2017).

Semelhantemente, o receptor Ar é interessante, pois, conforme a tabela 5, observam-se interações moderada e fraca para as moléculas em questão, o que possibilita estudá-las com mais detalhes pela ancoragem molecular.

Ar é um receptor nuclear que, após a interação com o andrógeno, liga-se ao DNA diretamente, numa região de regulação gênica específica, modulando a transcrição de gene. Assim, por consequência, efetua o controle fisiológico de maturação sexual masculina, como, por exemplo, o desenvolvimento e crescimento normais da próstata (PEREIRA DE JÉSUS-TRAN, CÔTÉ, et al., 2006).

Desta forma, os resultados das energias de interação para os receptores AhR e Ar, estão dispostos nas tabelas 5 e 6 , respectivamente.

Tabela 5: Resultados da ancoragem molecular realizada no receptor AhR

\begin{tabular}{cccc}
\hline Molécula & $\begin{array}{c}\text { MolDock } \\
\text { Score } \\
(\text { Kcal/mol })\end{array}$ & $\begin{array}{c}\text { Rerank } \\
\text { Score } \\
(\text { Kcal/mol })\end{array}$ & $\begin{array}{c}\text { HBond } \\
\text { (Kcal/mol) }\end{array}$ \\
\hline $\mathbf{6 m}$ & -159 & -113 & 0 \\
\hline $\mathbf{6 n}$ & -152 & -61 & 0 \\
$\mathbf{6 c}$ & -126 & -104 & 0 \\
$\mathbf{6 e}$ & -125 & -98 & 0 \\
$\mathbf{6 k}$ & -145 & -50 & 0 \\
\hline ivacaftor & -108 & 192 & 0 \\
\hline
\end{tabular}

Tabela 6: Resultados da ancoragem molecular realizada no receptor $\mathrm{Ar}$

\begin{tabular}{cccc}
\hline Molécula & $\begin{array}{c}\text { MolDock Score } \\
\text { (Kcal/mol) }\end{array}$ & $\begin{array}{c}\text { Rerank Score } \\
(\text { Kcal/mol) }\end{array}$ & $\begin{array}{c}\text { HBond } \\
(\text { Kcal/mol) }\end{array}$ \\
\hline $\mathbf{6 m}$ & -174 & -74 & $-0,6$ \\
\hline $\mathbf{6 n}$ & -145 & 36 & $-1,5$ \\
$\mathbf{D H T}$ & -114 & -102 & $-7,3$ \\
$\mathbf{6 c}$ & -120 & -92 & $-4,6$ \\
$\mathbf{6 e}$ & -127 & -102 & 0 \\
$\mathbf{6 k}$ & -149 & -113 & $-8,5$ \\
\hline ivacaftor & -70 & 220 & $-0,05$ \\
\hline
\end{tabular}


Os resultados das energias de interação das tabelas 5 e 6 mostraram-se coerentes com aqueles exibidos na tabela 3. Por exemplo, para o AhR, as moléculas 6n e 6k não tiveram interação, o que pode ser constatado pelos menores valores de Rerank Score - em módulo - , se comparado com aqueles obtidos para moléculas mais tóxicas, como a $\mathbf{6 c}$ e $\mathbf{6 e}$. No caso do ivacaftor, observa-se que o valor de energia é muito alto (192 e $220 \mathrm{Kcal} / \mathrm{mol}$ para AhR e Ar, respectivamente). Tal análise sugere que não foi possível encontrar um mínimo de energia para as conformações geradas no sítio de interação, o que pode explicar a baixa ou nenhuma interação ligante-proteína, refletindo a baixa toxicidade deste composto.

Observando as figuras 26 e 27, nota-se que para a molécula 6e, por exemplo, que exibiu maior afinidade pelo sítio de ligação dos receptores, a interação com os resíduos de aminoácidos hidrofóbicos foi menor. Entretanto, para as moléculas menos tóxicas, esse tipo de interação é mais acentuada. Por exemplo, no caso do ligante DHT (figura 27), as interações com os aminoácidos são através de ligação de hidrogênio, majoritariamente, confirmado pelo menor valor da energia de Hbond $(-7.3 \mathrm{Kcal} / \mathrm{mol})$, tabela 6 .

Logo, pode-se inferir que a presença de átomos de carbono dos anéis aromáticos, dos grupos sulfonila e carbonila, principalmente, contribui para que a molécula tenha uma conformação específica no sítio de ligação desses receptores. Com isso, as interações com os resíduos de aminoácidos de características hidrofóbicas são favorecidas. Assim, a relação proteína-ligante, neste caso, terá maior caráter repulsivo, que reflete em energias de interação menores (em módulo) e, possivelmente, contribui para toxicidades mais baixas. 


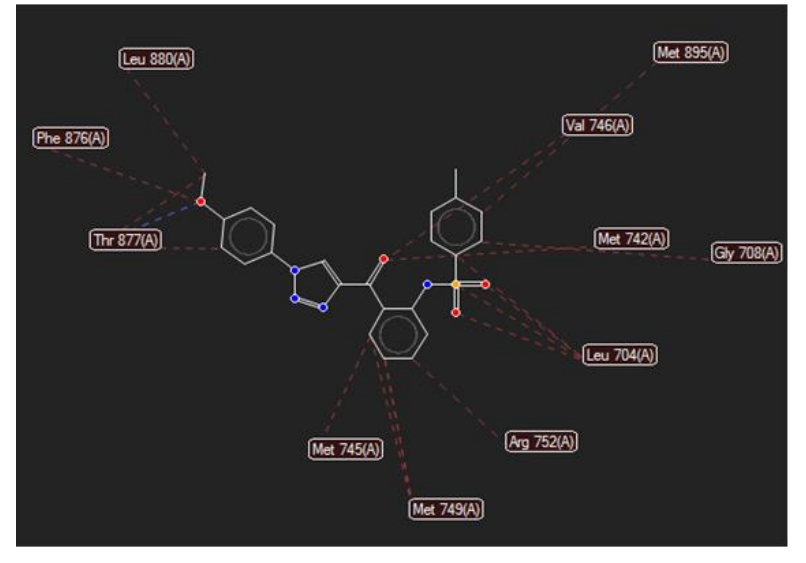

A

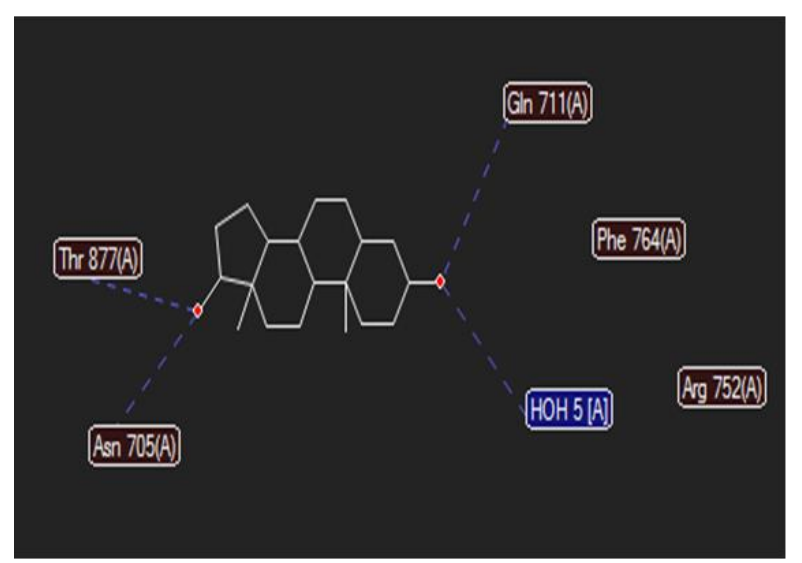

$\mathrm{C}$

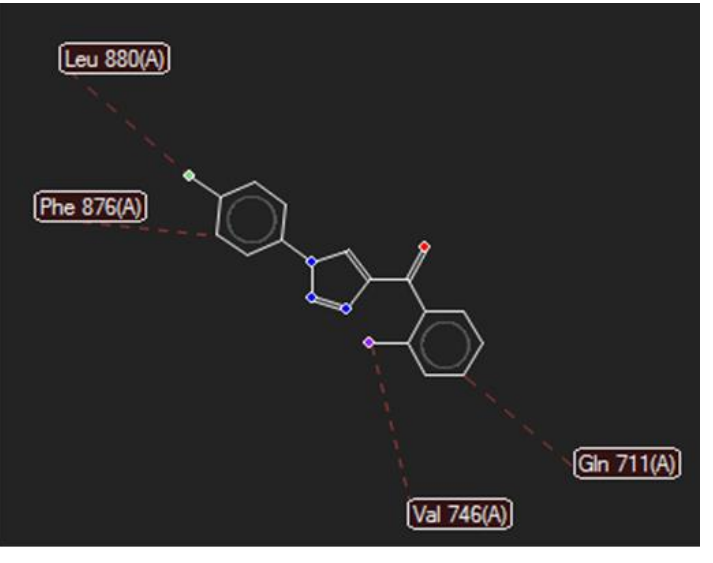

$\mathrm{B}$

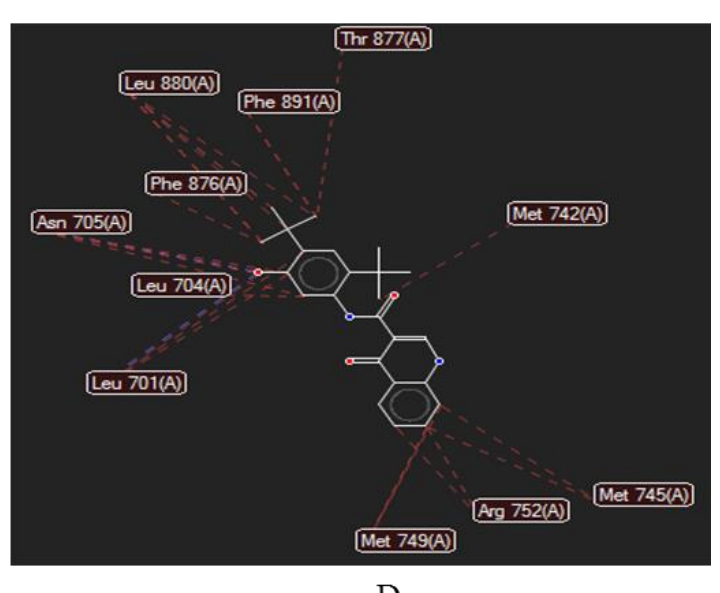

D

Figura 26: Interações entre os resíduos de aminoácidos do receptor Ar e as moléculas (A) - 6m; (B) - 6e; (C) - DHT; (D) - ivacaftor 


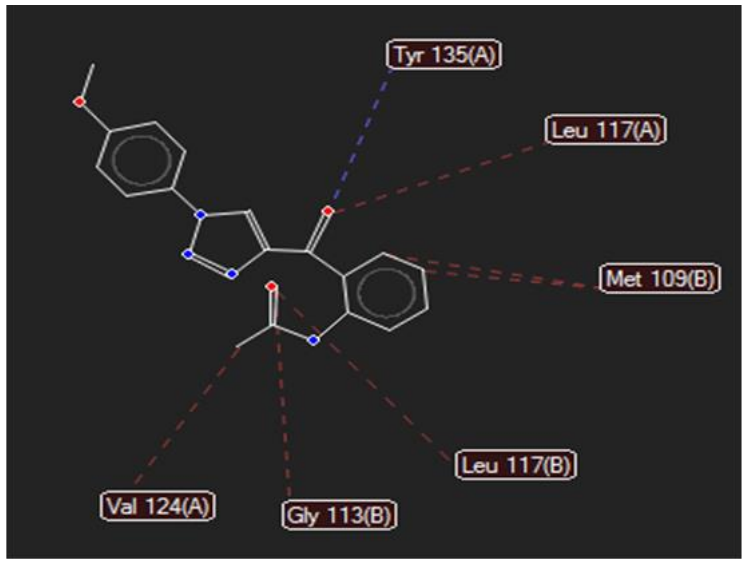

A

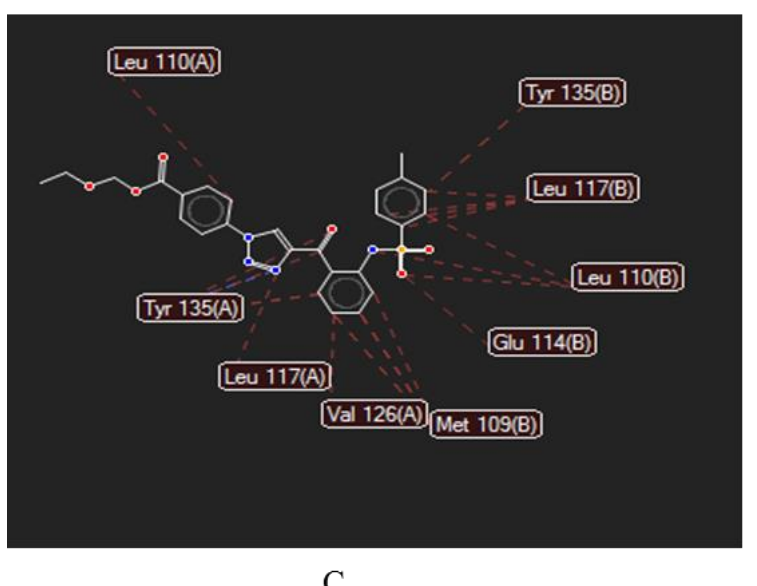

C

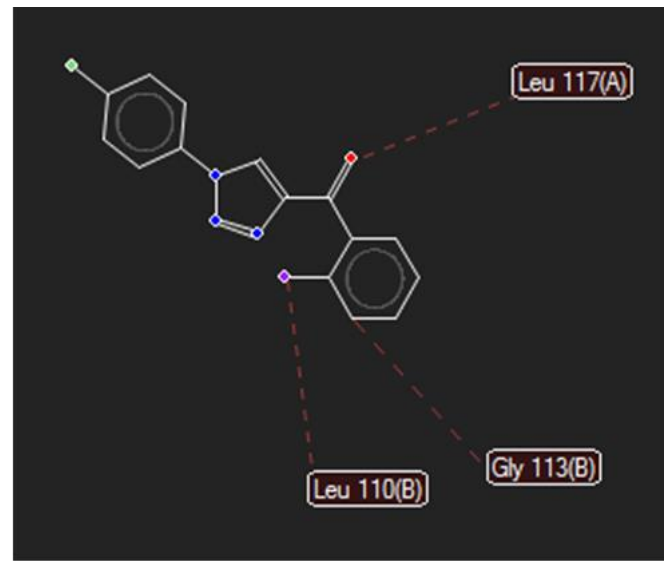

B

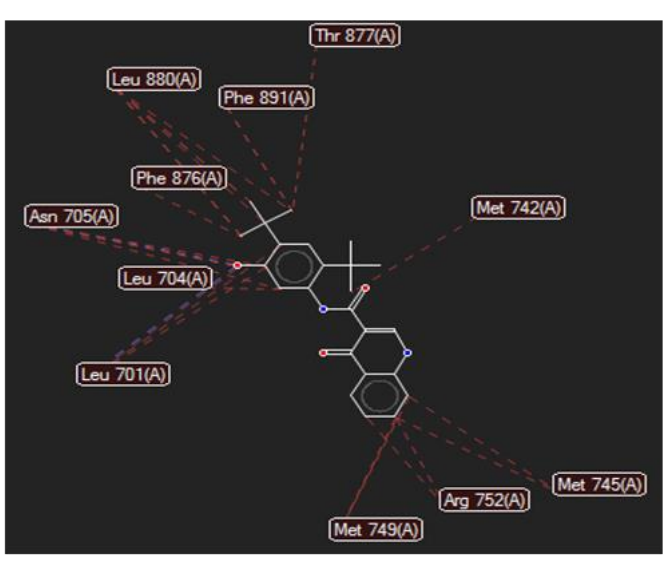

D

Figura 27: Interações entre os resíduos de aminoácidos do receptor AhR e as moléculas (A) -6k; (B) - 6e; (C) - 6n; (D) - ivacaftor 


\subsection{4}

\section{Estudos teóricos de ADME}

De acordo com as etapas anteriores de ancoragem molecular e do estudo toxicológico in silico, três moléculas se destacaram: $6 \mathbf{k}, \mathbf{6 m}$ e $\mathbf{6 n}$. Sendo assim, somente estas foram consideradas nos estudos teóricos de ADME. A figura 29 exemplifica os dados completos que são fornecidos pelo swissADMET quanto aos parâmetros farmacocinéticos e a tabela 7 dispõe os resultados dos parâmetros físicoquímicos.

Verifica-se que a molécula 6k apresentou resultados físico-químicos muito interessantes, não havendo nenhuma violação das regras estabelecidas pelo programa swissADMET. Por essa análise, infere-se que o composto pode ser considerado um candidato a fármaco, além de também se enquadrar nos parâmetros de Leadlikness. Neste conceito, as moléculas devem ser, preferencialmente, menores e menos hidrofóbicas do que as druglikeness (DAINA, MICHIELIN, et al., 2017).

O perfil farmacocinético da $\mathbf{6 k}$ também foi satisfatório, apresentando alta absorção gástrica e moderada solubilidade em água ( $\log \mathrm{S}=-5.50)$. Além disso, não foi capaz de atravessar a Barreira Hemato-encefálica (BHE) e não apresentou interação com glicoproteínas (P-gP), que pode estar associado ao menor potencial tóxico da molécula.

Quanto ao metabolismo, o swissADMET revelou que 6k é um inibidor enzimático, sendo um substrato para as isoformas CYP1A2, CYP2C19, CYP2C9 e CYP3A4; entretanto, não se obteve a mesma evidência observada no VirtualToxLab. Neste caso, o programa não mostrou nenhuma interação com as proteínas citadas, que pode estar associado com variações residuais dos valores obtidos dentro da margem de erro do programa. 


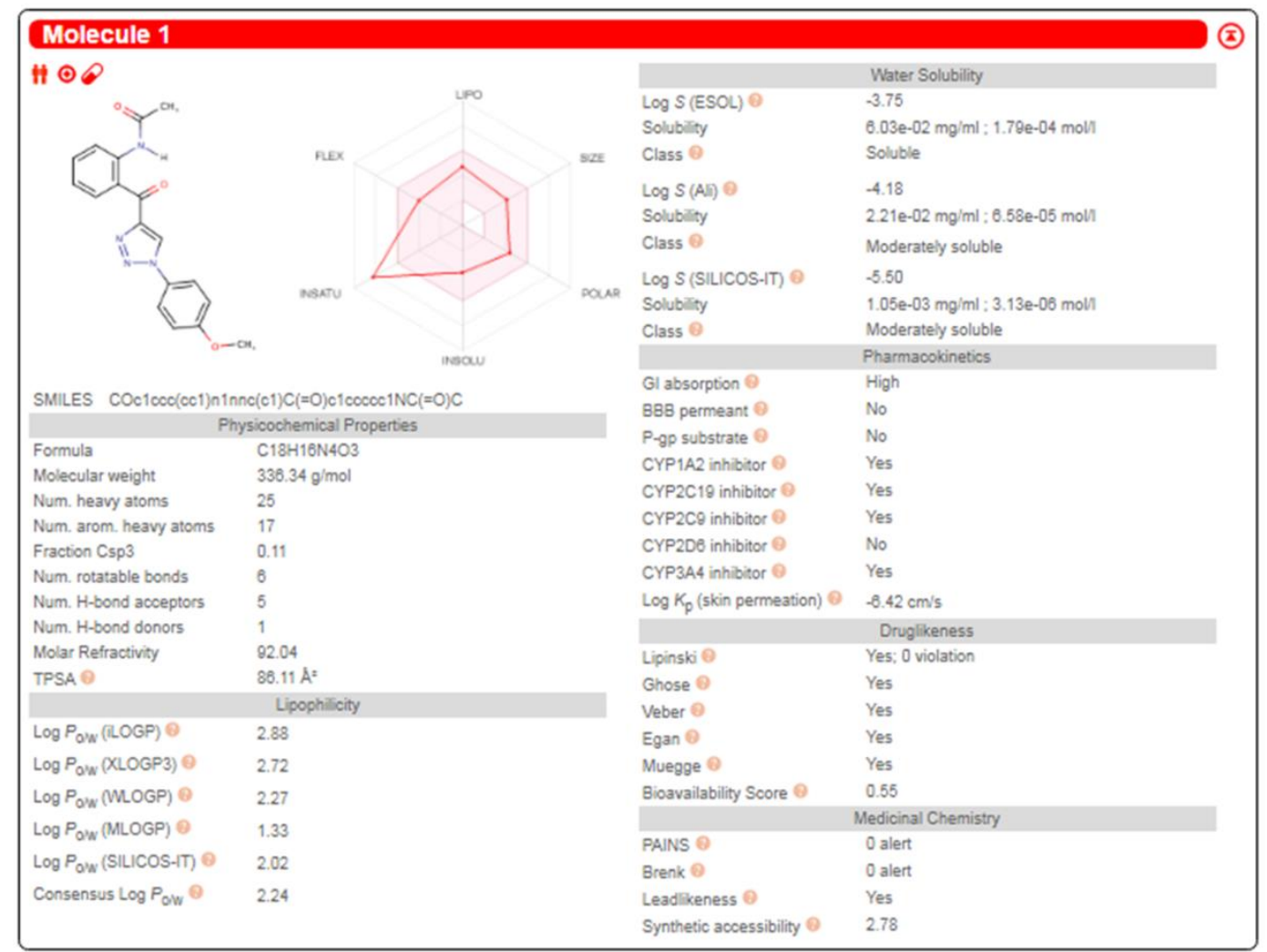

Figura 28: Informações completas geradas pelo programa SwissADME para a molécula $6 \mathrm{k}$ 
Tabela 7: Resultados dos parâmetros físico-químicos obtidos pelo swissADMET das moléculas que apresentaram resultados interessantes a parit dos estudos anteriores: $6 \mathrm{k}, 6 \mathrm{~m}$ e $6 \mathrm{n}$

\begin{tabular}{|c|c|c|c|c|c|c|c|c|c|c|}
\hline Molécula & MW $(\mathrm{g} / \mathrm{mol})$ & iLOGP & HBD & HBA & TPSA $(\AA)$ & RB & nAH & MR & PAINS \#alert & Brenk \#alert \\
\hline $6 \mathrm{k}$ & 336.34 & 2.88 & 1 & 5 & 86.11 & 6 & 17 & 92.04 & 0 & 0 \\
\hline $6 \mathrm{~m}$ & $\mathbf{4 4 8 . 4 9}$ & 3.54 & 1 & 6 & 111.56 & 7 & 23 & 119.81 & $\mathbf{1}$ & 0 \\
\hline $6 \mathrm{n}$ & $\mathbf{5 2 0 . 5 6}$ & 2.92 & 1 & 8 & 137.86 & $\mathbf{1 1}$ & 23 & $\mathbf{1 3 5 . 2 9}$ & $\mathbf{1}$ & $\mathbf{1}$ \\
\hline
\end{tabular}

*MW = peso molecular; iLOGP = coeficiente de partição octanol/água $; \mathrm{HBD}=$ número de doadores de ligação de hidrogênio; HBA = número de aceptores de ligação de hidrogênio; TPSA = área de superfície polar da molécula; RB = número de ligações rotacionáveis; nAH = número de anéis aromáticos; MR =refratividade molar; Pains e Brenk alert $=$ número de fragmentos indesejáveis 
O composto $\mathbf{6 m}$ apresentou propriedades druglikeness, sem violações; entretanto, não possui características de um fármaco líder (Leadlikness). Apenas um fragmento de alerta foi identificado na molécula. De forma geral, a absorção gastrointestinal (GI) foi alta, mas a solubilidade em água, baixa $(\log \mathrm{S}=-8.33)$. A molécula 113 inibiu as enzimas CYP2C19, CYP2C9 e CYP3A4 e, assim como a JFR49, não atravessa a BHE e não se liga a P-gP.

Por outro lado, o composto 6n apresentou características físico-químicas que culminaram em violações segundo as regras e, portanto, foi reprovado como druglikeness. $\mathrm{O}$ perfil farmacocinético não foi tão interessante, com baixa solubilidade e absorção GI.

Uma vez que aproximadamente $60 \%$ dos fármacos são reprovados na fase clínica devido às suas propriedades farmacocinéticas e metabólicas, os testes de AMDET in silico devem ser considerados na fase de planejamento de novos compostos, como uma excelente forma de economizar tempo e custos. 


\section{Perspectivas}

Como não foi possível a obtenção dos compostos 6l-q, propõe-se que a estratégia sintética adotada para a preparação das mesmas seja otimizada, incluindo a tentativa de obter os compostos a partir da metodologia anterior (implementada por Ligia Freitas).

É importante considerar que, embora a molécula 6k tenha sido obtida (com $5 \%$ ), a síntese da mesma precisa de otimização, de maneira a obter rendimentos mais elevados. Essa medida é crucial, principalmente, se for comprovada a atividade biológica do composto frente à CFTR, através dos estudos in vitro, que também representa um das perspectivas deste trabalho, sendo realizada em colaboração com a professora Margarida Amaral da Universidade de Lisboa, Portugal.

Sugere-se que a síntese da molécula 6q seja refeita diminuindo o equivalente da azida 5g, já que o excesso prejudica a pureza do produto final.

Como foi verificado que os compostos 113m, 114m e JFR49m tiveram afinidade pela CFTR, a síntese das mesmas é uma excelente proposta que pode contribuir para os estudos de Relação Estrutura - Atividade (SAR).

Além disso, também é interessante dar continuidade aos estudos computacionais, explorando outras ferramentas que possam auxiliar a análise mais minuciosa da proteína CFTR, como, por exemplo, o software TTD (Therapeutic Target Database). O de novo design também pode ser útil para a obtenção de informações interessantes quanto aos padrões de substituição que podem favorecer a interação com a proteína.

Ainda dentro desse escopo, sugerem-se os estudos de dinâmica molecular, pois podem auxiliar na quantificação dos efeitos dinâmicos da interação ligantereceptor, além de permitir avaliar o tempo de residência da molécula estudada no sítio de ligação da proteína.

Outra medida importante a ser considerada com a técnica proposta é a verificação da abertura da CFTR com dinâmicas moleculares de longa duração. Ademais, enfatiza-se a continuidade dos estudos e da aplicação de novas 
metodologias sintéticas de acoplamento C-N para a obtenção das quinolinonastriazóis, uma vez que, por este trabalho, também apresentaram resultados otimistas no contexto da ancoragem molecular.

Como forma de validar os resultados obtidos tanto da parte sintética como dos estudos computacionais, todos os compostos obtidos serão enviados para a etapa de avaliação in vitro (realizada em colaboração com a Universidade de Lisboa). Com isso, deseja-se analisar se, de fato, as moléculas estudadas possuem atividade frente à CFTR, como previsto pelos estudos in sílico. 


\section{Conclusão}

Os compostos 1,2,3-triazois 1,4-substituídos (6a-k) foram preparados com rendimentos de 5-96\%, através da estratégia sintética de cicloadição 1,3-dipolar entre enaminonas (3a-f) e azidas (5a-h). Graças à reação de organocatálise mediada por L-prolina na presença de DMA-DMF (1) e acetofenonas (2a-f), foi possível obter enaminonas de maneira mais rápida ( 2 a 5 horas). Adicionalmente, a metodologia apresentada é muito interessante por permitir que a reação de obtenção de 1,2,3-triazóis seja regiosseletiva, livre do uso de catalisadores (como cobre e paládio).

A atividade de todos os compostos 6a-q propostos frente à CFTR foi investigada por meio do método de ancoragem molecular, em que se verificaram energias de interação (Moldock Score) superiores, em módulo, àquela encontrada para a molécula de referência, o ivacaftor. Os resultados obtidos nesta fase se mostraram otimistas, uma vez que as moléculas $6 \mathbf{m}-\mathbf{n}$ apresentaram interações com os aminoácidos Arg933 e Tyr304 no sítio de ligação da CFTR. Essas interações são muito relevantes, pois, em conformidade com dados obtidos da literatura, contribuem efetivamente para a mudança conformacional da proteína, conduzindo à melhora nos sintomas inerentes à Fibrose Cística.

O software VirtualtoxLab® permitiu prever a toxicidade dos compostos sintetizados em comparação com o ivacaftor, onde se constatou que a maioria apresentou Toxpot consideravelmente elevado, exceto para os compostos $\mathbf{6 k}, \mathbf{6 m} \mathbf{m}$ 6n. O programa swissADME foi a ferramenta computacional usada para estudar o perfil farmacocinético das moléculas que se destacaram na etapa anterior $(\mathbf{6 k}, \mathbf{6 m}$ e 6n). Os dados apontaram que a 6k e 6m são compostos ativos, com características druglikeness, podendo representar uma alternativa farmacológica ao tratamento de FC.

Portanto, mediante a tudo que foi exposto, dentre os 1,2,3-triazois-1,4substituídos sintetizados, o composto $\mathbf{6 k}$ se evidenciou pelo baixo potencial tóxico (in silico) e por apresentar perfis farmacocinéticos interessantes que o destacam como druglikeness. Além disso, mesmo que os outros compostos ativos não tenham 
sido sintetizados, enfatiza-se que o presente trabalho contribuiu para o planejamento de moléculas promissoras frente ao tratamento de Fibrose Cística. 


\section{Procedimentos Experimentais}

\section{1 \\ Procedimentos experimentais (parte sintética)}

\subsection{1}

\section{Síntese da 4-aminobenzoato de 2-etoxietil (4g)}

Em um balão de $25 \mathrm{~mL}$ adicionou-se o ácido aminobenzoico (4) e o 2etoxietanol, sendo levados para uma placa em aquecimento. Em seguida, Logo em seguido, o ácido sulfúrico foi adicionado aos poucos e a reação ficou em refluxo a $135^{\circ} \mathrm{C}$, sob agitação, por $1 \mathrm{~h}$. Tendo passado esse tempo, esperou-se a reação esfriar e depois se verteu um pouco de água gelada e pedras de gelo no balão contendo a reação. O produto foi obtido após precipitação e filtração a vácuo.

Etoximetil 4-aminobenzoato (4g)

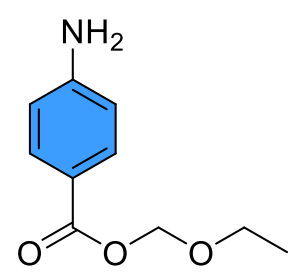

Rendimento: $61 \%$

FM: $\mathrm{C}_{10} \mathrm{H}_{13} \mathrm{NO}_{3}$

PM: $195.22 \mathrm{~g} / \mathrm{mol}$

$\mathrm{RMN}{ }^{1} \mathrm{H}\left(400 \mathrm{MHz}, \mathrm{CDCl}_{3}\right) \delta 7.89-7.85(\mathrm{~m}, 1 \mathrm{H}), 6.65-6.61(\mathrm{~m}, 1 \mathrm{H}), 4.42-$ $4.40(\mathrm{~m}, 1 \mathrm{H}), 3.75-3.73(\mathrm{~m}, 1 \mathrm{H}), 3.57(\mathrm{q}, \mathrm{J}=7.0 \mathrm{~Hz}, 1 \mathrm{H}), 1.22(\mathrm{t}, \mathrm{J}=7.0 \mathrm{~Hz}, 1 \mathrm{H})$. $\mathrm{RMN}{ }^{13} \mathrm{C}\left(101 \mathrm{MHz}, \mathrm{CDCl}_{3}\right) \delta 166.98,151.08,131.96,119.83,114.2566 .84$, $66.76,63.66,15.46$. 


\subsection{2}

\section{Síntese de arilazidas (5a-h)}

$1 \mathrm{~g}$ da arilanilina correspondente (4a-h) foi dissolvido em uma solução de $\mathrm{H}_{2} \mathrm{SO}_{4} 6 \mathrm{~mol} / \mathrm{L}$ e colocado em banho de gelo. Em seguida, $\mathrm{NaNO}_{2}(12,2 \mathrm{mmol}, 8 \mathrm{~g})$ (dissolvido em água) é adicionado à solução inicial. A mistura foi agitada por 30 minutos e, após esse tempo, adicionou-se a azida de sódio $(32,52 \mathrm{mmol}, 2 \mathrm{~g})$ por gotejamento, sob agitação rigorosa. A reação foi acompanhada por TLC e após 1h30 de reação, verificou-se a formação do produto por TLC. A reação foi extraída com acetato de etila /água e seca com sulfato de sódio anidro para posterior evaporação no evaporador rotatório.

Ácido 4-azidobenzoico (5a)

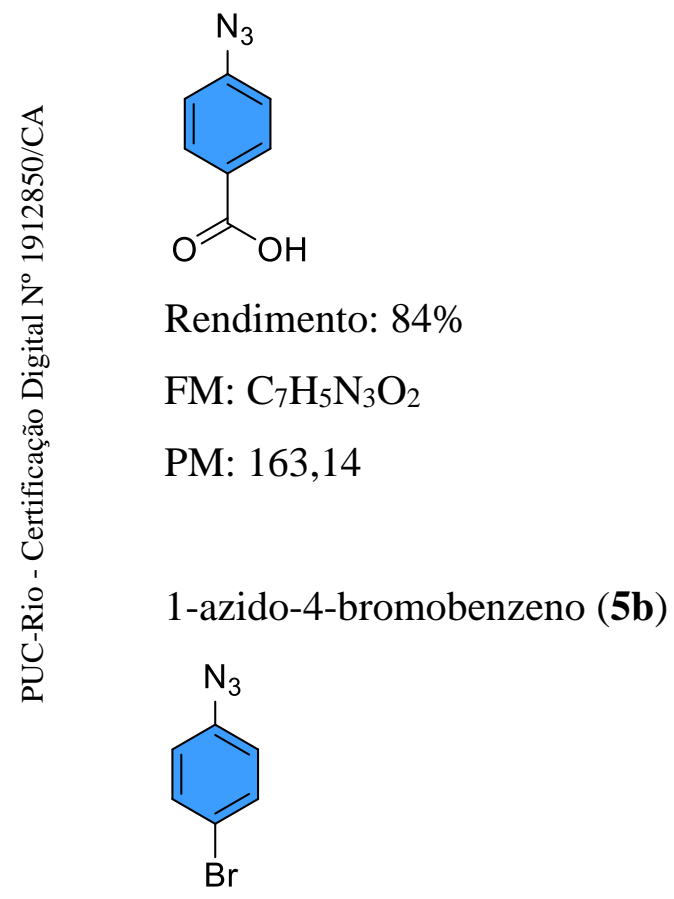

Rendimento: $42 \%$

FM: $\mathrm{C}_{7} \mathrm{H}_{5} \mathrm{~N}_{3} \mathrm{O}_{2}$

PM: 198,02 
1-azido-4-nitrobenzeno (5c)

$\mathrm{NO}_{2}$

Rendimento: 95\%

FM: $\mathrm{C}_{6} \mathrm{H}_{4} \mathrm{~N}_{4} \mathrm{O}_{2}$

PM: 164,12

1-azido-4-clorobenzeno (5d)<smiles>[N-]c1ccc(Cl)cc1</smiles>

Rendimento: $87 \%$

FM: $\mathrm{C}_{6} \mathrm{H}_{4} \mathrm{ClN}_{3}$

PM:153,57

1-azido-4-metilbenzeno (5e)<smiles>Cc1ccc(N)cc1</smiles>

Rendimento: $44 \%$

FM: $\mathrm{C}_{7} \mathrm{H}_{7} \mathrm{~N}_{3}$

PM: 133,15 
1-azido-4-fluorobenzeno (5f)

F

Rendimento: $61 \%$

FM: $\mathrm{C}_{6} \mathrm{H}_{4} \mathrm{FN}_{3}$

PM: 137,12

Etoximetil 4-azidobenzoato (5g)<smiles>CCOCOC(=O)c1ccc(N)cc1</smiles>

Rendimento: $57 \%$

FM: $\mathrm{C}_{10} \mathrm{H}_{11} \mathrm{~N}_{3} \mathrm{O}_{3}$

PM: 221,22

RMN ${ }^{1} \mathrm{H}\left(400 \mathrm{MHz}, \mathrm{CDCl}_{3}\right) \delta 8.07-8.03(\mathrm{~m}, 1 \mathrm{H}), 7.07-7.04(\mathrm{~m}, 1 \mathrm{H}), 4.46-$ $4.44(\mathrm{~m}, 1 \mathrm{H}), 3.76-3.74(\mathrm{~m}, 1 \mathrm{H}), 3.57$ (q, J = 7.0 Hz, 1H), $1.25-1.21(\mathrm{~m}, 2 \mathrm{H})$.

1-azido-4-metoxibenzeno $(\mathbf{5 h})$

$\mathrm{OCH}_{3}$

Rendimento: $88 \%$

FM: $\mathrm{C}_{7} \mathrm{H}_{7} \mathrm{~N}_{3} \mathrm{O}$

PM: 149,15

$\mathrm{RMN}^{1} \mathrm{H}\left(400 \mathrm{MHz}, \mathrm{CDCl}_{3}\right) \delta 6.97-6.94(\mathrm{~m}, 1 \mathrm{H}), 6.91-6.87(\mathrm{~m}, 1 \mathrm{H}), 3.79(\mathrm{~s}$, $2 \mathrm{H})$.

$\mathrm{RMN}{ }^{13} \mathrm{C}\left(101 \mathrm{MHz}, \mathrm{CDCl}_{3}\right) \delta 156.96,132.34,120.02 .115 .16,55.63,55.49$. 


\subsection{3}

\section{Síntese da N-(2-acetilfenil)acetamida (2c)}

A 2-amoniacetofenona 1c $(1.48 \mathrm{mmol}, 200 \mathrm{mg})$ é misturada com ácido acético $(10.36 \mathrm{~mL})$ e colocada sob agitação a $50^{\circ} \mathrm{C}$ durante $1 \mathrm{~h}$. A partir de então, foi adicionado ao balão o anidrido acético $(1.63 \mathrm{mmol}, 0,15 \mathrm{~mL})$, ficando sob agitação por mais $1 \mathrm{~h}$. A solução foi resfriada à temperatura ambiente, e o sólido obtido, filtrado e lavado com água gelada.

N-(2-acetilfenil)acetamida (2c)<smiles>CC(=O)Nc1ccccc1C(C)=O</smiles>

Rendimento: $34 \%$

$\mathrm{FM}: \mathrm{C}_{10} \mathrm{H}_{11} \mathrm{NO}_{2}$

PM: 177.20

$\mathrm{RMN}^{1} \mathrm{H}\left(400 \mathrm{MHz}, \mathrm{CDCl}_{3}\right) \delta 2.23(\mathrm{~s}, 1 \mathrm{H}), 8.73(\mathrm{dd}, \mathrm{J}=8.5,1.0 \mathrm{~Hz}, 1 \mathrm{H}), 7.89(\mathrm{dd}$, $\mathrm{J}=8.0,1.5 \mathrm{~Hz}, 1 \mathrm{H}), 7.55(\mathrm{ddd}, \mathrm{J}=8.6,7.5,1.5 \mathrm{~Hz}, 1 \mathrm{H}), 7.13-7.09(\mathrm{~m}, 1 \mathrm{H}), 2.66$ (s, 1H), $2.23(\mathrm{~s}, 1 \mathrm{H})$.

$\mathrm{RMN}{ }^{13} \mathrm{C}\left(101 \mathrm{MHz}, \mathrm{CDCl}_{3}\right) \delta 203.44,169.46,141.03,135.41,131.62,122.34$, $122.33,122.26,121.69,120.73,120.69,28.95,24.47$.

\subsection{4}

\section{Síntese da N-(2-acetilfenil)-4-metilbenzenosulfonamida (2d)}

Em um balão de 100mL, foram adicionados o cloreto de tosila ( $2.96 \mathrm{mmol}$, $562 \mathrm{mg})$, a 2-aminoacetofenona $1 \mathrm{c}(2.96 \mathrm{mmol}, 400 \mathrm{mg})$ e diclorometano (80 $\mathrm{mL})$. A atmosfera do balão foi trocada com argônio e, em seguida, adicionou-se a piridina $(8 \mathrm{~mL})$ à reação. A mesma ficou em agitação por $5 \mathrm{~h}$, e por, foi feita uma TLC para verificar a formação de produto. Também foi adicional um pouco de solução aquosa de $\mathrm{HCl}(50 \%)$ para neutralizar a piridina. A extração foi feita com $\mathrm{Nacl}$ e diclorometano. 
N-(2-acetilfenil)-4-metilbenzenosulfonamida (2d)

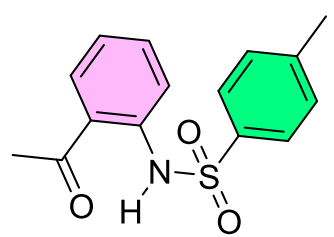

Rendimento: $73 \%$

FM: $\mathrm{C}_{10} \mathrm{H}_{11} \mathrm{NO}_{2}$

PM: 177,20

RMN ${ }^{1} \mathrm{H}\left(400 \mathrm{MHz}, \mathrm{CDCl}_{3}\right) \delta 11.45(\mathrm{~s}, 1 \mathrm{H}), 7.81-7.67(\mathrm{~m}, 1 \mathrm{H}), 7.47-7.42(\mathrm{~m}$, 1H), $7.22(\mathrm{~d}, \mathrm{~J}=8.0 \mathrm{~Hz}, 1 \mathrm{H}), 7.08-7.03(\mathrm{~m}, 1 \mathrm{H}), 2.56(\mathrm{~s}, 1 \mathrm{H}), 2.36(\mathrm{~s}, 1 \mathrm{H})$.

\subsection{5}

\section{Síntese da N-(4-acetilfenil)acetamida (2e)}

A 4-amoniacetofenona 1d (3.7 mmol, 500mg) é misturada com ácido acético $(36 \mathrm{~mL})$ e colocada sob agitação a $50^{\circ} \mathrm{C}$ durante $1 \mathrm{~h}$. A partir de então, foi adicionado ao balão o anidrido acético $(0,38 \mathrm{~mL})$, ficando sob agitação por mais 1h. A solução foi resfriada à temperatura ambiente, e o sólido obtido, filtrado e lavado com água gelada.

N-(4-acetilfenil)acetamida (2e)<smiles>CC(=O)Nc1ccc(C(C)=O)cc1</smiles>

Rendimento: $67 \%$

FM: $\mathrm{C}_{10} \mathrm{H}_{11} \mathrm{NO}_{2}$

PM: 177,20

$\mathrm{RMN}{ }^{1} \mathrm{H}\left(400 \mathrm{MHz}, \mathrm{CDCl}_{3}\right) \delta 7.92(\mathrm{~d}, J=8.7 \mathrm{~Hz}, 1 \mathrm{H}), 7.83(\mathrm{~s}, 1 \mathrm{H}), 7.63(\mathrm{~d}, \mathrm{~J}=$ $8.5 \mathrm{~Hz}, 1 \mathrm{H}), 2.57(\mathrm{~s}, 2 \mathrm{H}), 2.21(\mathrm{~s}, 2 \mathrm{H})$. 
$\mathrm{RMN}{ }^{13} \mathrm{C}\left(101 \mathrm{MHz}, \mathrm{CDCl}_{3}\right) \delta 197.17,168.76,142.76,132.83,129.77$ (s), 118.90, 26.54, $24.78(\mathrm{~d}, J=7.8 \mathrm{~Hz})$.

\subsection{6}

\section{Síntese da N-(4-acetilfenil)-4-metilbenzenosulfonamida (2f)}

Em um balão de $100 \mathrm{~mL}$, foram adicionados o cloreto de tosila $(2.95 \mathrm{mmol}$, $560 \mathrm{mg})$, a 4-aminoacetofenona $\mathbf{1 d}(2.95 \mathrm{mmol}, 400 \mathrm{mg})$ e diclorometano $(80 \mathrm{~mL})$. A atmosfera do balão foi trocada com argônio e, em seguida, adicionou-se a piridina $(8 \mathrm{~mL})$ à reação. A mesma ficou em agitação por $5 \mathrm{~h}$, e por, foi feita uma TLC para verificar a formação de produto. Também foi adicional um pouco de solução aquosa de $\mathrm{HCl}(50 \%)$ para neutralizar a piridina. A extração foi feita com $\mathrm{Nacl}$ e diclorometano.

$\mathrm{N}$-(4-acetilfenil)-4-metilbenzenosulfonamida (2f)<smiles>CC(=O)c1ccc(NS(=O)(=O)c2ccc(C)cc2)cc1</smiles>

FM: $\mathrm{C}_{15} \mathrm{H}_{15} \mathrm{NO}_{3} \mathrm{~S}$

PM: 289,35

$\mathrm{RMN}{ }^{1} \mathrm{H}\left(400 \mathrm{MHz}, \mathrm{CDCl}_{3}\right) \delta 7.84(\mathrm{~d}, \mathrm{~J}=8.8 \mathrm{~Hz}, 1 \mathrm{H}), 7.72(\mathrm{~d}, \mathrm{~J}=8.3 \mathrm{~Hz}, 1 \mathrm{H})$, $7.13(\mathrm{~d}, \mathrm{~J}=8.8 \mathrm{~Hz}, 1 \mathrm{H}), 2.53(\mathrm{~s}, 1 \mathrm{H}), 2.38(\mathrm{~s}, 1 \mathrm{H})$.

$\mathrm{RMN}{ }^{13} \mathrm{C}\left(101 \mathrm{MHz}, \mathrm{CDCl}_{3}\right) \delta 197.03,151.05,144.37,141.20,136.25,133.16$, 129.87, 127.40, 118.99, 113.78. 


\subsection{7}

\section{Síntese de enaminonas (3a-d)}

Para a formação das enamoninas 3a-d, a acetofenona apropriada (200mg) é transferida para um balão volumétrico de $10 \mathrm{~mL}$ e, em seguida, adiciona-se o volume de DMF-DMA $(0,26 \mathrm{~mL}, 1,99 \mathrm{mmol})$. A mistura é colocada em agitação e aquecimento a 80 graus. Ao atingir a temperatura, a L-prolina (18 mg, 0,16 mmol) é adicionada à reação. A formação da enaminona é acompanhada por TLC, podendo a agitação ser mantida por 1 a 2 horas. A enaminona não é isolada e o excesso de DMF-DMA é evaporado no evaporador rotatório.

(E)-3-(dimetilamino)-1-fenilprop-2-en-1-ona (3a)<smiles>CN(C)/C=C/C(=O)c1ccccc1</smiles>

FM: $\mathrm{C}_{11} \mathrm{H}_{13} \mathrm{NO}$

PM: $175.23 \mathrm{~g} / \mathrm{mol}$

(E)-1-(2-bromophenyl)-3-(dimethylamino)prop-2-en-1-one (3b)<smiles>CN(C)/C=C/C(=O)c1ccccc1Br</smiles>

FM: $\mathrm{C}_{11} \mathrm{H}_{12} \mathrm{BrNO}$

PM: $254.13 \mathrm{~g} / \mathrm{mol}$ 
(E)-N-(2-(3-(dimetilamino)acriloil)fenil)acetamida (3c)<smiles>CC(=O)Nc1ccccc1C(=O)/C=C/N(C)C</smiles>

FM: $\mathrm{C}_{13} \mathrm{H}_{16} \mathrm{~N}_{2} \mathrm{O}_{2}$

PM: $232.28 \mathrm{~g} / \mathrm{mol}$

(E)-N-(2-(3-(dimetilamino)acriloil)fenil)-4-metilbenzonesulfonamida (3d)

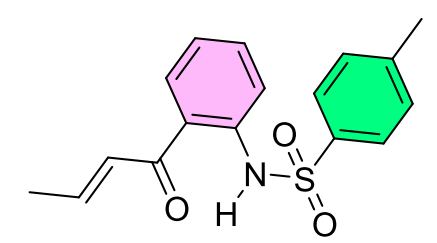

FM: $\mathrm{C}_{18} \mathrm{H}_{20} \mathrm{~N}_{2} \mathrm{O}_{3} \mathrm{~S}$

PM: $344.43 \mathrm{~g} / \mathrm{mol}$

\subsection{8}

\section{Síntese dos 1,2,3-triazóis-1,4-substituídos}

Na etapa 2, o excesso de DMF-DMA resultante da reação de formação da enaminona (item 7.2.1) é retirado por rota evaporador, e, em seguida, é adicionada a azida solubilizada em DMSO. A reação é colocada em aquecimento, 90 graus, e agitação por 13 a 14 horas. A reação é acompanhada por tlc. Após o término da reação, o produto é vertido em um béquer de $100 \mathrm{~mL}$ com água destilada gelada. O produto precipita puro e, em seguida, é filtrado à vácuo. 
Formato de 4- (4-benzoil-1H-1,2,3-triazol-1-il) fenil (6a)

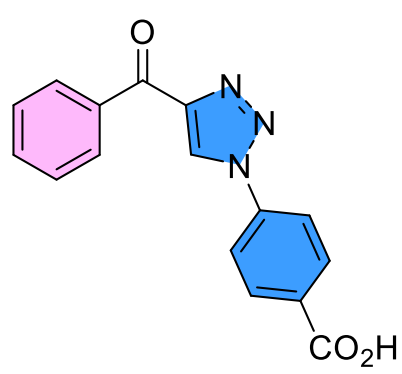

Rendimento: $47 \%$

FM: $\mathrm{C}_{16} \mathrm{H}_{11} \mathrm{~N}_{3} \mathrm{O}_{3}$

PM: 293,28

RMN ${ }^{1} \mathrm{H}(400 \mathrm{MHz}, \mathrm{DMSOd}) \delta 9.80(\mathrm{~s}, 1 \mathrm{H}), 8.32-8.30(\mathrm{~m}, 1 \mathrm{H}), 8.16(\mathrm{~s}, 2 \mathrm{H})$, 7.98 (ddd, $\mathrm{J}=14.2,7.1,1.3 \mathrm{~Hz}, 2 \mathrm{H}), 7.82$ (dd, J = 7.5, $1.2 \mathrm{~Hz}, 1 \mathrm{H}), 7.90$ (td, J = $8.1,1.4 \mathrm{~Hz}, 1 \mathrm{H}), 7.23(\mathrm{~d}, \mathrm{~J}=8.6 \mathrm{~Hz}, 1 \mathrm{H})$.

(1-(4-bromofenil)-1H-1,2,3-triazol-4-il)(fenil)metanona (6b)<smiles>O=C(c1ccccc1)c1cn(-c2ccc(Br)cc2)nn1</smiles>

Rendimento: $56 \%$

FM: $\mathrm{C}_{15} \mathrm{H}_{10} \mathrm{BrN}_{3} \mathrm{O}$

PM: 328,17

RMN ${ }^{1} \mathrm{H}(400 \mathrm{MHz}, \mathrm{DMSOd}) \delta 9.61(\mathrm{~s}, 1 \mathrm{H}), 8.26(\mathrm{~d}, \mathrm{~J}=8.5 \mathrm{~Hz}, 2 \mathrm{H}), 8.04-8.00$ (m, 2H), $7.88-7.84(\mathrm{~m}, 2 \mathrm{H}), 7.76-7.72(\mathrm{~m}, 1 \mathrm{H}), 7.64-7.61(\mathrm{~m}, 2 \mathrm{H})$.

$\mathrm{RMN}{ }^{13} \mathrm{C}\left(101 \mathrm{MHz}, \mathrm{CDCl}_{3}\right) \delta 185.36,148.72,136.39,135.34,133.58,133.21$, $130.59,128.45,126.20,123.57,122.21$. 
(1-(4-nitrofenil)-1H-1,2,3-triazol-4-il)(fenil)metanona (6c)

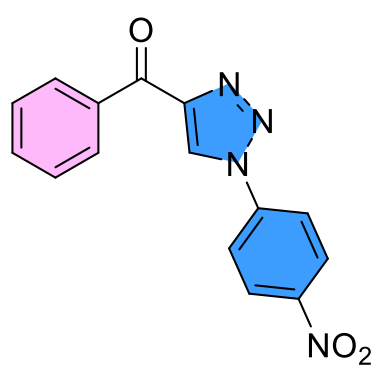

Rendimento: $28 \%$

FM: $\mathrm{C}_{15} \mathrm{H}_{10} \mathrm{~N}_{4} \mathrm{O}_{3}$

PM: 294,27

RMN ${ }^{1} \mathrm{H}(400 \mathrm{MHz}, \mathrm{DMSOd}) \delta 9.81(\mathrm{~s}, 1 \mathrm{H}), 8.51(\mathrm{~d}, \mathrm{~J}=9.2 \mathrm{~Hz}, 2 \mathrm{H}), 8.39(\mathrm{~d}, \mathrm{~J}=$ $9.2 \mathrm{~Hz}, 2 \mathrm{H}), 8.28(\mathrm{dd}, \mathrm{J}=8.3,1.2 \mathrm{~Hz}, 2 \mathrm{H}), 7.79-7.72(\mathrm{~m}, 1 \mathrm{H}), 7.67-7.61(\mathrm{~m}$, $2 \mathrm{H})$.

Formato 4-(4-(2-bromobenzoil)-1H-1,2,3-triazol-1-yl)fenil (6d)

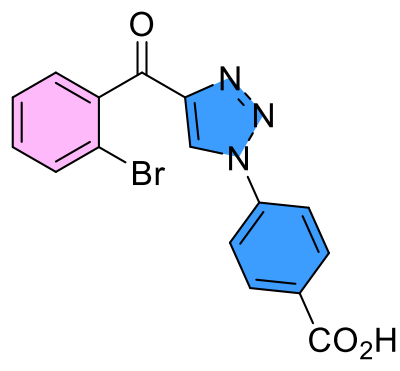

Rendimento: $89 \%$

FM: $\mathrm{C}_{16} \mathrm{H}_{10} \mathrm{BrN}_{3} \mathrm{O}_{3}$

PM: 328,17

RMN ${ }^{1} \mathrm{H}(400 \mathrm{MHz}, \mathrm{DMSOd}): 9.71(\mathrm{~s}, 1 \mathrm{H}), 8.16(\mathrm{~s}, 5 \mathrm{H}), 7.80(\mathrm{~d}, \mathrm{~J}=7.7 \mathrm{~Hz}, 1 \mathrm{H})$, $7.66(\mathrm{dd}, \mathrm{J}=7.3,1.7 \mathrm{~Hz}, 1 \mathrm{H}), 7.60-7.51(\mathrm{~m}, 2 \mathrm{H}), 2.53(\mathrm{~d}, \mathrm{~J}=15.6 \mathrm{~Hz}, 3 \mathrm{H})$ 


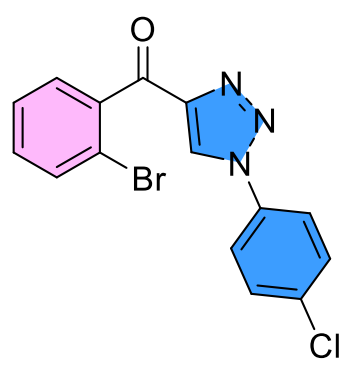

Rendimento: $32 \%$

FM: $\mathrm{C}_{15} \mathrm{H}_{9} \mathrm{BrClN}_{3} \mathrm{O}$

PM: 362,61

RMN ${ }^{1} \mathrm{H}: \mathrm{RMN}{ }^{1} \mathrm{H}\left(400 \mathrm{MHz}, \mathrm{CDCl}_{3}\right) \delta 8.66(\mathrm{~s}, 1 \mathrm{H}), 7.79-7.75(\mathrm{~m}, 2 \mathrm{H}), 7.72$ $(\mathrm{dd}, \mathrm{J}=7.9,1.1 \mathrm{~Hz}, 1 \mathrm{H}), 7.60-7.55(\mathrm{~m}, 2 \mathrm{H}), 7.60-7.55(\mathrm{~m}, 2 \mathrm{H}), 7.51-7.46(\mathrm{~m}$, 2H), $7.45-7.37(\mathrm{~m}, 2 \mathrm{H}), 7.34-7.29(\mathrm{~m}, 1 \mathrm{H})$.

$\mathrm{RMN}{ }^{13} \mathrm{C}:\left(101 \mathrm{MHz}, \mathrm{CDCl}_{3}\right): 147.79,147.79,141.47,139.06,135.65,134.73$, $133.86,133.71,132.18,131.82,130.23,130.15,128.93,127.46,127.20,125.64$, 125.57, 122.05, 120.05, 120.07, 118.92 .

Fenil(1-(p-tolil)-1H-1,2,3-triazol-4-il)metanona (6f)

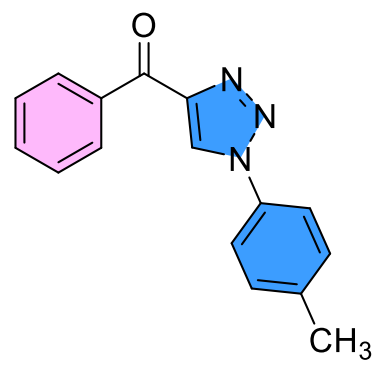

Rendimento: $24 \%$

FM: $\mathrm{C}_{16} \mathrm{H}_{13} \mathrm{~N}_{3} \mathrm{O}$

PM: 263,30

RMN ${ }^{1} \mathrm{H}\left(400 \mathrm{MHz}, \mathrm{CDCl}_{3}\right) \delta 8.68(\mathrm{~s}, 1 \mathrm{H}), 8.51(\mathrm{~d}, \mathrm{~J}=7.3 \mathrm{~Hz}, 2 \mathrm{H}), 7.71(\mathrm{~d}, \mathrm{~J}=$ $8.4 \mathrm{~Hz}, 2 \mathrm{H}), 7.66$ (d, J = 7.4 Hz, 1H), 7.58 (d, J = 7.8 Hz, 1H), 7.39 (s, 1H), 7.28 (s, $7 \mathrm{H})$.

$\mathrm{RMN}^{13} \mathrm{C}:\left(101 \mathrm{MHz}, \mathrm{CDCl}_{3}\right): \delta 185.62,139.82,136.51,136.48,133.40,130.67$, $130.48,130.44,128.45,120.71$. 
(1-(4-fluorofenil)-1H-1,2,3-triazol-4-il)(fenil)metanona (6g)

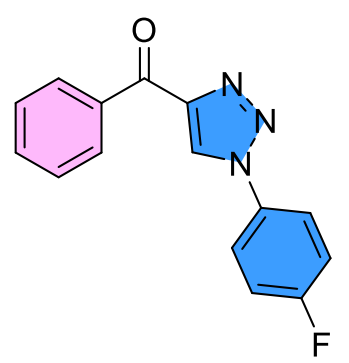

Rendimento: $12 \%$

FM: $\mathrm{C}_{15} \mathrm{H}_{10} \mathrm{FN}_{3} \mathrm{O}$

PM: 267,26

$\mathrm{RMN}{ }^{1} \mathrm{H}\left(400 \mathrm{MHz}, \mathrm{CDCl}_{3}\right) \delta 8.66(\mathrm{~s}, 1 \mathrm{H}), 8.51-8.47(\mathrm{~m}, 2 \mathrm{H}), 7.83-7.77(\mathrm{~m}$, 2H), $7.68-7.63(\mathrm{~m}, 1 \mathrm{H}), 7.58-7.54(\mathrm{~m}, 2 \mathrm{H}), 7.32-7.27(\mathrm{~m}, 2 \mathrm{H})$.

(2-bromofenil)(1-(4-nitrofenil)-1H-1,2,3-triazol-4-il)metanona (6h)<smiles>O=C(c1cn(-c2ccc([N+](=O)[O-])cc2)nn1)c1ccccc1Br</smiles>

Rendimento: $96 \%$

FM: $\mathrm{C}_{15} \mathrm{H}_{9} \mathrm{BrN}_{4} \mathrm{O}_{3}$

PM: 373,17

RMN ${ }^{1} \mathrm{H}\left(400 \mathrm{MHz}, \mathrm{CDCl}_{3}\right) \delta 8.80(\mathrm{~s}, 1 \mathrm{H}), 8.49(\mathrm{~d}, J=8.9 \mathrm{~Hz}, 1 \mathrm{H}), 8.07(\mathrm{~s}, \mathrm{~J}=$ $9.0 \mathrm{~Hz}, 1 \mathrm{H}), 7.74(\mathrm{~d}, \mathrm{~J}=7.9 \mathrm{~Hz}, 1 \mathrm{H}), 7.66(\mathrm{~s}, 1 \mathrm{H}), 7.52-7.42(\mathrm{~m}, 2 \mathrm{H})$, $\mathrm{RMN}{ }^{13} \mathrm{C}:\left(101 \mathrm{MHz}, \mathrm{CDCl}_{3}\right): \delta 148.21,147.89,140.39,138.86,133.77,132.39$, $130.15,127.30,125.74,125.62,121.13,120.10$. 
Etoximetil 4-(4-benzoil-1H-1,2,3-triazol-1-il) benzoato (6i)

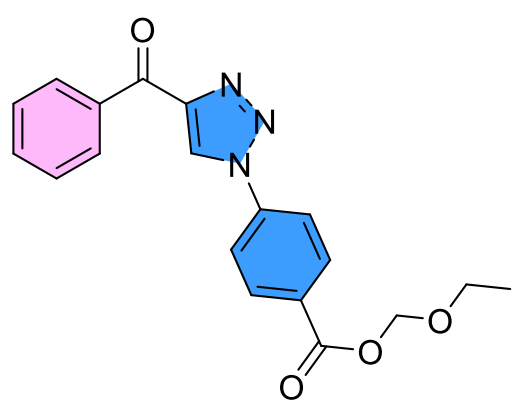

Rendimento: $45 \%$

FM: $\mathrm{C}_{19} \mathrm{H}_{17} \mathrm{~N}_{3} \mathrm{O}_{4}$

PM: 351,36

RMN ${ }^{1} \mathrm{H}\left(400 \mathrm{MHz}, \mathrm{CDCl}_{3}\right) \delta 8.81(\mathrm{~s}, 1 \mathrm{H}), 8.53-8.47(\mathrm{~m}, 2 \mathrm{H}), 8.33-8.28(\mathrm{~m}$, 2H), $8.10-8.04(\mathrm{~m}, 1 \mathrm{H}), 7.99-7.92(\mathrm{~m}, 2 \mathrm{H}), 7.70-7.64(\mathrm{~m}, 1 \mathrm{H}), 7.60-7.54$ (m, 2H), $7.28(\mathrm{~s}, 1 \mathrm{H}), 7.11-7.06(\mathrm{~m}, 1 \mathrm{H}), 4.56-4.52(\mathrm{~m}, 2 \mathrm{H}), 4.49-4.46(\mathrm{~m}$, $1 \mathrm{H}), 3.84-3.81(\mathrm{~m}, 2 \mathrm{H}), 3.65-3.59(\mathrm{~m}, 2 \mathrm{H})$.

$\mathrm{RMN}^{13} \mathrm{C}:\left(101 \mathrm{MHz}, \mathrm{CDCl}_{3}\right): \delta 185.62,139.82,136.51,136.48,133, .40,130.67$, $130.48,130.44,128.45,120.71$.

(1-(4-chorofenil)-1H-1,2,3-triazol-4-il)(fenil)metanona (6j)<smiles>O=C(c1ccccc1)c1cn(-c2ccc(Cl)cc2)nn1</smiles>

Rendimento: $22 \%$

FM: $\mathrm{C}_{15} \mathrm{H}_{10} \mathrm{ClN}_{3} \mathrm{O}$

PM: 283,72

$\mathrm{RMN}{ }^{1} \mathrm{H}\left(400 \mathrm{MHz}, \mathrm{CDCl}_{3}\right) \delta 8.68(\mathrm{~s}, 1 \mathrm{H}), 8.50-8.47(\mathrm{~m}, 2 \mathrm{H}), 7.80-7.75(\mathrm{~m}$, $2 \mathrm{H}), 7.59-7.54(\mathrm{~m}, 4 \mathrm{H})$.

$\mathrm{RMN}^{13} \mathrm{C}:\left(101 \mathrm{MHz}, \mathrm{CDCl}_{3}\right): \delta 185.32,148.82,136.26,135.50,134.86,133.48$, $133.48,130.64,130.23,128.59,126.19,122.00$. 


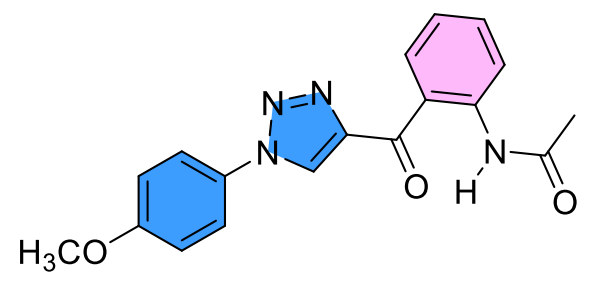

Rendimento: $5 \%$

FM: $\mathrm{C}_{18} \mathrm{H}_{16} \mathrm{~N}_{4} \mathrm{O}_{3}$

PM: 336,35

RMN ${ }^{1} \mathrm{H}\left(400 \mathrm{MHz}, \mathrm{CDCl}_{3}\right) \delta 11.21(\mathrm{~s}, 1 \mathrm{H}), 8.70(\mathrm{~d}, J=8.3 \mathrm{~Hz}, 1 \mathrm{H}), 8.70(\mathrm{~d}, \mathrm{~J}=$ $8.3 \mathrm{~Hz}, 1 \mathrm{H}), 8.55(\mathrm{~s}, 1 \mathrm{H}), 7.72-7.68(\mathrm{~m}, 1 \mathrm{H}), 7.65-7.60(\mathrm{~m}, 1 \mathrm{H}), 7.09-7.05$ (m, 1H), 3.89 (s, 2H), $2.26(\mathrm{~s}, 2 \mathrm{H})$.

$\mathrm{RMN}{ }^{13} \mathrm{C}:\left(101 \mathrm{MHz}, \mathrm{CDCl}_{3}\right): \delta 188.41,169.19,160.52,148.65,141.24,135,19$, $134.08,129.57,126.84,122.46,115.10,115.02,55.64,25.86$.

\section{2 \\ Procedimentos experimentais (parte computacional)}

\subsection{1}

\section{Ancoragem molecular}

A primeira etapa do processo de ancoragem molecular foi a otimização das estruturas de todas as moléculas de interesse no programa Spartan Pro®, utilizando o pelo método semi-empírico Austin Model (AM1).

Posteriormente, a estrutura cristalográfica do complexo proteína (CFTR)ligante (ivacaftor) foi obtida da Protein Data Bank (PDB), sob o código 6O2P. O método de obtenção da proteína descrito pelo PDB é a Microscopia Eletrônica (ME), com a resolução de 3.3 Å. O sistema de expressão da proteína é Homo sapiens, contendo uma mutação, e de peso molecular de 178.06 Da. O software utilizado foi o Molegro Virtual Docker, versão 6.0.

Para a etapa de re-acoragem e ancoragem molecular, foram utilizados os seguintes parâmetros: número de corridas $=30$; número de iterações $=2000$; 
tamanho da população = 50. Além disso, um comando é dado ao Molegro para que identifique as cavidades na estrutura cristalográfica da proteína. Das cavidades identificadas, prevaleceram aquelas mais próximas ao ligante complexado à proteína. O Grid foi de 0,3 А̊. O algoritmo genético utilizado foi Moldock Optimizer. Foi solicitado ao programa retornar as dez melhores poses encontradas em cada etapa do processo de ancoragem molecular.

Para a ancoragem molecular nos receptores AhR e Ar foram utilizadas as estruturas cristalográficas do PDB sob o código 4M4X (2.55 ̊̊) e 1T7R (1.40 ̊̊) respectivamente.

\subsection{2}

\section{Análise toxicológica in silico}

As moléculas propostas foram inseridas individualmente no programa VirtualToxLab após o processo de otimização das estruturas.

\subsection{3}

\section{Estudos teóricos in silico}

As moléculas de interesse foram inseridas no formato SMILE no programa SwissADME, gratuitamente disponível no site www.swissadme.ch. 


\section{Referências}

AGALAVE, S. G., MAUJAN, S. R., PORE, V. S. "Click chemistry: 1,2,3-triazoles as pharmacophores", Chemistry - An Asian Journal, v. 6, n. 10, p. 2696-2718, 2011.

AMARAL, M. D., HUTT, D. M., TOMATI, V., et al. "CFTR processing, trafficking and interactions", Journal of Cystic Fibrosis, v. 19, p. S33-S36, 2020.

ATHANAZIO, R. A., DA SILVA FILHO, L. V. R. F., VERGARA, A. A., et al. "Brazilian guidelines for the diagnosis and treatment of cystic fibrosis", Jornal Brasileiro de Pneumologia, v. 43, n. 3, p. 219-245, 2017.

AUGUSTO, F., MARSON, L. "Custo da medicina de precisão em um centro de referência para o tratamento de fibrose cística", Jornal Brasileiro de Pneumologia, v. 46, n. 2, p. 1-3, 2020.

BALFOUR-LYNN, I. M., KING, J. A. "CFTR modulator therapies - Effect on life expectancy in people with cystic fibrosis", Paediatric Respiratory Reviews, n. xxxx, 2020. DOI: 10.1016/j.prrv.2020.05.002. Disponível em: https://doi.org/10.1016/j.prrv.2020.05.002.

BARRY, P. J., DONALDSON, A. L., JONES, A. M. Ivacaftor for cystic fibrosis, British Medical Association, v. 361, n. May, p. 1-7, 2018.

BEAR, C. E. "A Therapy for Most with Cystic Fibrosis", Cell, v. 180, n. 2, p. 211, 2020.

BIEGER, A. M., MARSON, F. A. de L., BERTUZZO, C. S. "Prevalence of $\Delta$ F508 mutation in the cystic fibrosis transmembrane conductance regulator gene among cystic fibrosis patients from a Brazilian referral center", Jornal de Pediatria, v. 88, n. 6, p. 531-534, 2012.

BOLLU, R., PALEM, J. D., BANTU, R., et al. "Rational design, synthesis and antiproliferative evaluation of novel 1,4-benzoxazine-[1,2,3]triazole hybrids", European Journal of Medicinal Chemistry, v. 89, p. 138-146, 2015.

CABELlO, G. M. K. "Avanços da Genética na Fibrose Cística", Revista Hospital Universitário Pedro Ernesto, v. 10, n. 4, 2011.

CALDERONE, V., GIORGI, I., LIVI, O., et al. "Benzoyl and/or benzyl substituted 1,2,3-triazoles as potassium channel activators. VIII", European Journal of Medicinal Chemistry, v. 40, n. 6, p. 521-528, 2005.

CAREY, F. A.; SUNDBERG, R. J.; Advanced Organic Chemistry - Part A: Structure and Mechanisms, $5^{\text {th }}$ ed., Springer, 2007. 
CHENG, S. H., GREGORY, R. J., MARSHALL, J., et al. "Defective Intracellular Transport and Processing of CFTR Is the Molecular Basis of Most Cystic Fibrosis", Cell, v. 63, p. 827-834, 1990.

CHENG, L., QIAN, L., TAN, Y., et al. "Expressão não equilibrada do receptor de hidrocarboneto arílico nos linfócitos T CCR6+ CD4+ e CD4+ CD25+ do sangue periférico na artrite reumatoide", Revista Brasileira de Reumatologia, v. 57, n. 3, p. 190-196, 2017. DOI: 10.1016/j.rbr.2016.04.003. Disponível em: http://dx.doi.org/10.1016/j.rbr.2016.04.003.

CUNHA, S. do D., MOMESSO, M. A. "Estudo químico quântico da reatividade de aridinona e diaziridona através de cálculos semi-empíricos", Química Nova, v. 22, n. 1, p. 22-25, 1999.

CLAYDEN, Jonathan; GREEVES, Nick; WARREN Stuart. Química Orgânica, $2^{a}$ edição. Oxford, 2012.

DAINA, A., MICHIELIN, O., ZOETE, V. "SwissADME: A free web tool to evaluate pharmacokinetics, drug-likeness and medicinal chemistry friendliness of small molecules", Scientific Reports, v. 7, n. October 2016, p. 1-13, 2017.

DECHECCHI, M. C., TAMANINI, A., CABRINI, G. "Molecular basis of cystic fibrosis: from bench to bedside", Annals of Translational Medicine, v. 6, n. 17, p. 334-334, 2018.

DOIRON, J. E., LE, C. A., ODY, B. K., et al. "Evaluation of 1,2,3-Triazoles as Amide Bioisosteres In Cystic Fibrosis Transmembrane Conductance Regulator Modulators VX-770 and VX-809", Chemistry - A European Journal, , v. 25, n. 14, p. 3662-3674, 2019

DONALDSON, S. H., M.PILEWSKI, J., GRIESE, M., et al. "Tezacaftor / Ivacaftor in Subjects with Cystic Fibrosis and", American Journal of Respiratory and Critical Care Medicine, v. 197, n. 2, p. 214-224, 2018.

DONALDSON, S. H., SOLOMON, G. M., ZEITLIN, P. L., et al. "Pharmacokinetics and safety of cavosonstat ( N91115) in healthy and cystic fi brosis adults homozygous for F 508 DEL - CFTR ", Journal of Cystic Fibrosis, v. 16, n. 3, p. 371-379, 2017.

DÖRING, G., FLUME, P., HEIJERMAN, H., et al. "Treatment of lung infection in patients with cystic fibrosis: Current and future strategies, Journal of Cystic Fibrosis, v. 11, n. 6, p. 461-479, 2012.

ESS, D. H., HOUK, K. N. "Theory of 1,3-dipolar cycloadditions: Distortion/interaction and frontier molecular orbital models", Journal of the American Chemical Society, v. 130, n. 31, p. 10187-10198, 2008.

FAJAC, I., WAINWRIGHT, C. E. "New treatments targeting the basic defects in cystic fibrosis", La Presse Medicale, v. 46, p. e165-e175, 2017. 
FIRMIDA, M. D. C. "Fisiopatologia e Manifestações Clínicas da Fibrose Cística", Revista Hospital Universitário Pedro Ernesto, v. 10, n. 4, 2011.

GIULIANO, K. A., WACHI, S., DREW, L., et al. "Use of a High-Throughput Phenotypic Screening Strategy to Identify Amplifiers, a Novel Pharmacological Class of Small Molecules That Exhibit Functional Synergy with Potentiators and Correctors", SLAS Discovery, v. 23, p. 111-121, 2018.

HAARDT, M., BENHAROUGA, M., LECHARDEUR, D., et al. "C-terminal Truncations Destabilize the Cystic Fibrosis Transmembrane Conductance Regulator without Impairing Its", The Journal of Biological Chemistry, v. 274, n. 31, p. 21873-21877, 1999.

HEBERLE, G., F. DE AZEVEDO, W. "Bio-Inspired Algorithms Applied to Molecular Docking Simulations", Current Medicinal Chemistry, v. 18, n. 9, p. 1339-1352, 2011.

ISYAKU, Y., UZAIRU, A., UBA, S. "Computational studies of a series of 2substituted phenyl-2-oxo-, 2-hydroxyl- and 2-acylloxyethylsulfonamides as potent anti-fungal agents", Heliyon, v. 6, n. 4, p. e03724, 2020.

KOCK, C., HOIBY, N. "Diagnosis and treatment of infectious exacerbation of cystic fibrosis", Respiration, v. 36, n. 9, p. 525-532, 2000.

KUMAR, D., KOMMI, D. N., CHOPRA, P., et al. "Activation of Methyl Ketones or Active Methylene Compounds and DMF-DMA for Syntheses of (2E) -3Dimethylamino-2- propen-1-ones L-Proline-Catalyzed", European Journal of Organic Chemistry, p. 6407-6413, 2012.

KUMAR, R., VATS, L., BUA, S., et al. "Design and synthesis of novel benzenesulfonamide containing 1,2,3-triazoles as potent human carbonic anhydrase isoforms I, II, IV and IX inhibitors", European Journal of Medicinal Chemistry, v. 155 , p. $545-551,2018$.

LIU, F., ZHANG, Z., LEVIT, A., et al. "Structural identification of a hotspot on CFTR for potentiation", Science, v. 364, n. 6446, p. 1184-1188, 2019.

FARIAS, L.C.F. Síntese e relação entre a estrutura e atividade de derivados de triazóis para o tratamento da Fibrose Cística. Dissertação (Mestrado em Química) - Faculdade de Química - Pontifícia Universidade Católica. Rio de Janeiro, p. 90. 2019.

LOPES-PACHECO, M. "CFTR Modulators: The Changing Face of Cystic Fibrosis in the Era of Precision Medicine", Frontiers in Pharmacology, v. 10, n. February, p. 1-29, 2020.

MELO, J. O. F., DONNICI, C. L., AUGUSTI, R., et al. "Heterociclos 1,2,3triazólicos: Histórico, métodos de preparação, aplicações e atividades farmacológicas", Quimica Nova, , v. 29, n. 3, p. 569-579, 2006. 
MIGNANI, S., RODRIGUES, J., TOMAS, H., et al. "Present drug-likeness filters in medicinal chemistry during the hit and lead optimization process: how far can they be simplified?", Drug Discovery Today, v. 23, n. 3, p. 605-615, 2018.

RANG, C., KEATING, D., WILSON, J., et al. "Re-Imagining Cystic Fibrosis Care: Next Generation Thinking", European Respiratory Journal, p. 1-42, 2020.

RASKIN, S., PHILLIPS, J. A. "DNA Analysis of Cystic Fibrosis in Brazil by Direct PCR Amplification From Guthrie Cards", American Journal of Medical Genetics, v. 46, p. 665-669, 1993.

REIS, F. J. C. DAMACENO, N. "Fibrose Cística". Jornal de Pediatria, 1998. , v. 74, n. 6, p. 76-94.

RIBEIRO, J. D., RIBEIRO, M. Â. G. d. O., RIBEIRO, A. F. Controvérsias na fibrose cística - Do pediatra ao especialista, Jornal de Pediatria, v. 78, n. SUPPL. 2, p. 171-186, 2002.

ROSA, F. R., DIAS, F. G., NOBRE, L. N., et al. "Fibrose cística: Uma abordagem clínica e nutricional", Revista de Nutrição, v. 21, n. 6, p. 725-737, 2008.

RUSECKAITE R AS, RANGER T, TACEY M, DEAN J, GARDAM M, BELL S, B. N. "Cystic Fibrosis Data Registry", Australian Cystic Fibrosis Data Registry, p. 1-45, 2017.

SCHMIDT, B. Z., HAAF, J. B., LEAL, T., et al. "Cystic fibrosis transmembrane conductance regulator modulators in cystic fibrosis: Current perspectives", Clinical Pharmacology: Advances and Applications, v. 8, p. 127-140, 2016.

SKILTON, M., KRISHAN, A., PATEL, S., et al. "Potentiators (specific therapies for class III and IV mutations) for cystic fibrosis", Cochrane Database of Systematic Reviews, v. 2019, n. 1, 2019.

SLOANE, P. A., ROWE, S. M. "Cystic fibrosis transmembrane conductance regulator protein repair as a therapeutic strategy in cystic fibrosis Peter", Current Opinion on Pulmonary Medicine, v. 16, n. 6, p. 591-597, 2010.

SOUZA, R. O. M. A. de, MIRANDA, L. S. de M. e. "Strategies Towards the Synthesis of $\mathrm{N}^{2}$-Substituted 1 , 2 , 3-Triazoles", Academia Brasileira de Ciências, v. 91, p. 1-24, 2019.

THOMAS, J., GOYVAERTS, V., LIEKENS, S., et al. "Metal-Free Route for the Synthesis of 4-Acyl-1,2,3-Triazoles from Readily Available Building Blocks", Chemistry European Journal, v. 22, p. 9966-9970, 2016.

THOMSEN, R., CHRISTENSEN, M. H. "MolDock: A new technique for highaccuracy molecular docking", Journal of Medicinal Chemistry, v. 49, n. 11, p. 3315-3321, 2006. 
VAN GOOL, K., NORMAN, R., DELATYCKI, M. B., et al. "Understanding the costs of care for cystic fibrosis: An analysis by age and health state", Value in Health, v. 16, n. 2, p. 345-355, 2013.

VEDANI, A., DOBLER, M., HU, Z., et al. "OpenVirtualToxLab - A platform for generating and exchanging in silico toxicity data", Toxicology Letters, v. 232, p. 519-532, 2015.

VERLI, H., BARREIRO, E. J. "Um Paradigma da Química Medicinal: A flexibilidade dos ligantes e receptores", Quimica Nova, v. 28, n. 1, p. 95-102, 2005.

WAN, J. P., CAO, S., LIU, Y. "Base-Promoted Synthesis of N-Substituted 1,2,3Triazoles via Enaminone-Azide Cycloaddition Involving Regitz Diazo Transfer", Organic Letters, v. 18, n. 23, p. 6034-6037, 2016.

XU, S., ZHUANG, X., PAN, X., et al. "1-Phenyl-4-benzoyl-1H-1,2,3-triazoles as Orally Bioavailable Transcriptional Function Suppressors of Estrogen-Related Receptor $\alpha$ ", Journal of Medicinal Chemistry, v. 56, p. 4631-4640, 2013.

YEH, H. I., SOHMA, Y., CONRATH, K., et al. "A common mechanism for CFTR potentiators", Journal of General Physiology, v. 149, n. 12, p. 1105-1118, 2017.

ZHAO, J. W., GUO, J. W., HUANG, M. J., et al. "Design, synthesis and biological evaluation of new steroidal $\beta$-triazoly enones as potent antiproliferative agents", Steroids, v. 150, n. May, p. 108431, 2019. DOI: 10.1016/j.steroids.2019.108431. Disponível em: https://doi.org/10.1016/j.steroids.2019.108431.

KAKUDA, S. et al. Synthesis of Pterocarpan Derivatives and their Inhibitory Effects against Microbial Growth and Biofilms. ChemistrySelect, v. 1, n. 14, p. 4203-4208, 2016. 


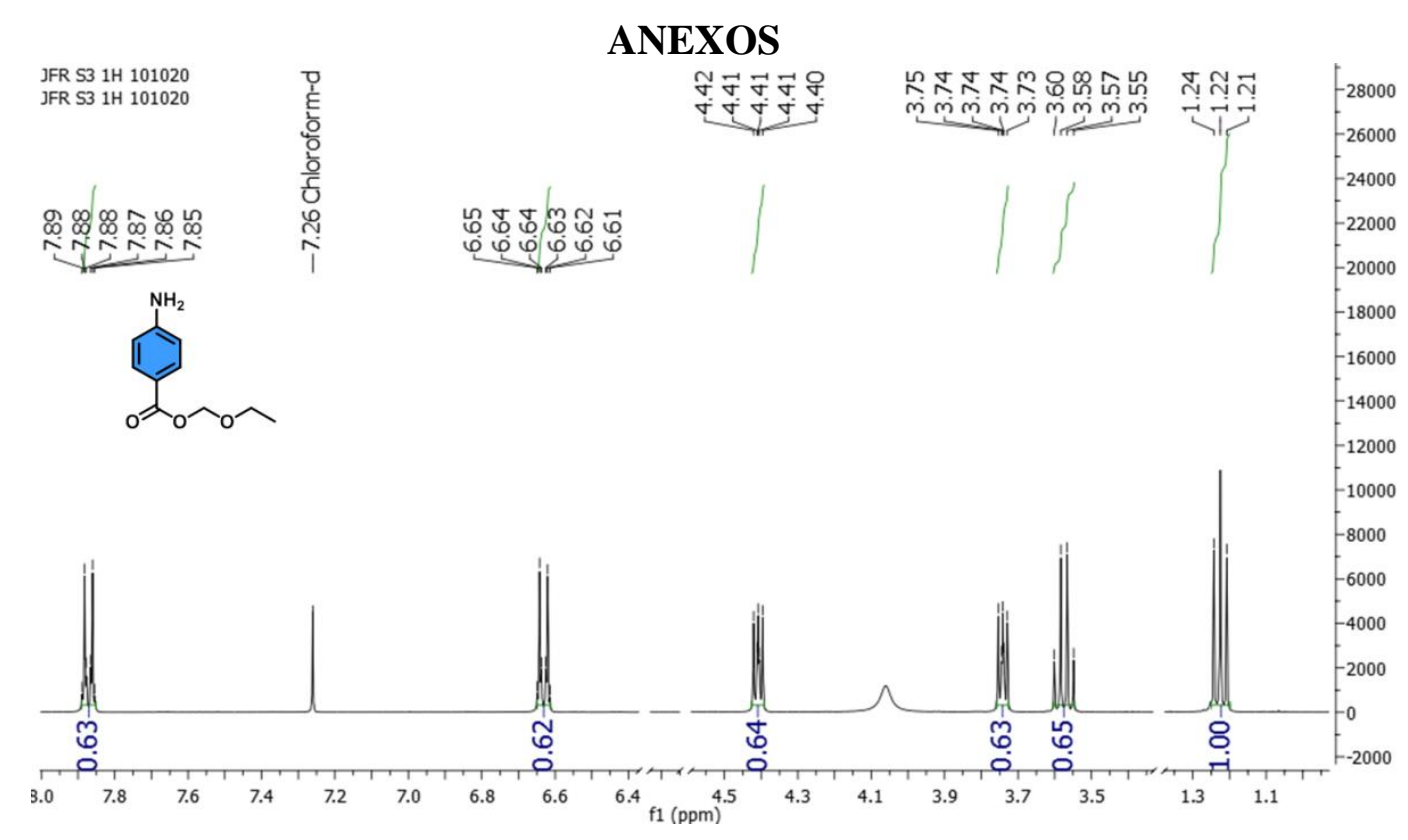

Figura 29: Espectro de RMN 1H do composto $4 \mathrm{~g}$

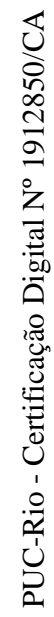

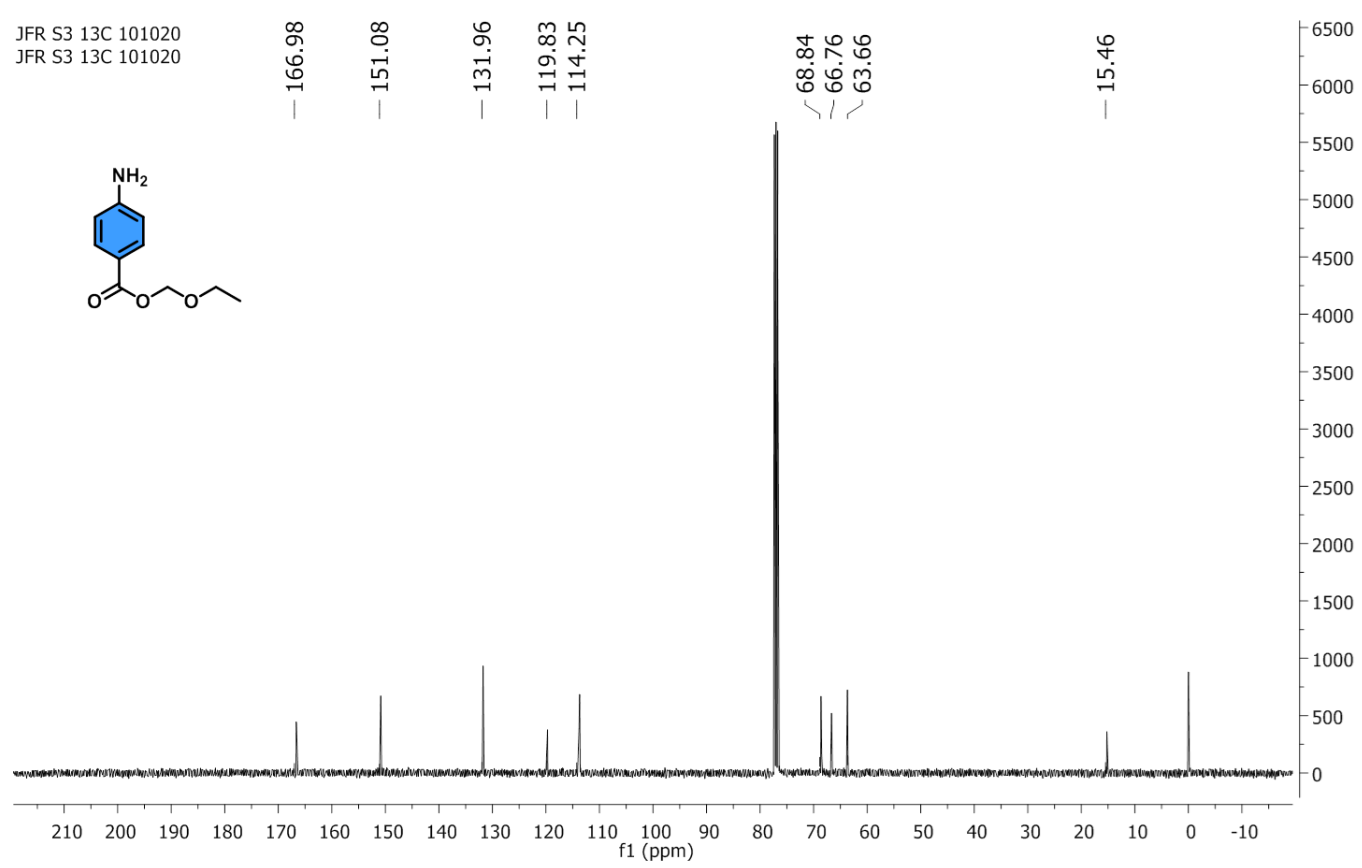

Figura 30: Espectro de RMN 13C do composto 4g 


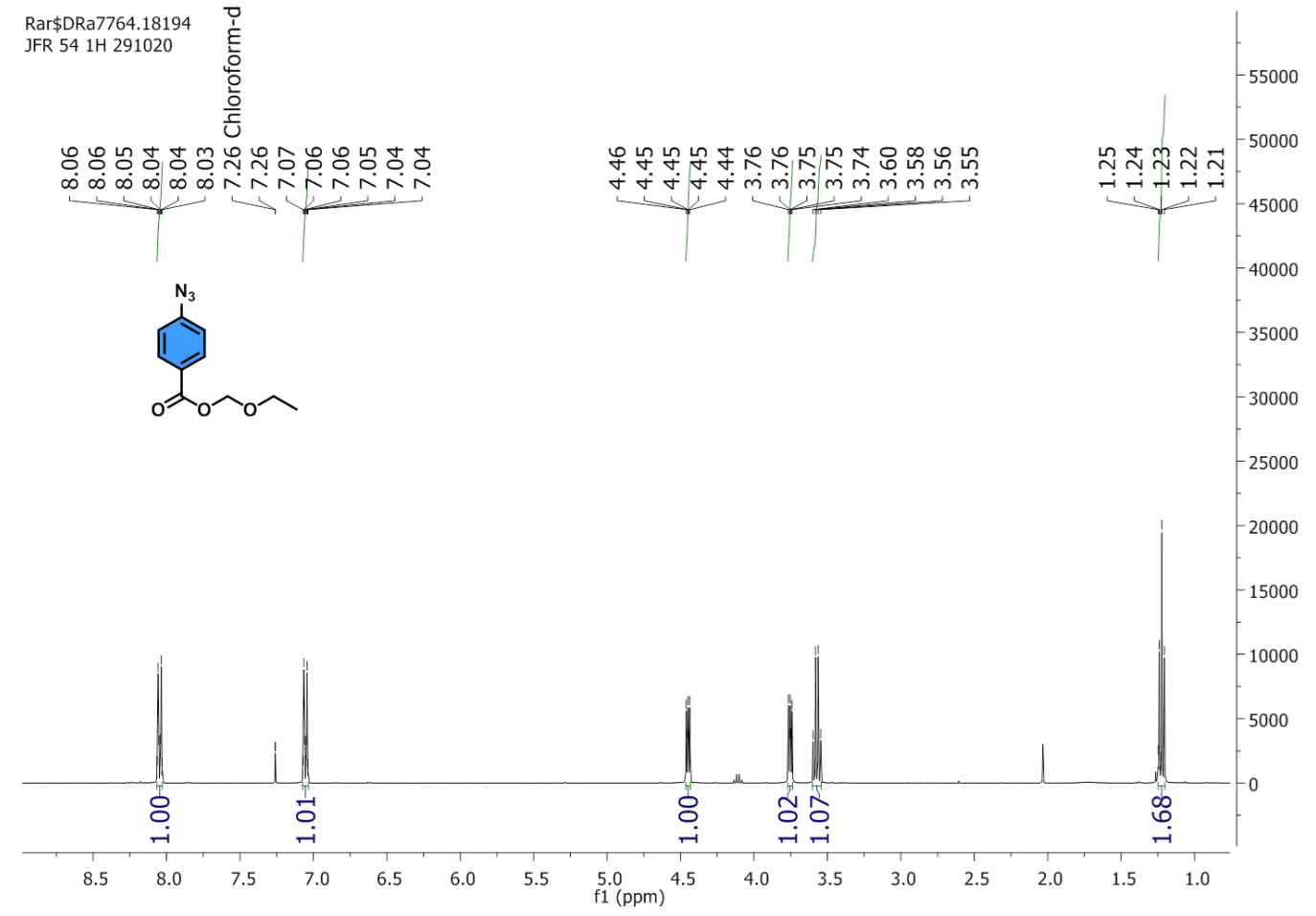

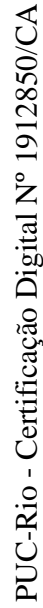

Figura 31: Espectro de RMN 1H do composto $5 \mathrm{~g}$ 


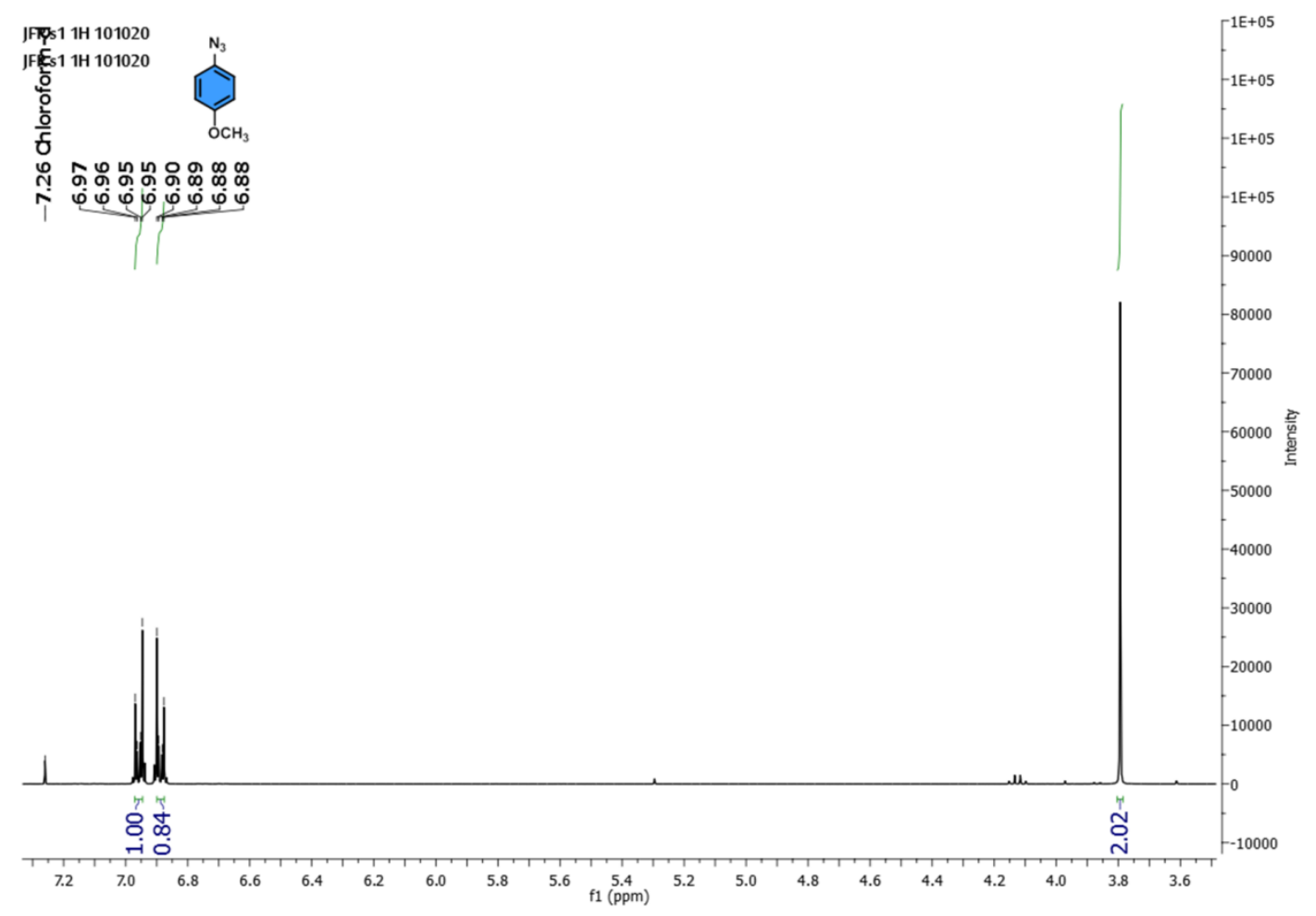

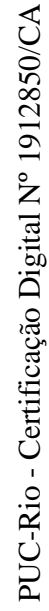

Figura 32: Espectro de RMN $1 \mathrm{H}$ do composto $\mathbf{5 h}$ 


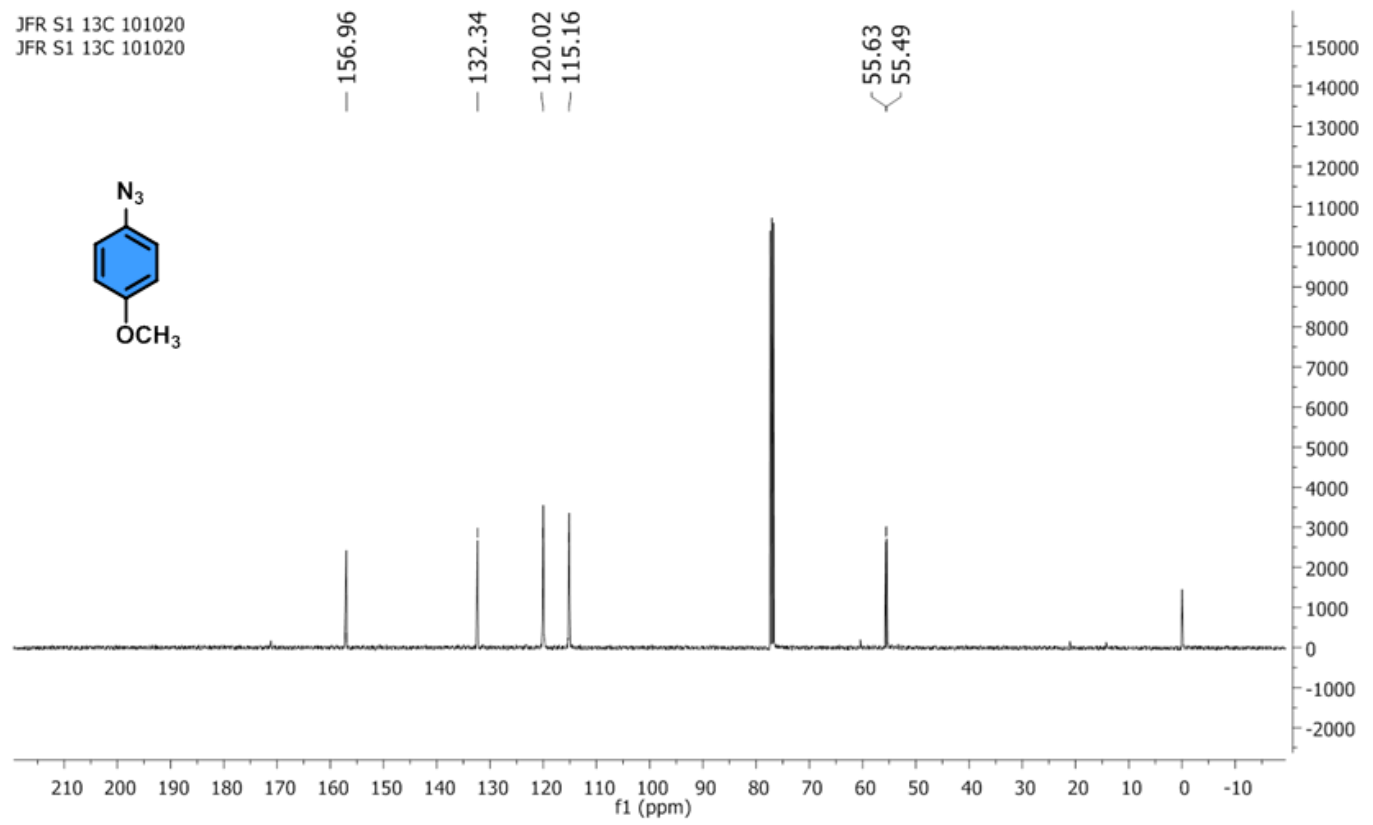

Figura 33: Espectro de RMN 13C do composto $\mathbf{5 h}$

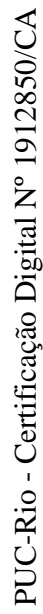

JFR S2 1H 081020

JFR S2 1H 081020

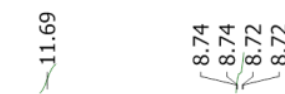

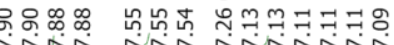
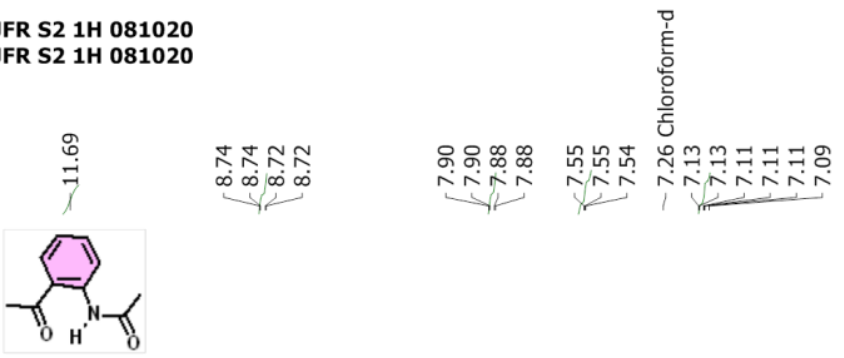


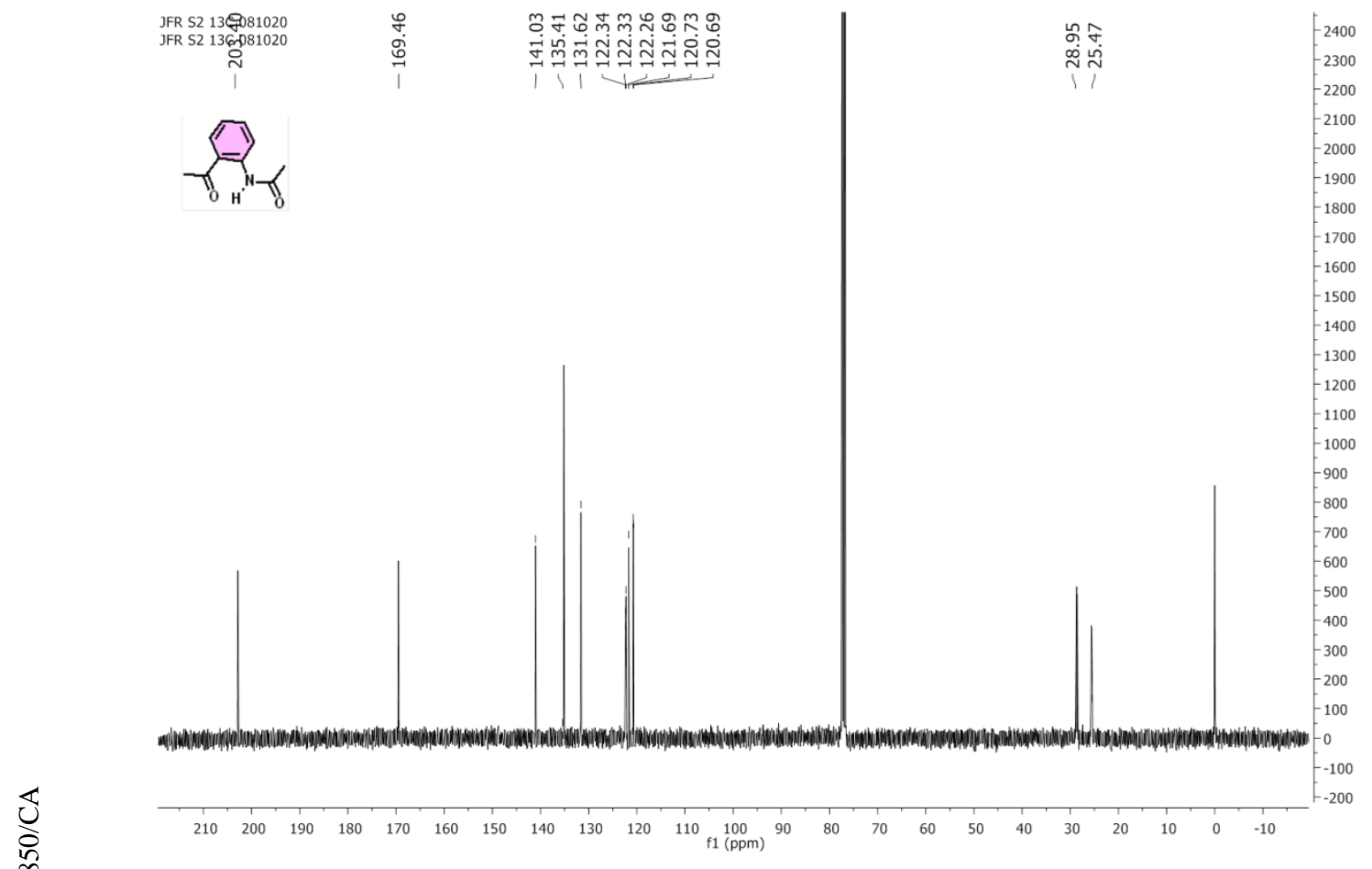

Figura 35: Espectro de RMN 13C do composto 2c 


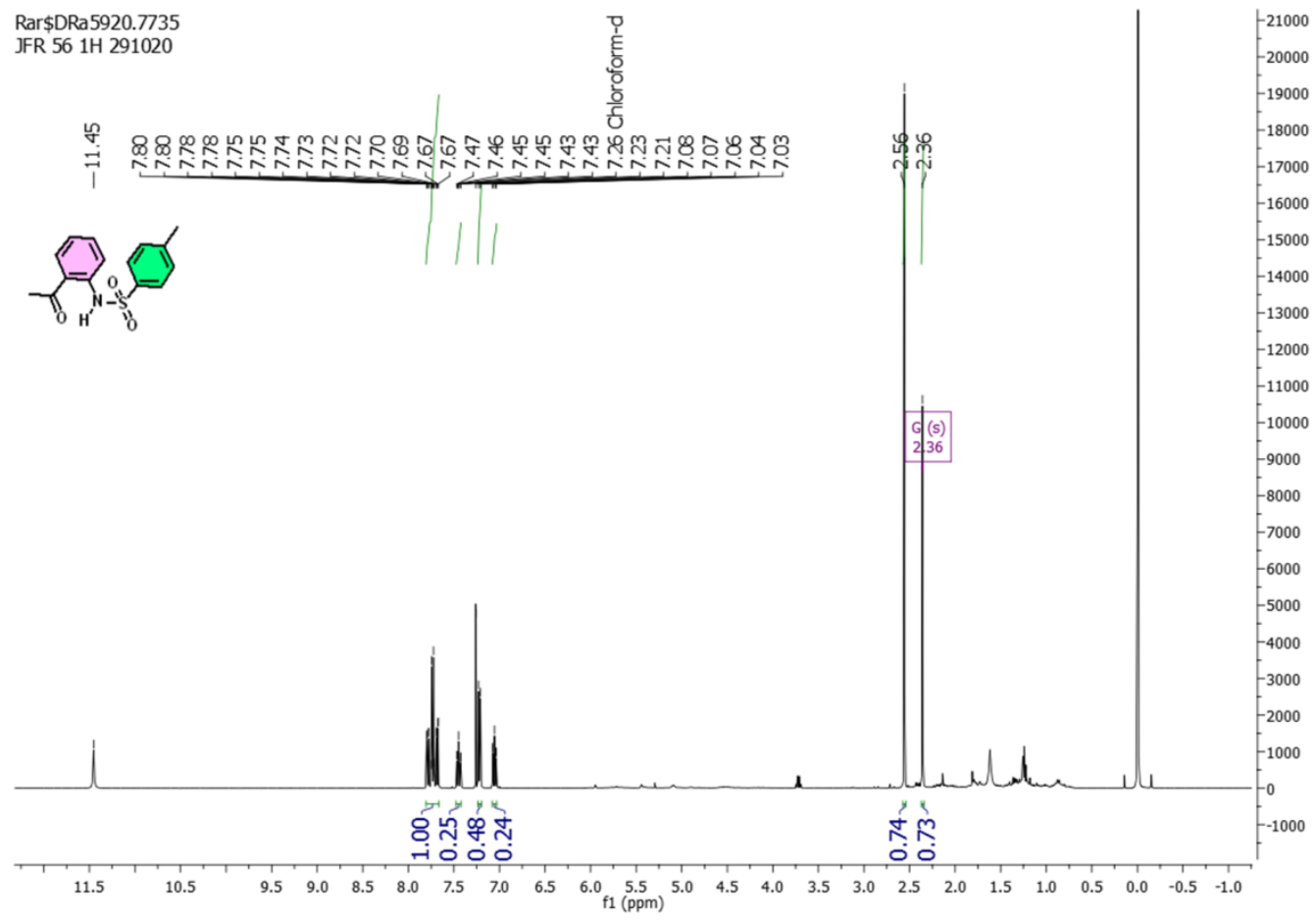

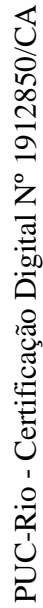

Figura 36: Espectro RMN H do composto 2d 


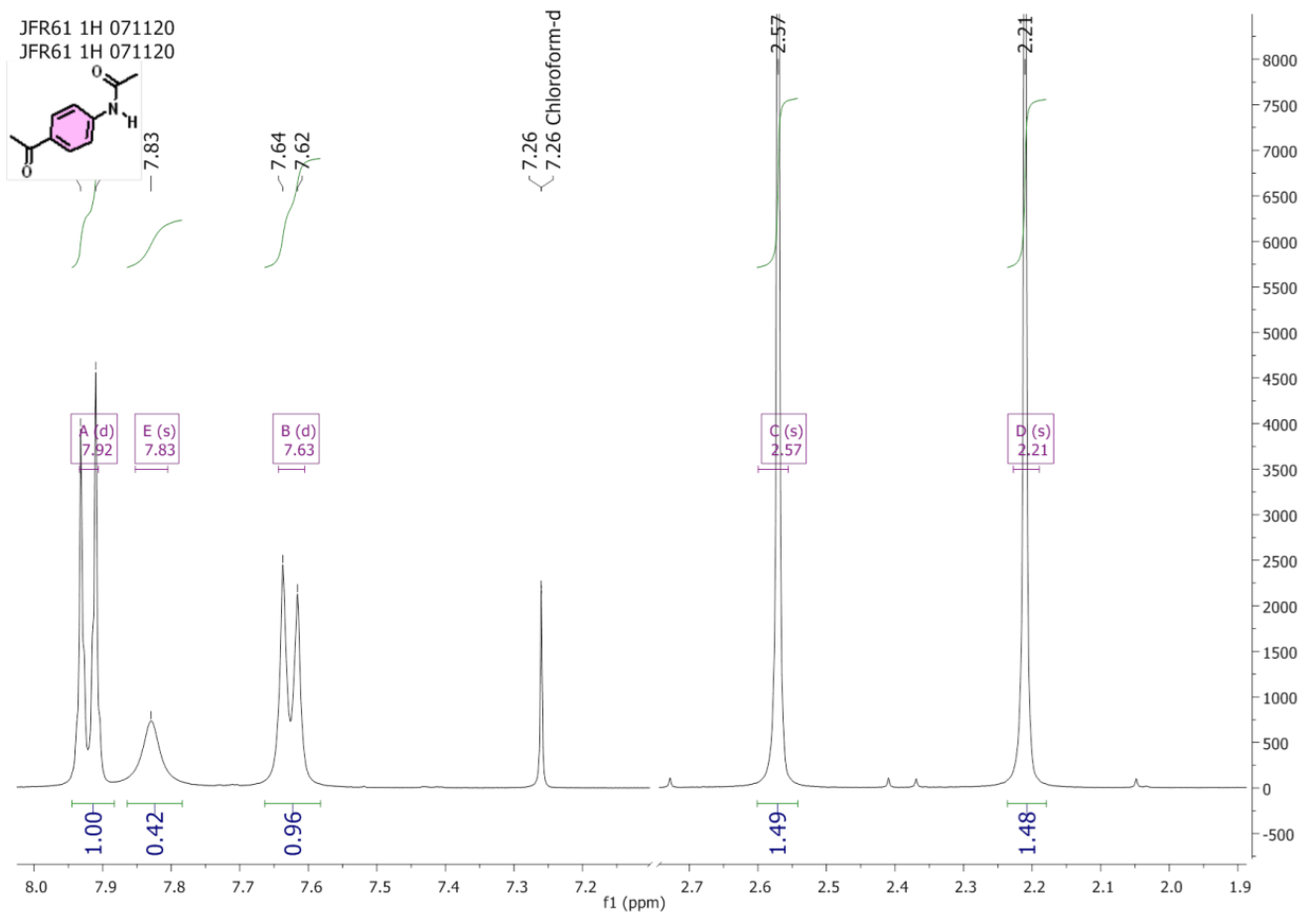

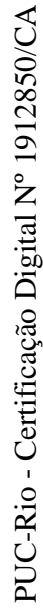

Figura 37: Espectro de RMN 1H do composto $2 \mathrm{e}$ 


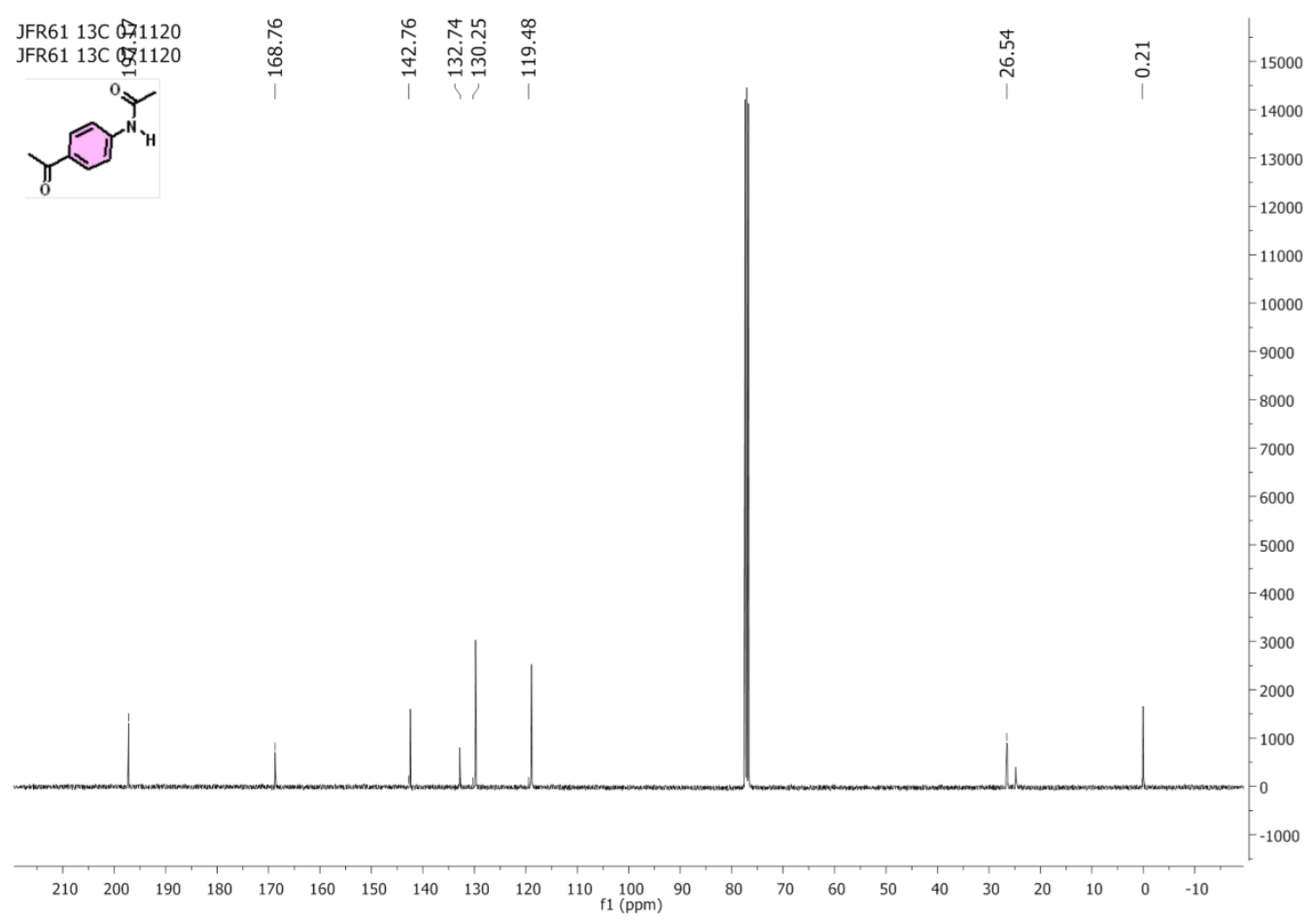

Figura 38: Espectro de RMN 13C do composto $2 e$

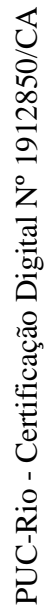

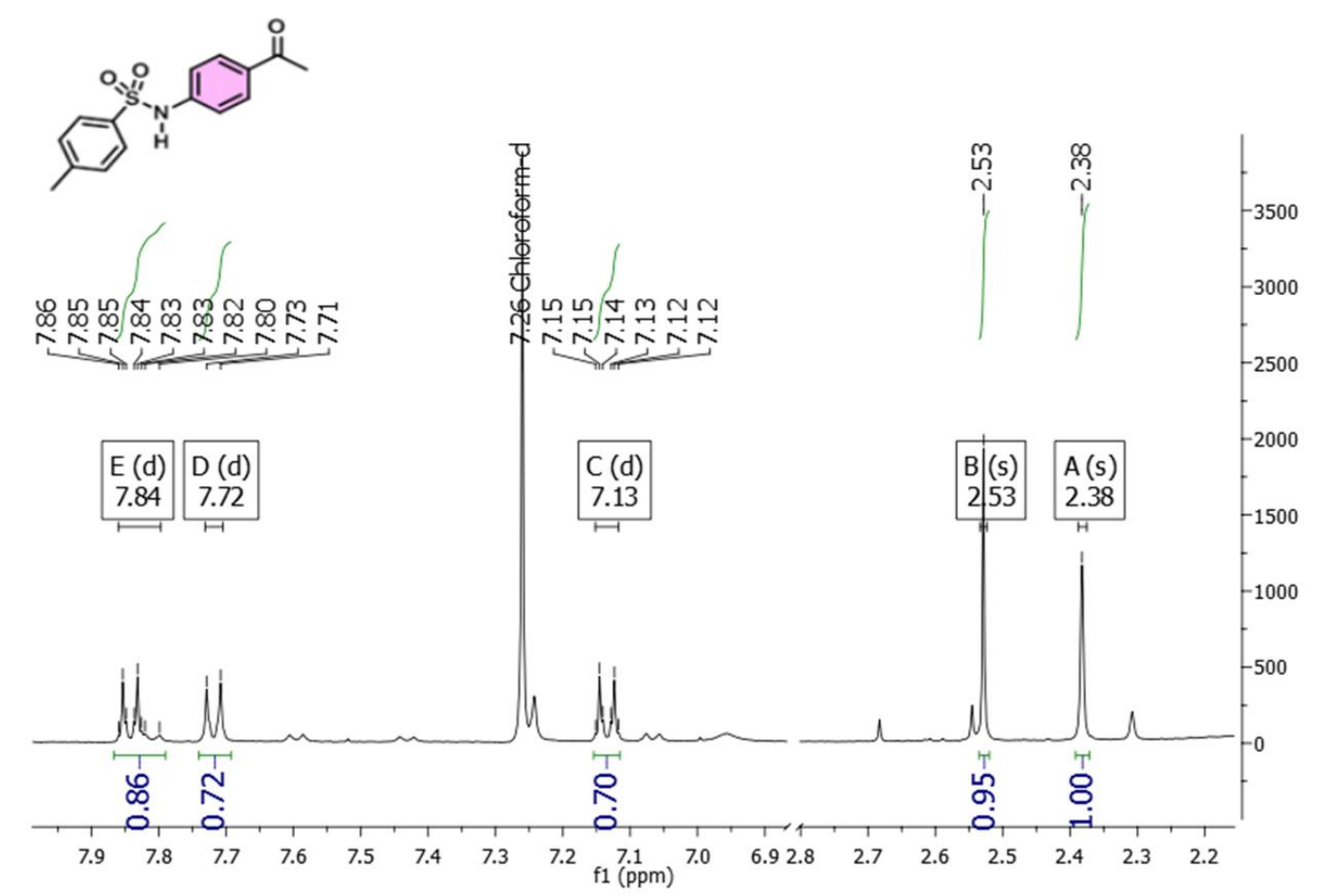

Figura 39: Espectro de RMN 1H do composto $2 f$ 


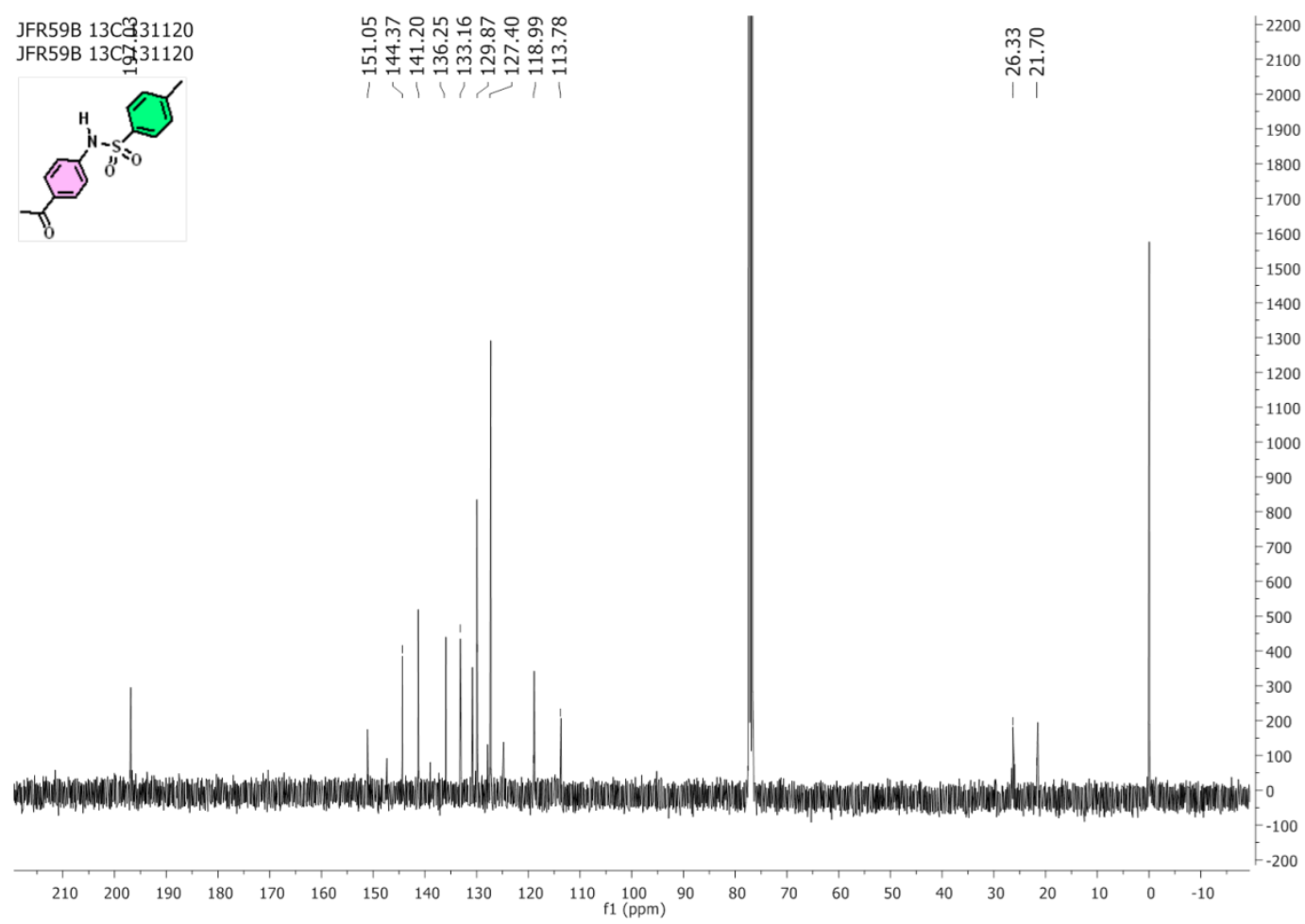

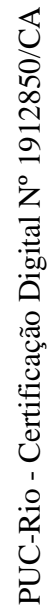

Figura 40: Espectro de RMN 13C do composto $2 \mathrm{f}$

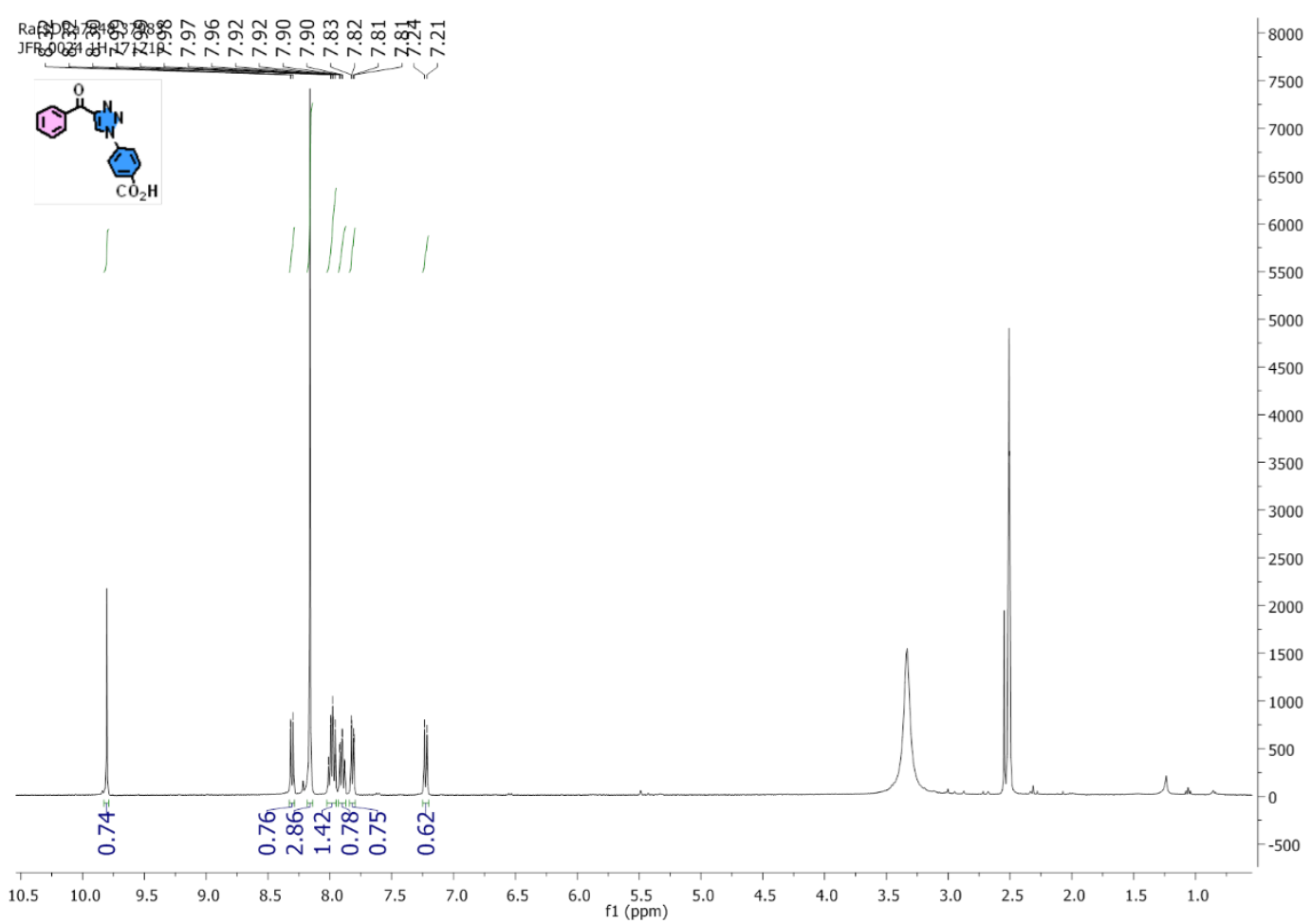

Figura 41: Espectro de RMN 1H do composto 6a 


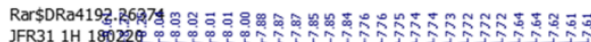

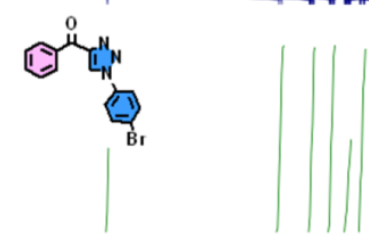

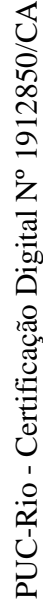

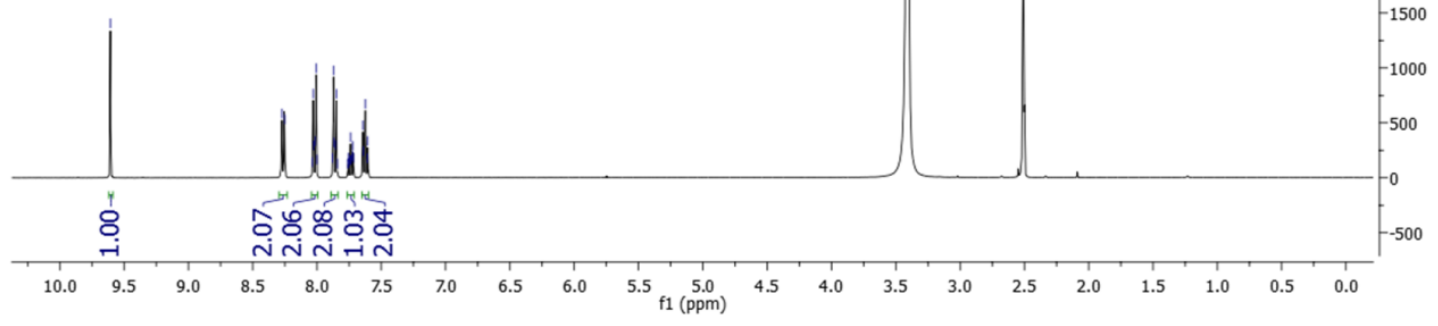

Figura 42: Espectro de RMN $1 \mathrm{H}$ do composto $6 \mathbf{b}$ 


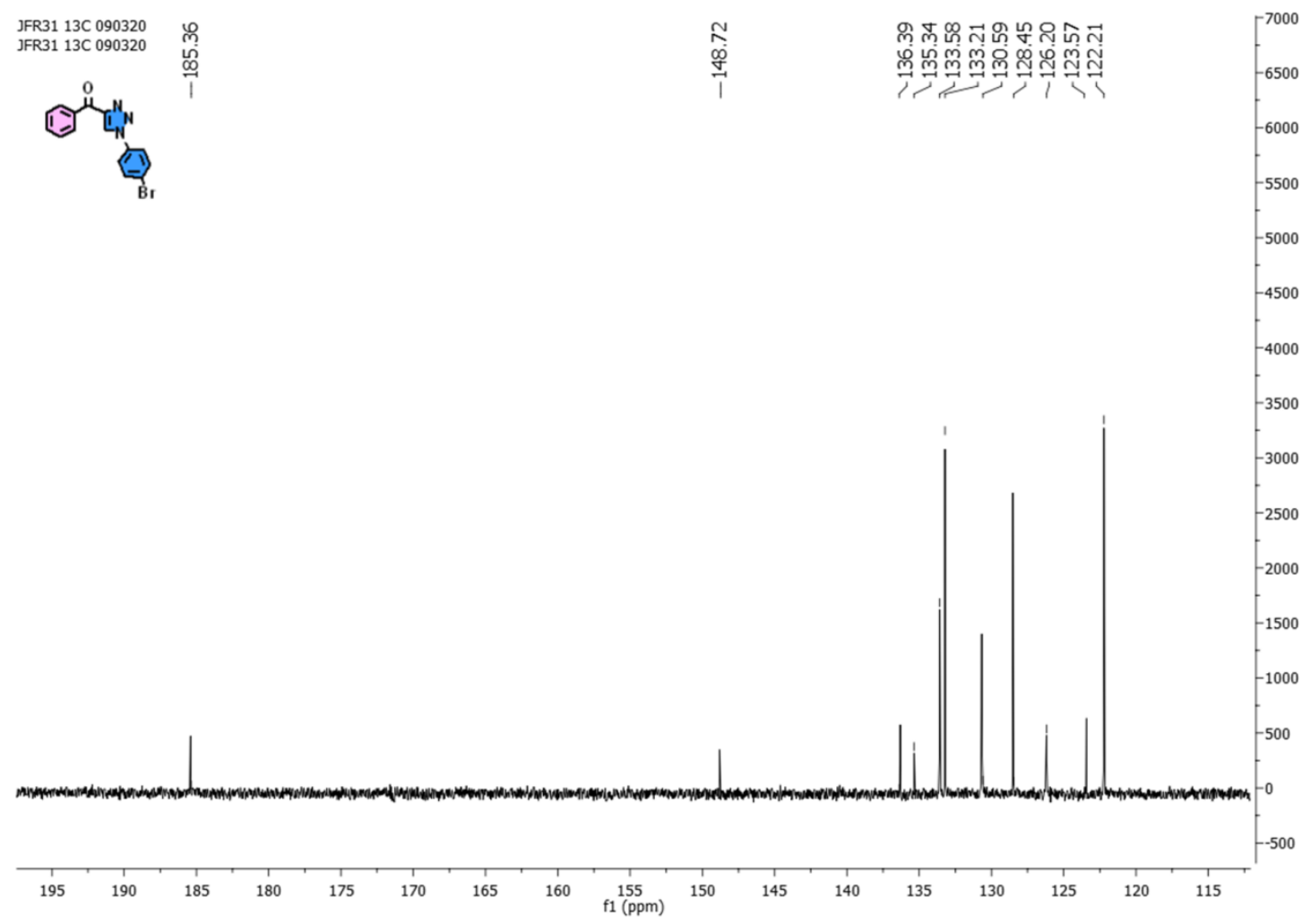

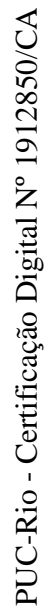

Figura 43: Espectro de RMN 13C do composto 6b

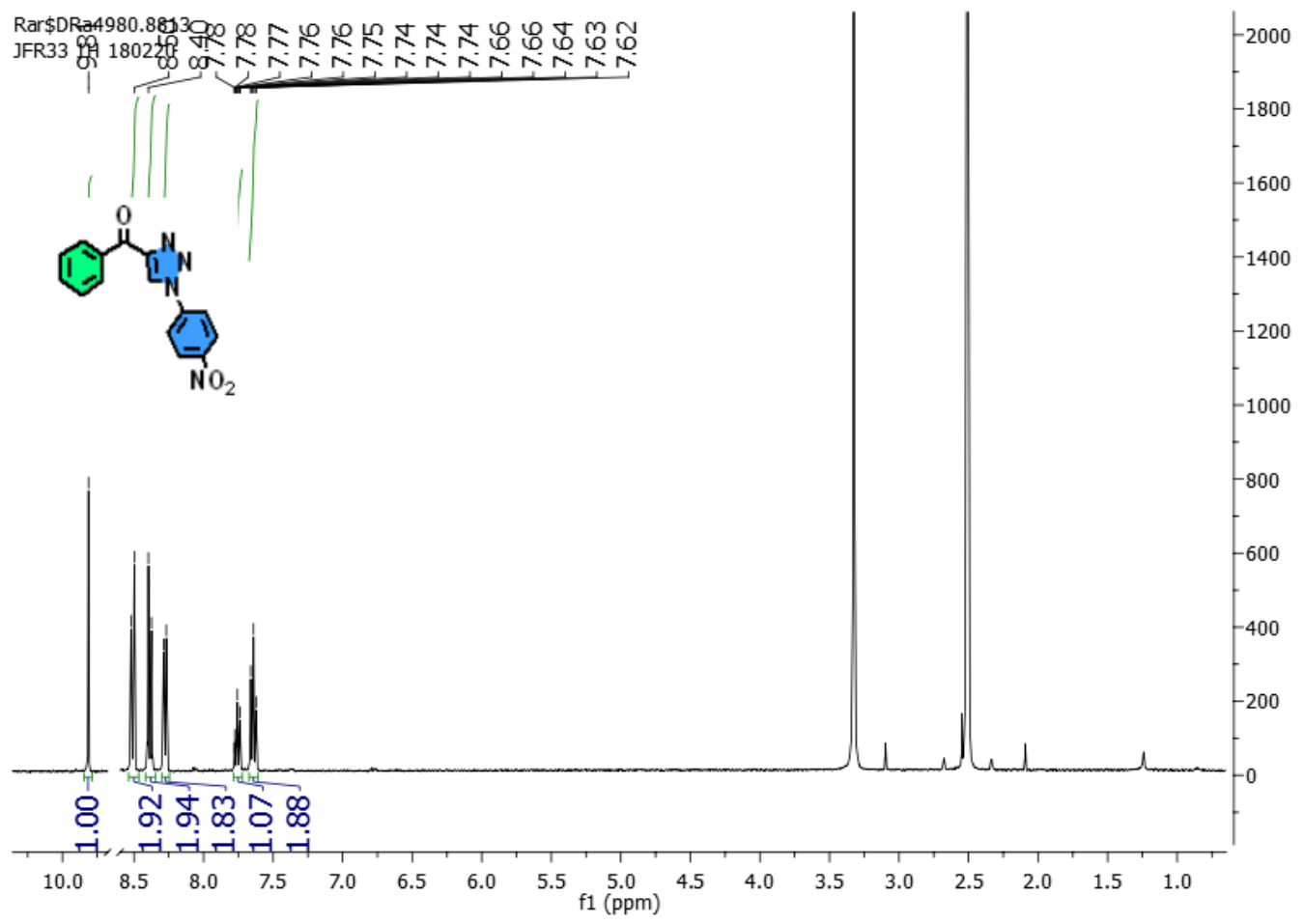

Figura 44: Espectro de RMN 1H do composto 6c 


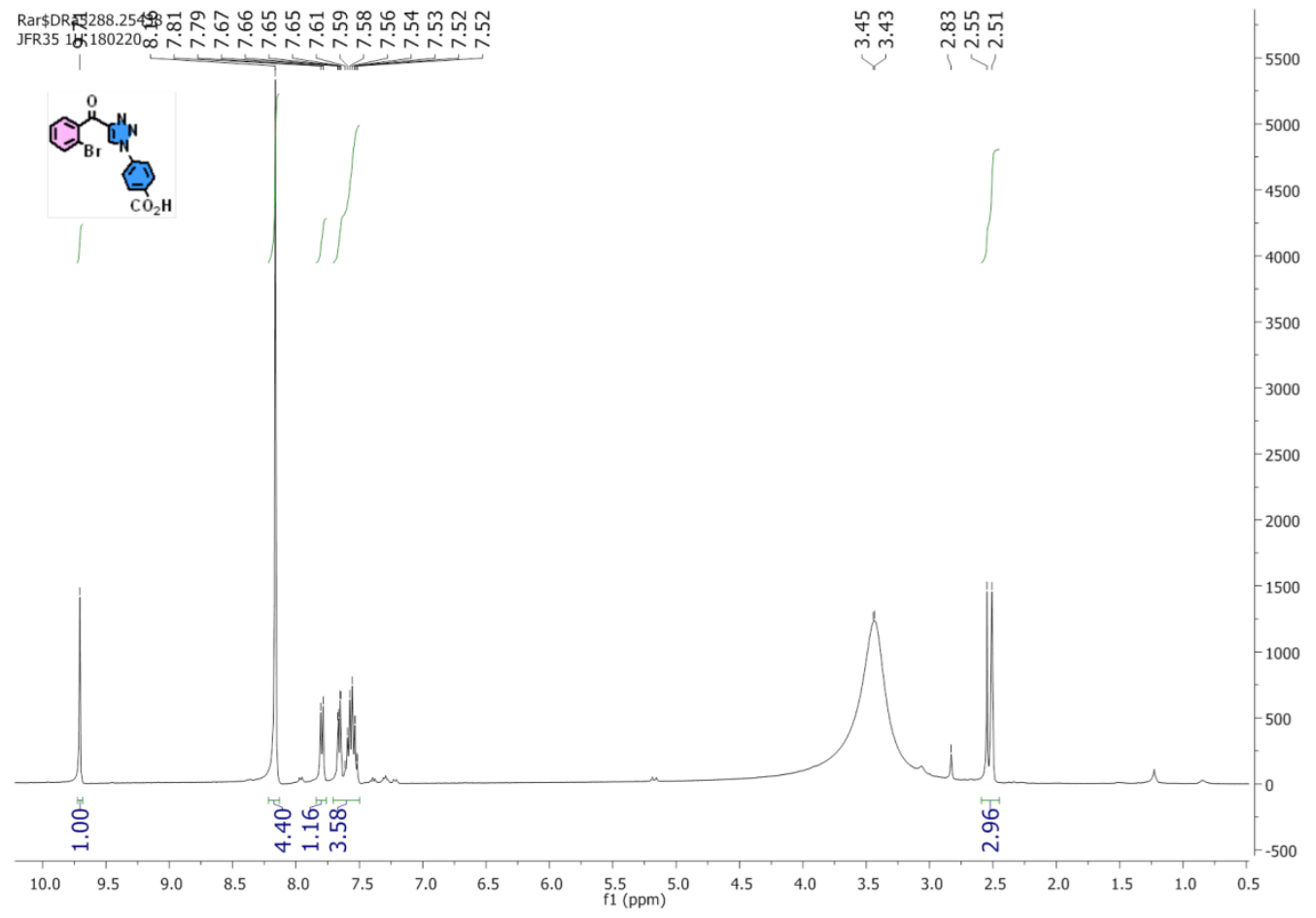

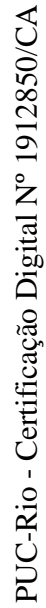

Figura 45: Espectro de RMN 1H do composto 6d 


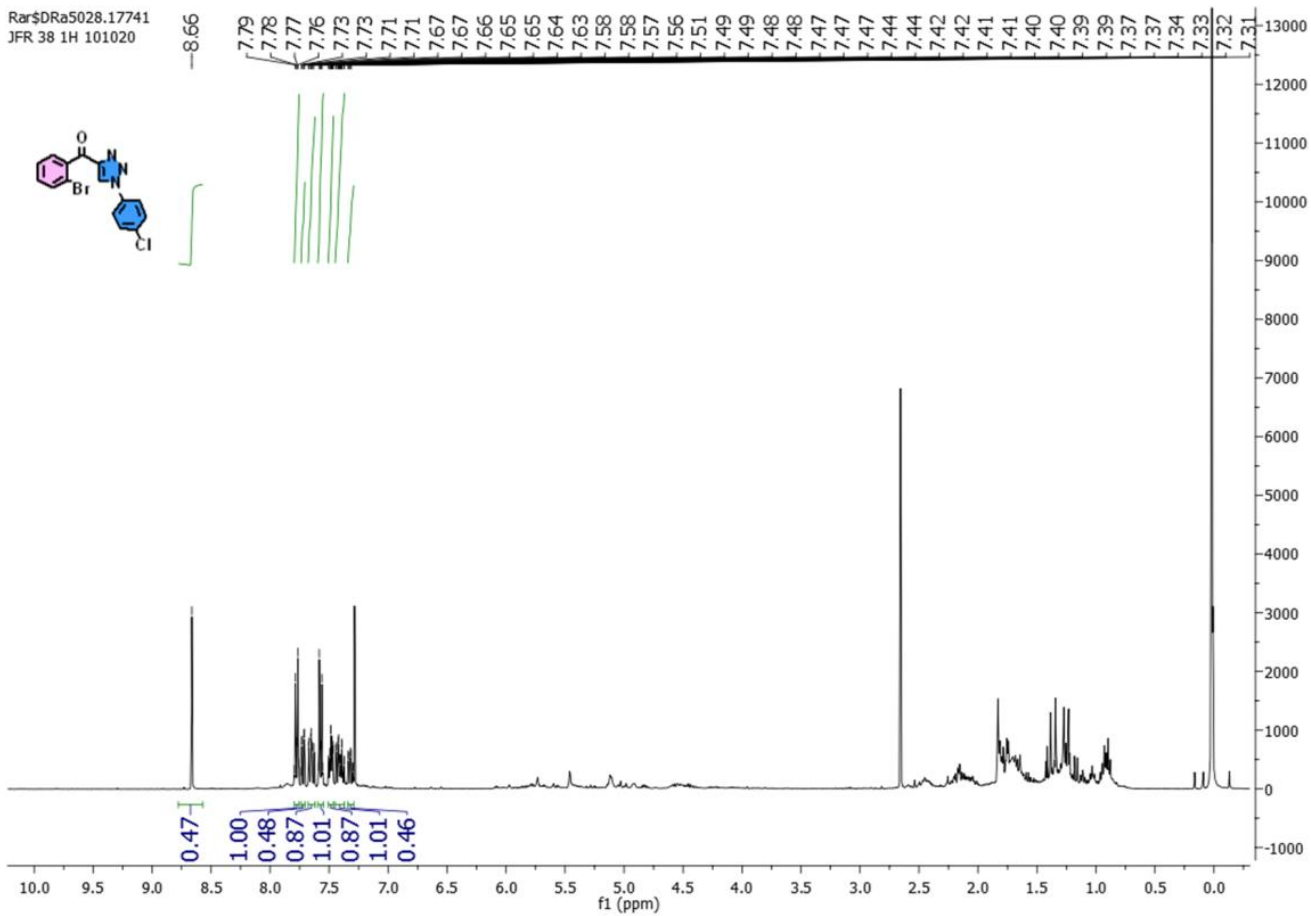

Figura 46: Espectro de RMN 1H do composto 6e

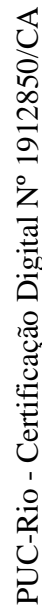

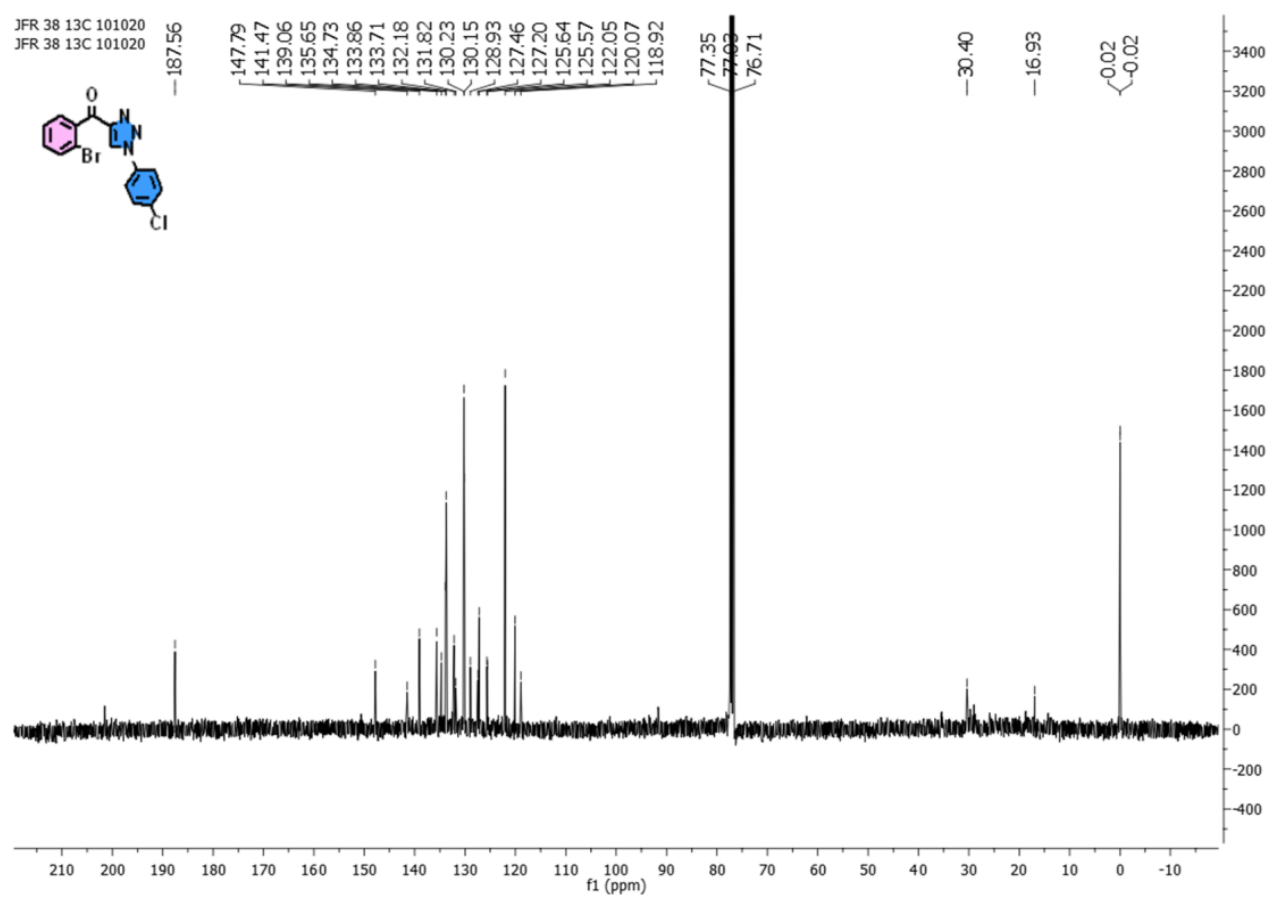

Figura 47: Espectro de RMN 13C do composto 6 e 


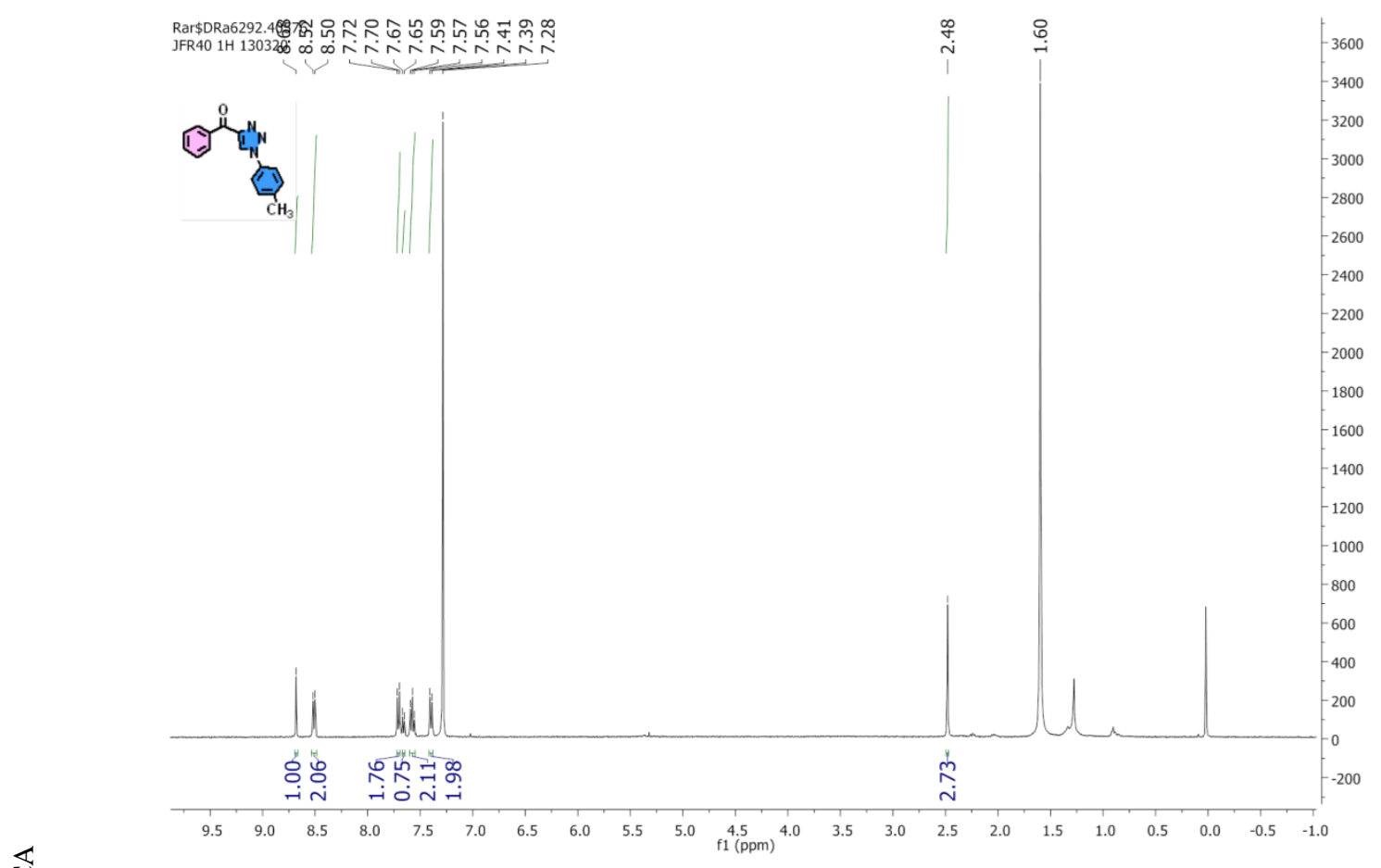

Figura 48: Espectro de RMN $1 \mathrm{H}$ do composto $6 f$
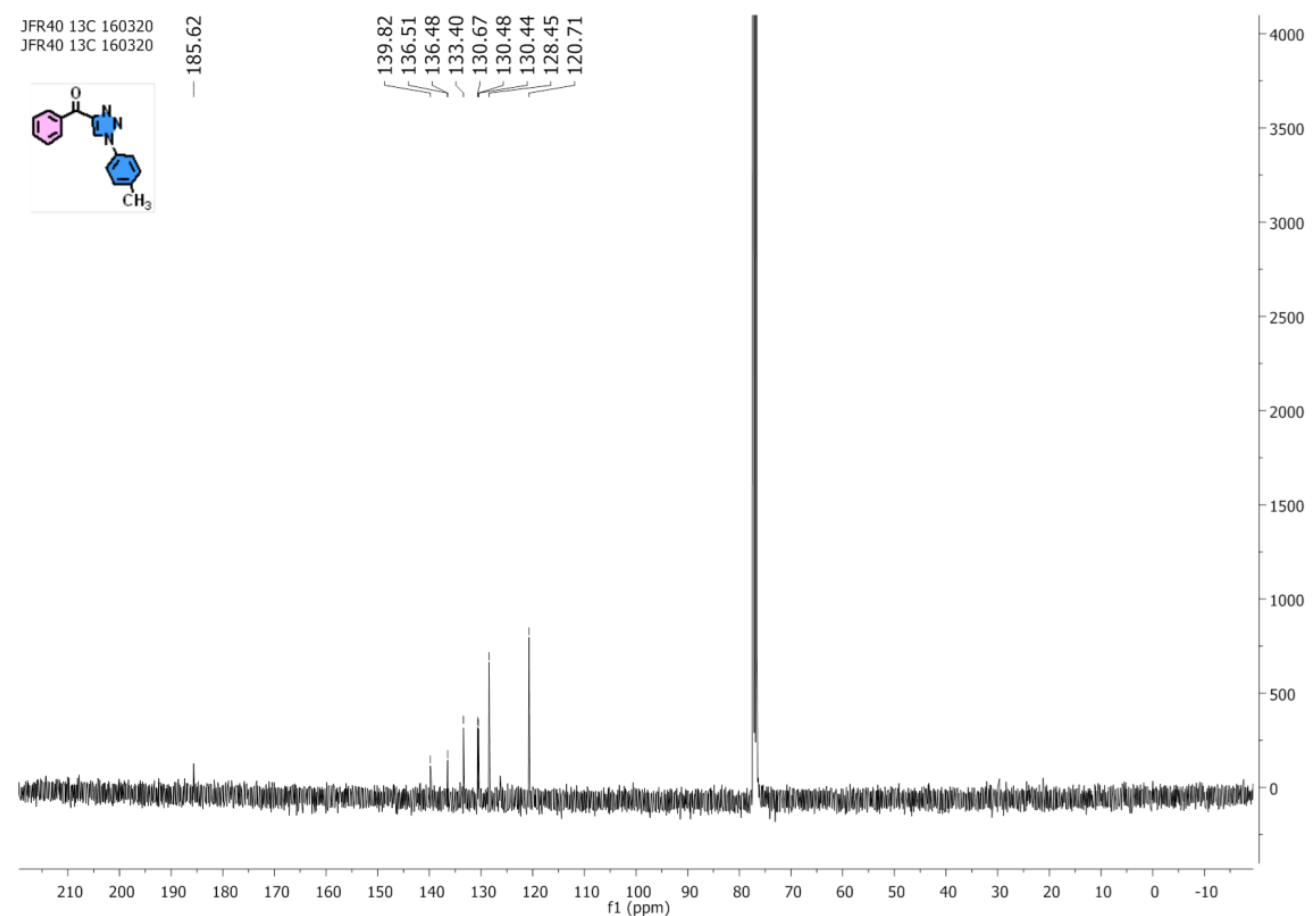

4000

300

3000

Figura 49: Espectro de RMN 13C do composto $6 \mathbf{f}$ 


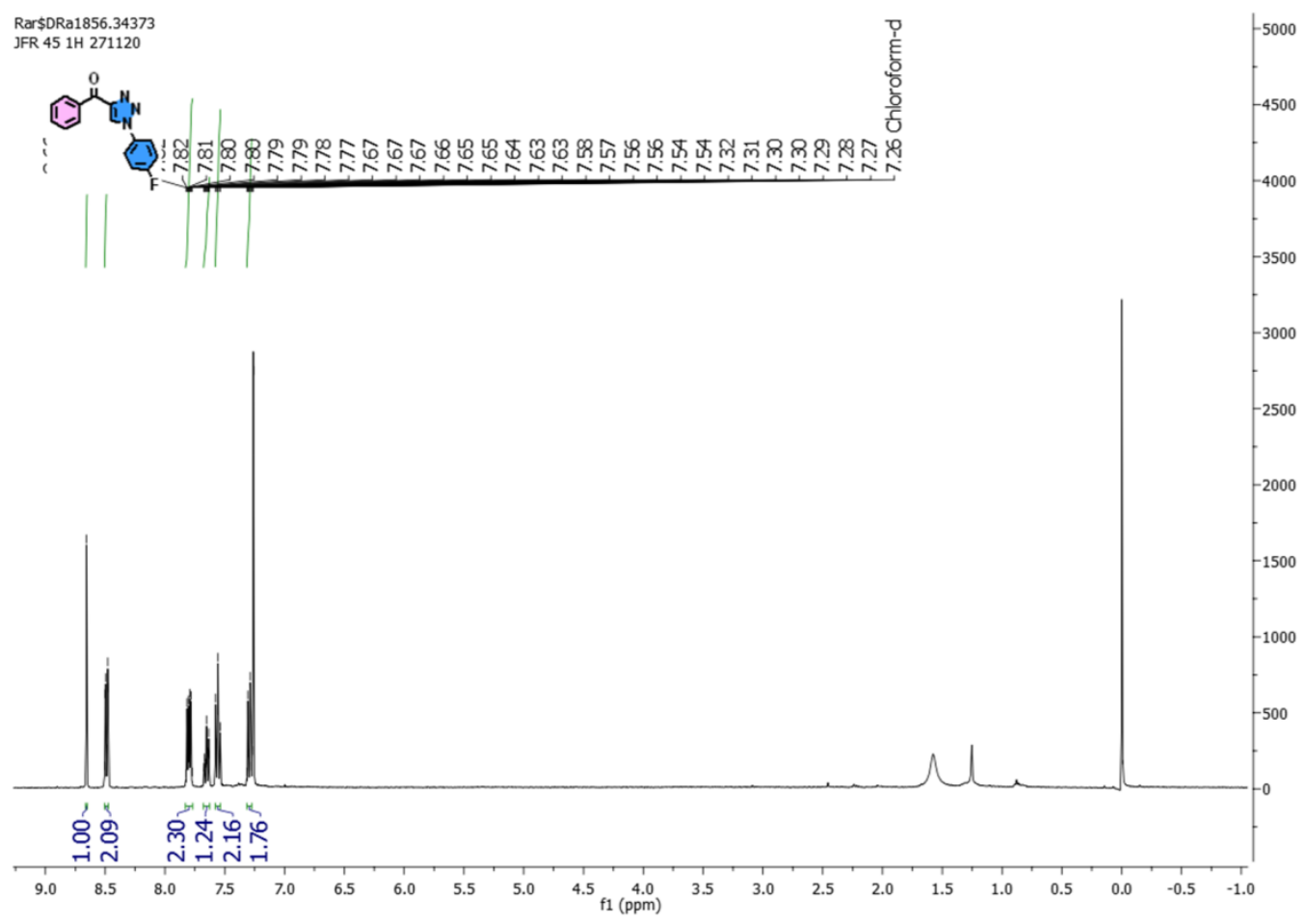

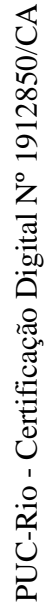

Figura 50: Espectro de RMN 1H do composto $6 \mathrm{~g}$

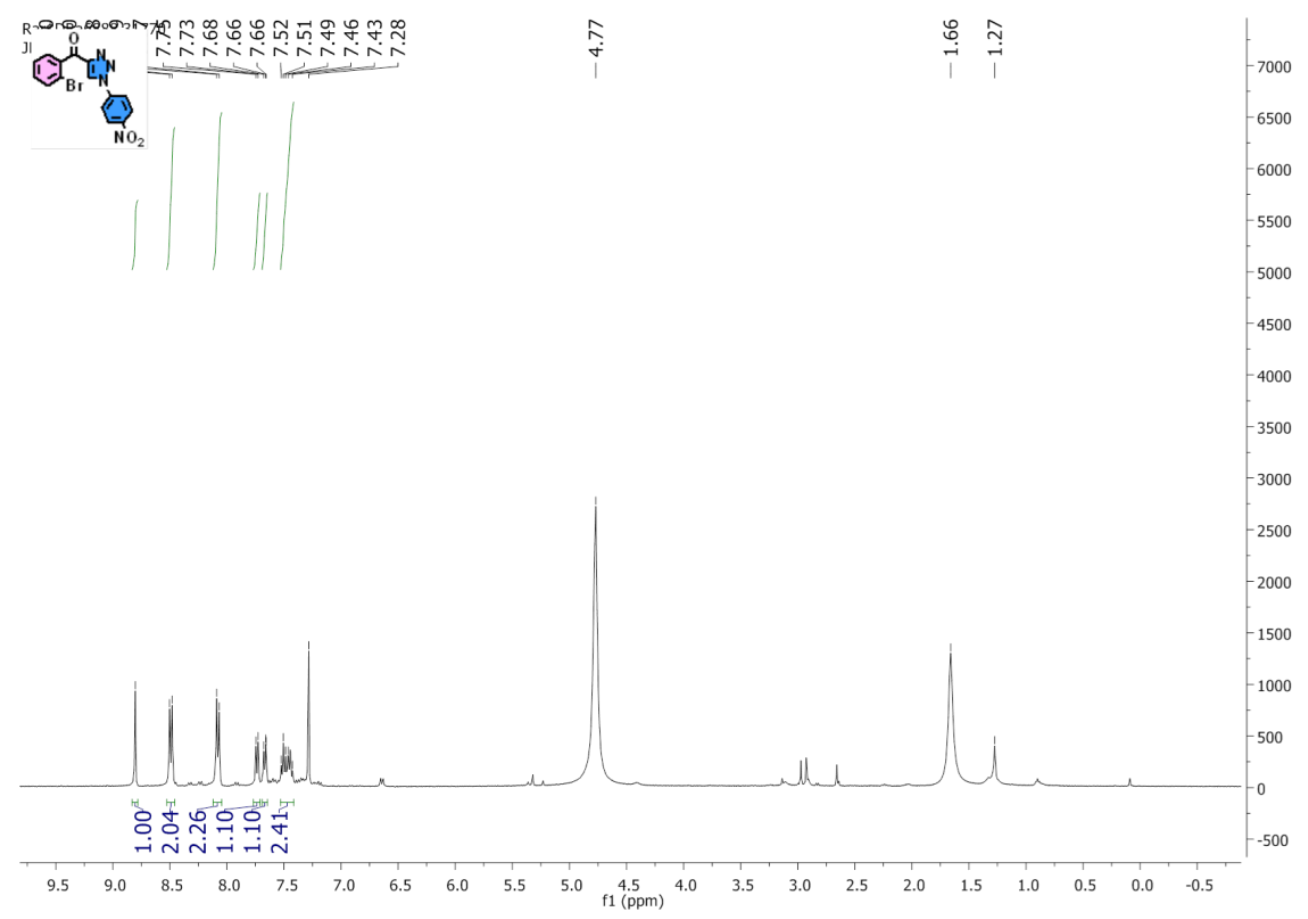

Figura 51: Espectro de RMN 1H do composto $6 \mathbf{h}$ 


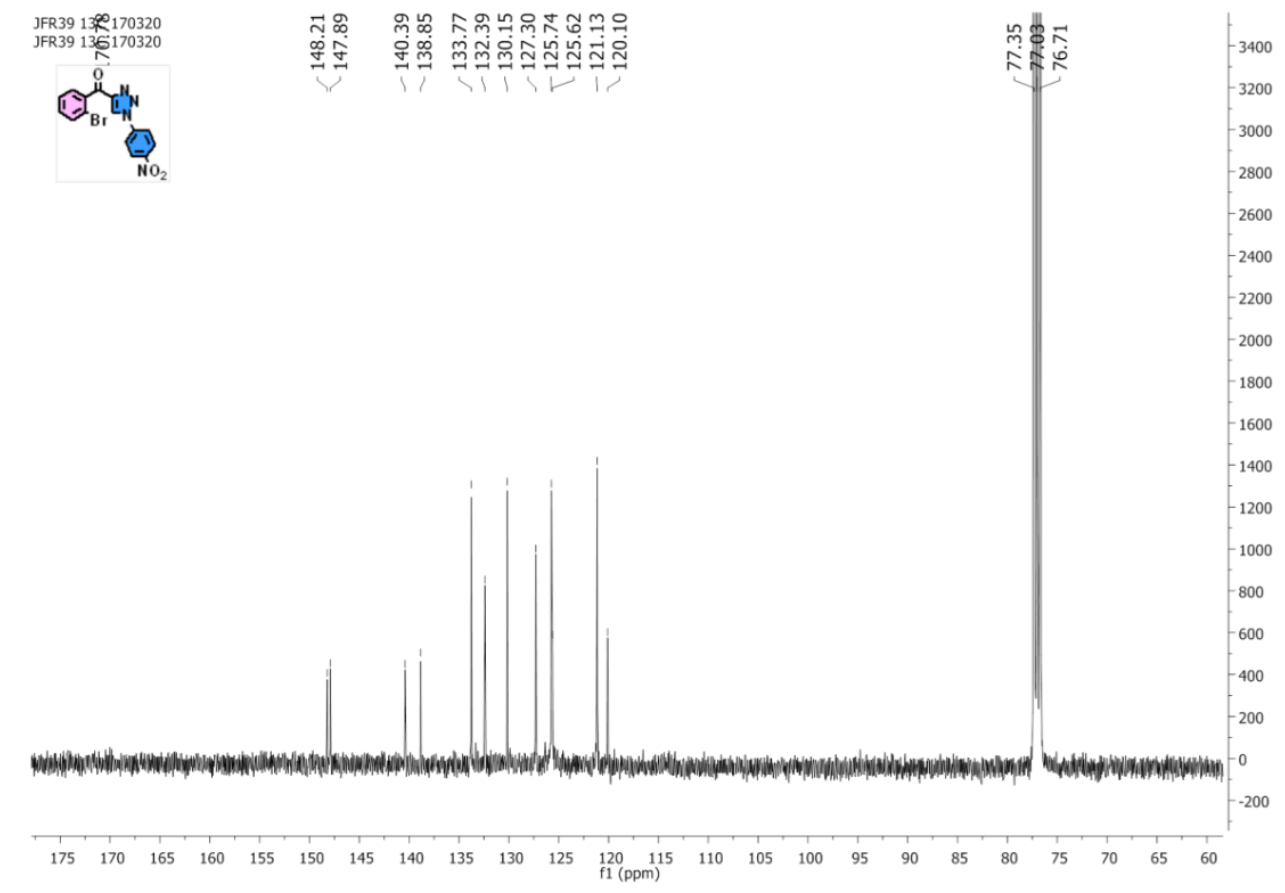

Figura 52: Espectro de RMN 13C do composto 6 h

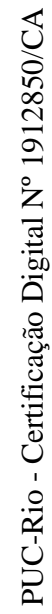

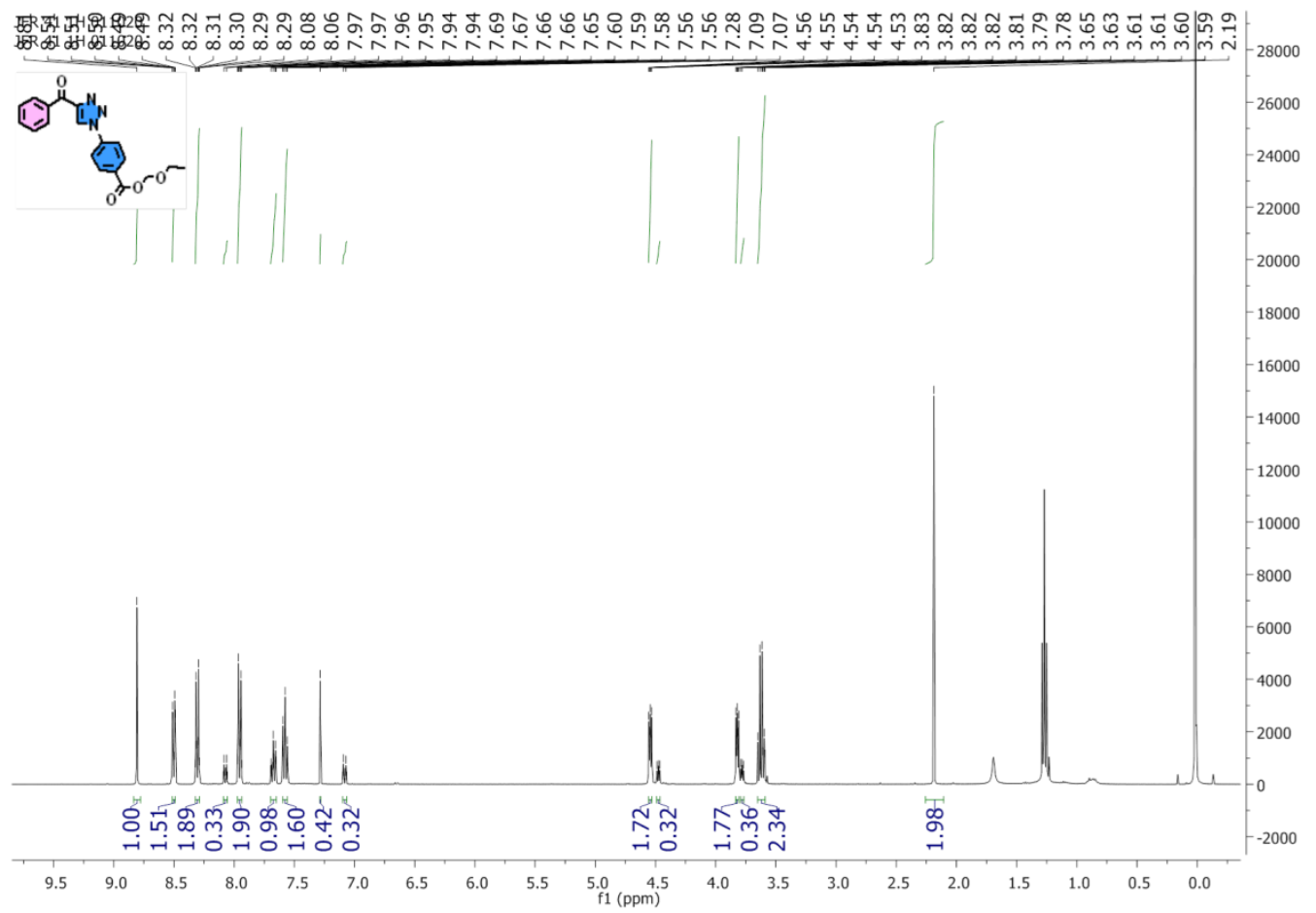

Figura 53: Espectro de RMN 1H do composto $6 \mathbf{i}$ 


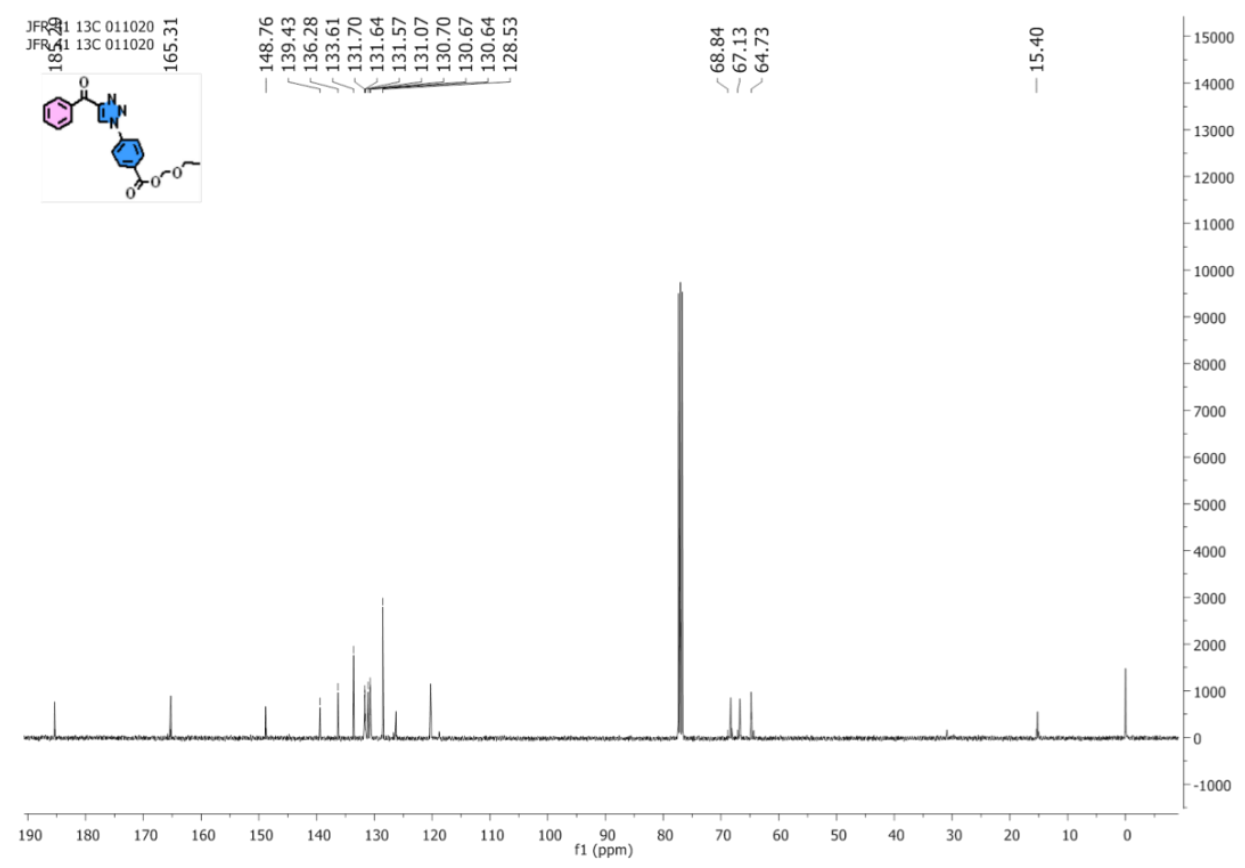

Figura 54: Espectro de RMN 13C do composto $6 \mathbf{i}$

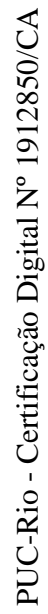

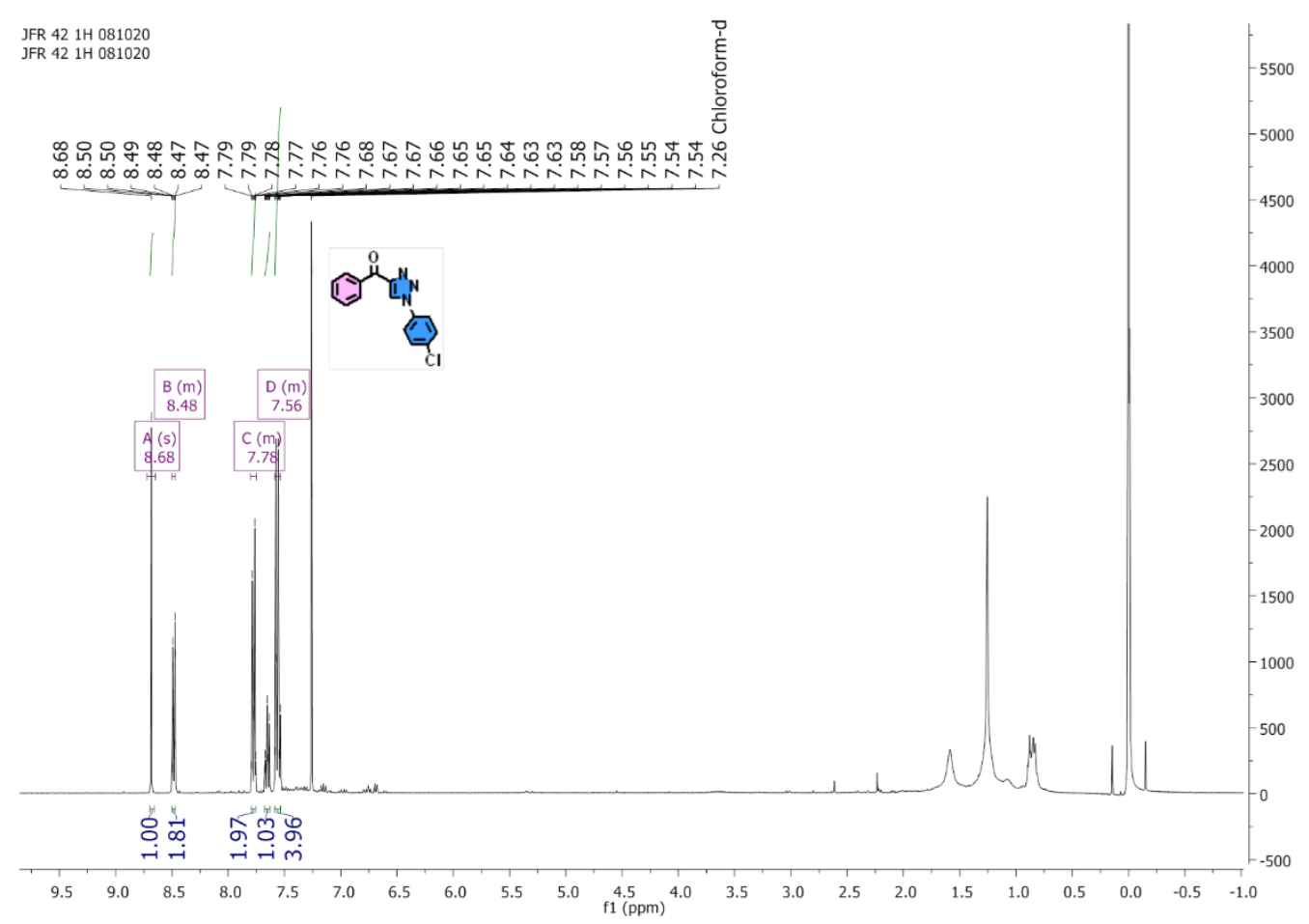

Figura 55: Espectro de RMN 1H do composto 6j 


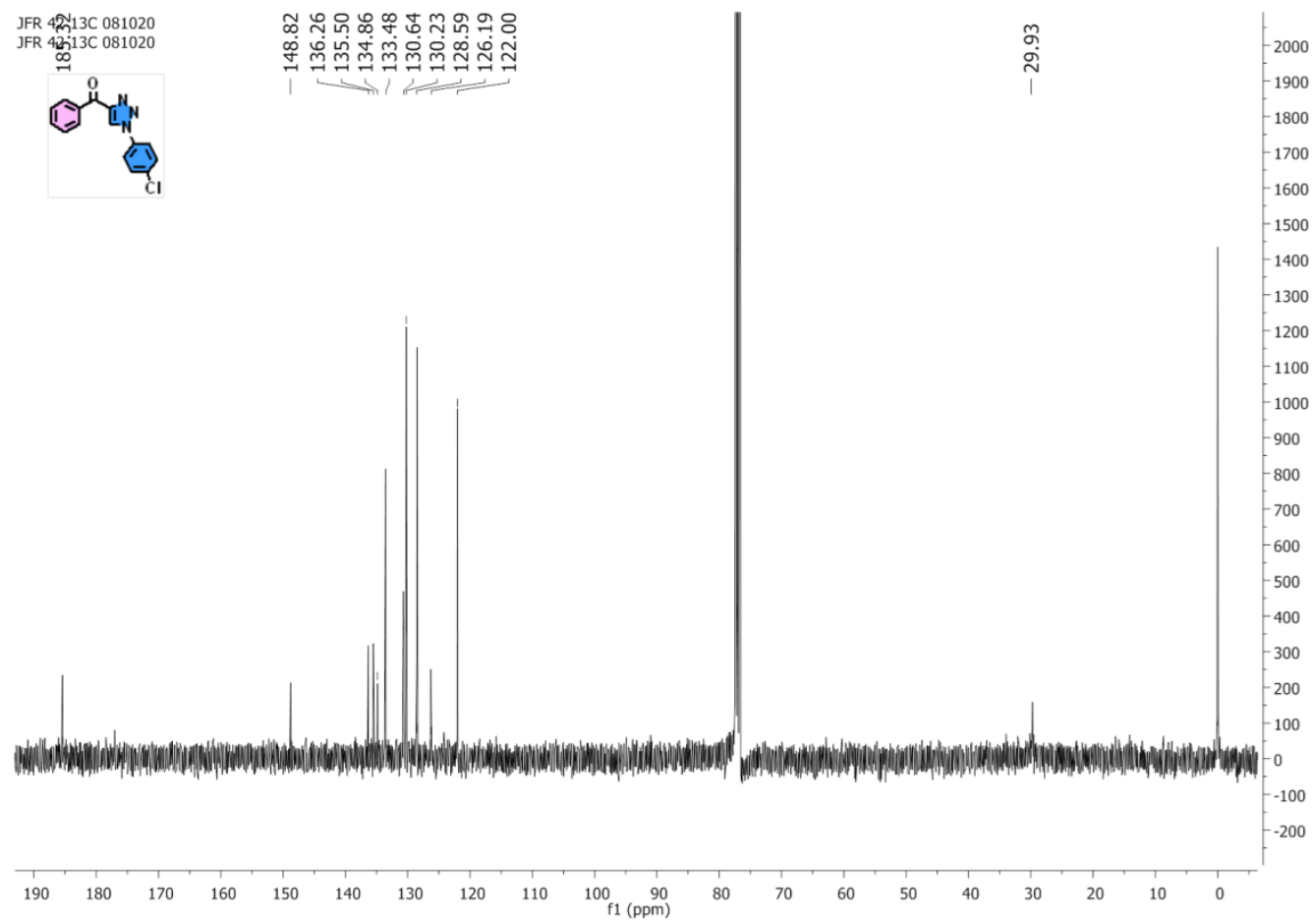

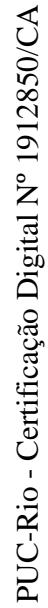

Figura 56: Espectro de RMN13C do composto 6j

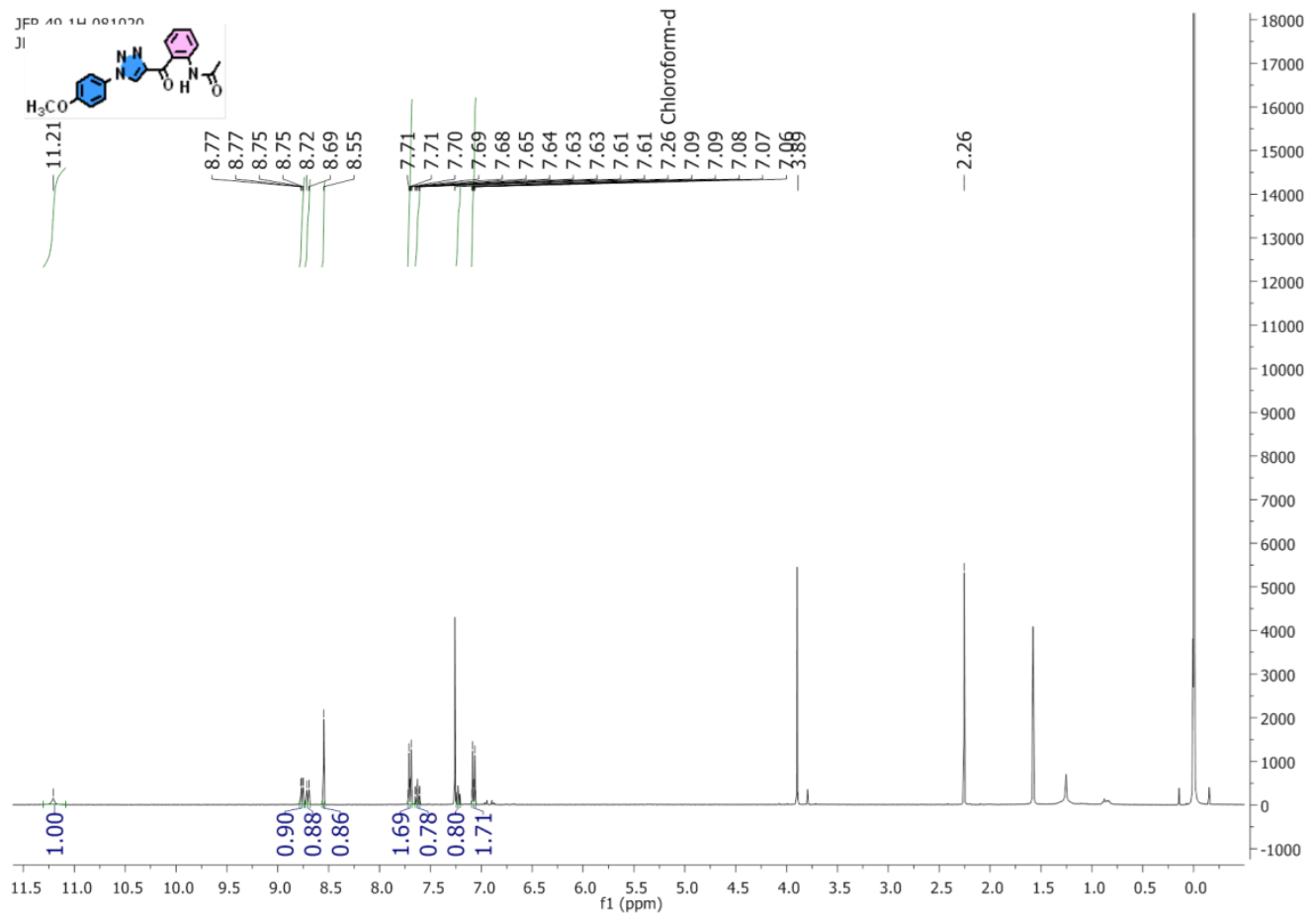

Figura 57: Espectro de 1H do composto 6k 


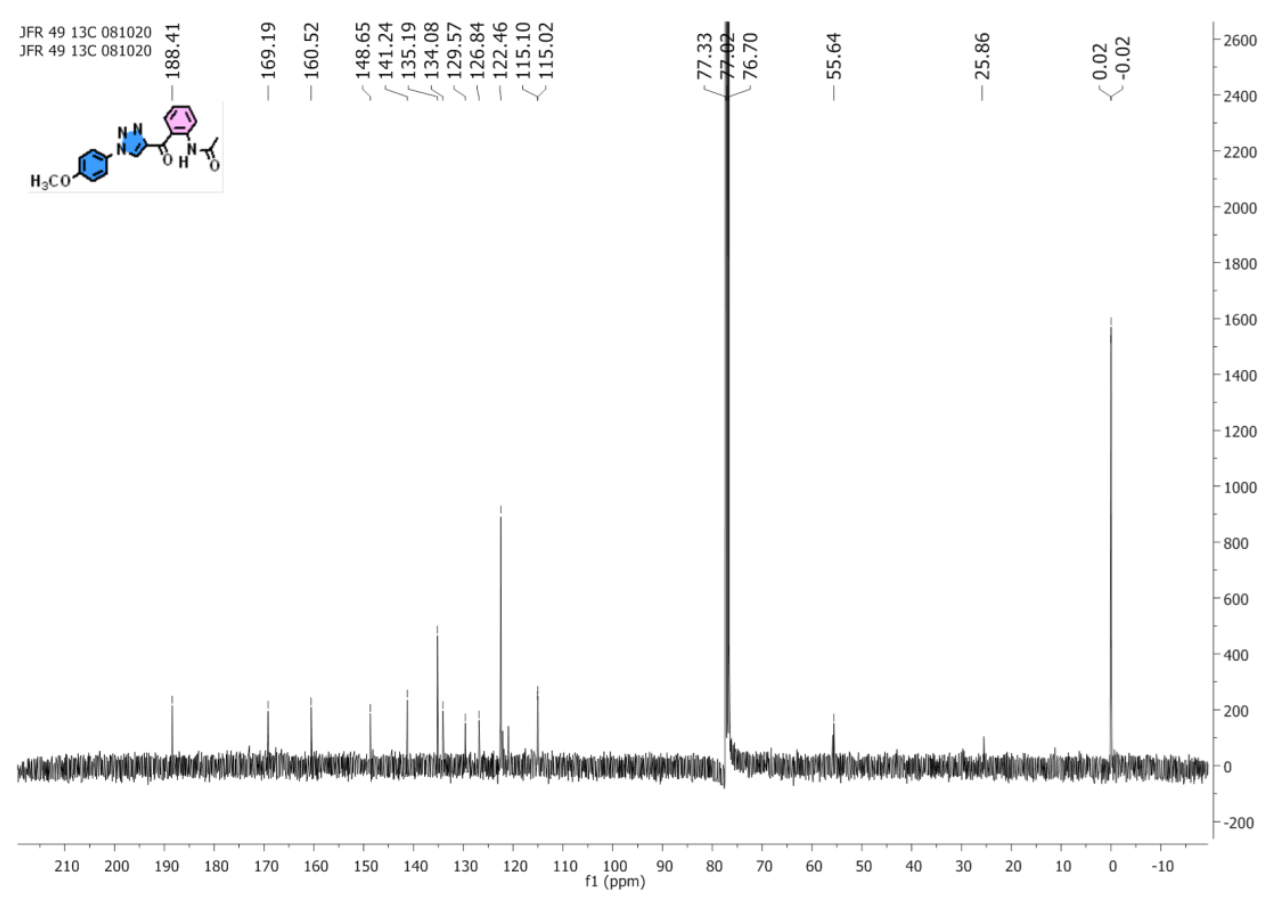

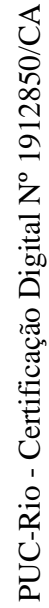

Figura 58: Espectro de 13C do composto 6k 